CLEBER SILVA FERREIRA DA LUZ

\title{
METODOLOGIA E FERRAMENTAS PARA PARALELIZAÇÃO DE LAÇOS PERFEITAMENTE ANINHADOS COM PROCESSAMENTO HETEROGÊNEO.
}

Tese apresentada à Escola Politécnica da Universidade de São Paulo para obtenção do Título de Doutor em Ciências. 
CLEBER SILVA FERREIRA DA LUZ

\section{METODOLOGIA E FERRAMENTAS PARA PARALELIZAÇÃO DE LAÇOS PERFEITAMENTE ANINHADOS COM PROCESSAMENTO HETEROGÊNEO.}

Tese apresentada à Escola Politécnica da Universidade de São Paulo para obtenção do Título de Doutor em Ciências.

Área de Concentração:

Engenharia de Computação

Orientadora:

Liria Matsumoto Sato 
Este exemplar foi revisado e alterado em relação à versão original, sob responsabilidade única do autor e com a anuência de seu orientador.

São Paulo, 3 de maio de 2018.

Assinatura do autor

Assinatura do orientador

\section{FICHA CATALOGRÁFICA}

Luz, Cleber

Metodologia e Ferramentas para Paralelização de Laços Perfeitamente Aninhados Com Processamento Heterogêneo./ Silva Ferreira da Luz. - ed. rev. - São Paulo, 2018.

$130 \mathrm{p}$.

Tese (Doutorado) - Escola Politécnica da Universidade de São Paulo. Departamento de Engenharia de Computação e Sistemas Digitais (PCS).

1. Computação Paralela \#1. 2. Computação Distribuída \#2. 3. Laços Aninhados \#3. \#4. Paralelização de Laços \#5. Balaceamento de Carga I. Universidade de São Paulo. Escola Politécnica. Departamento de Engenharia de Computação e Sistemas Digitais (PCS). II. t. 


\section{AGRADECIMENTOS}

A minha orientadora, Prof. Dra. Liria Matsumoto Sato, agradeço o apoio e incentivo.

A minha família, em especial a minha querida mãe, Marlucia, pelas orações.

A todos os amigos que conheci nesses cinco anos de estudos realizados na POLI, em especial ao meu amigo Ricardo Jacomini.

A todos do laboratório LAHPC em especial ao professor Dr. Edson Midorikawa e aos meus amigos, Fernando Kakugawa, Darlon Vasata, Artur Baruchi e Charles Rodamilans.

Ao CNPq pelo suporte financeiro que possibilitou o desenvolvimento deste trabalho. 
“A grandiosa Revolução Humana de uma única pessoa irá um dia impulsionar a mudança total do destino de um país e, além disso, será capaz de transformar o destino de toda a humanidade." Dr. Daisaku Ikeda 


\section{RESUMO}

Aplicações podem apresentar laços perfeitamente aninhados que demandam um alto poder de processamento. Diversas aplicações científicas contêm laços aninhados em suas estruturas. Tais laços podem processar computações heterogêneas. Uma solução para reduzir o tempo de execução desta classe de aplicações é a paralelização destes laços. A heterogeneidade dos tempos de execução de computações presentes nas iterações de laços perfeitamente aninhados demanda uma paralelização adequada visando uma distribuição de carga homogênea entre os recursos computacionais para reduzir a ociosidade de tais recursos. Esta heterogeneidade implica em um número ideal de recursos computacionais a partir do qual, o seu aumento não impactaria no ganho de desempenho, uma vez que, o tempo mínimo possível é o tempo de execução da tarefa que consome o maior tempo de processamento. Neste trabalho é proposta uma metodologia e ferramentas para paralelização de laços perfeitamente aninhados sem dependência de dados e com processamento heterogêneo em sistemas paralelos e distribuídos. A implementação da metodologia proposta em aplicações melhora o desempenho da execução e reduz a ociosidade dos recursos de processamento. Na metodologia proposta, alguns procedimentos são apoiados por ferramentas desenvolvidas para auxiliá-los. O sistema de processamento poderá ser: um computador Multicore, um Cluster real ou virtual alocado na nuvem. Resultados experimentais são apresentados neste trabalho. Tais resultados mostram a viabilidade e eficiência da metodologia proposta. 


\begin{abstract}
Applications may have nested perfectly loops that require a high processing power. Various scientific applications contain nested loops in their structures. Such loops can process heterogeneous computations. A solution to reduce the execution time of this class of applications is the parallelization of these loops. The heterogeneity of the execution times of computations present in the iterations of nested perfectly loops demands an adequate parallelization aiming at a homogeneous load distribution among the computational resources to reduce the idleness of such resources. This heterogeneity implies an ideal number of computational resources which, its increase would not impact the performance gain, since the minimum possible time is the execution time of the task that consumes the longest processing time. In this work is proposed a methodology and tools for parallelization of loops perfectly nested with heterogeneous processing in parallel and distributed systems. The implementation of proposed methodology in application improves execution performance and reduce idles of the processing resources. In the methodology proposed, some procedures are supported by tools developed to assist them. The processing system can be: a computer multicore, a cluster real or virtual allocated in cloud. Experimental results are presented in this work. These results show the feasibility and efficiency of the proposed methodology.
\end{abstract}




\section{SUMÁRIO}

\section{Lista de Ilustrações}

1 Introdução 17

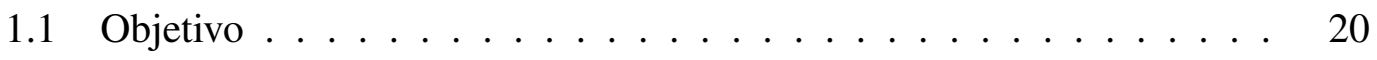

1.2 Justificativa e Motivação . . . . . . . . . . . . . . . . . . 21

1.3 Contribuições . . . . . . . . . . . . . . . . . . . 23

1.4 Metodologia de Desenvolvimento Desta Tese . . . . . . . . . . . 23

1.5 Organização do Texto . . . . . . . . . . . . . . 25

2 Conceitos $\quad 27$

2.1 Laços Aninhados . . . . . . . . . . . . . . . . . . 27

2.2 Modelos de programação paralela. . . . . . . . . . . . . . . 32

2.3 Escalonamento . . . . . . . . . . . . . . 33

2.3.1 Técnicas de Escalonamento de Tarefas . . . . . . . . . . 33

2.3.2 Técnicas de Escalonamento de Iterações de Laço Paralelo . . 35

3 Trabalhos Relacionados $\quad 37$

3.1 Melhoria no Balanceamento de Carga Usando Self Schedule em Intel

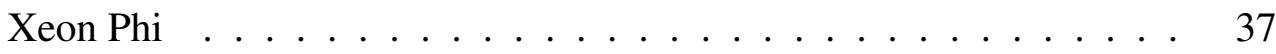

3.2 HOMP: Distribuição Automatizada de Laços Paralelos em Sistemas de Aceleradores Altamente Paralelos . . . . . . . . . . . . . . . . 38 
3.3 Escalonamento de Laços com Dependência de Iterações em Cluster Heterogêneo . . . . . . . . . . . . . . . . . 38

3.4 Eficiência no Escalonamento de Laços Aninhados Paralelos em Sistemas Multicores ..................... 39

3.5 Escalonamento Dinâmico de Laços Aninhados com Dependência em Cluster Heterogêneo . . . . . . . . . . . . . . . . . . . . . . . 39

3.6 Melhoria no Escalonamento de Tarefas Dependentes para Aplicações em Grid . . . . . . . . . . . . . . . . . . . . . . 40 40

3.7 Um Algoritmo Heurístico para Paralelização de Laços Aninhados . . 40

3.8 Laços Coalescing: Uma técnica de compilação para a transformação de espaços iterativos não uniforme . . . . . . . . . . . . . . . 41

3.9 Considerações Sobre as Propostas Apresentadas . . . . . . . . . . . . 41

4 Metodologia e Ferramentas para Paralelização de Laços Perfeitamente Aninhados Com Processamento Heterogêneo.

4.1 Estratégia de Paralelização da Aplicação . . . . . . . . . . . . . . . . 44

4.2 Descrição da Metodologia . . . . . . . . . . . . . . . . . 46

4.3 Preparação da Aplicação Paralelizada . . . . . . . . . . . . . . . . . 47

4.3.1 Criação do Arquivo de Tempos Iniciais . . . . . . . . . . . . 48

4.3 .2 Linearização . . . . . . . . . . . . . . . . . . . . . 48

4.3.3 Preparação da Paralelização do Código da Aplicação . . . . . 52

4.4 Execução da Aplicação . . . . . . . . . . . . . . . . . . . . . . 62

4.4.1 Leitura $\operatorname{dos}$ Tempos . . . . . . . . . . . . . . 63 
4.4.2 Cálculo do Valor Inicial do Número Ideal de Recursos de Processamento ........................ 64

4.4.3 Escalonamento .................. 65

4.4 .4 Processamento . . . . . . . . . . . . . . . 67

5 Implementações, Resultados e Análises

5.1 Metodologia de Teste e Análise . . . . . . . . . . . . . . . 70

5.2 Ambientes de Execução . . . . . . . . . . . . . . . . . . . . 70

5.3 Avaliação da Proposta . . . . . . . . . . . . . . . . . 71

5.3 .1 Caso de Teste $1 \ldots \ldots \ldots 72$

5.3.1.1 Resultados e Análises - Cenário 1 . . . . . . . . 73

Escalabilidade e Desempenho - Cenário $1 \ldots 73$

Ociosidade dos Recursos de Processamento - Cenário 174

Heterogeneidade x Desempenho - Cenário 1 . . . . . 76

Speedup - Cenário $1 \ldots \ldots$. . . . . . . . 76

5.3.2 Caso de Teste $2 \ldots \ldots \ldots 77$

5.3.2.1 Resultados e Análises - Cenário 2 . . . . . . . . 78

Escalabilidade e Desempenho - Cenário $2 \ldots 79$

Ociosidade dos Recursos de Processamento - Cenário 279

Speedup - Cenário $2 \ldots \ldots$. . . . . . . 81

5.3 .3 Caso de Teste $3 \ldots \ldots \ldots 2 \ldots$

5.3.3.1 Resultados e Análises - Cenário 3 . . . . . . . . 83 
Escalabilidade e Desempenho - Cenário $3 \ldots 83$

Ociosidade dos Recursos de Processamento - Cenário 384

Speedup - Cenário $3 \ldots \ldots$. . . . . . . . . 86

5.3.4 Comparação Entre a Metodologia Proposta com Plataformas de Processamento Paralelos e Distribuídos . . . . . . . . . . . 86

5.3.4.1 Cenário $1 \ldots \ldots \ldots$. . . . . . . . . . . 87

Comparação Entre a Plataforma de Processamento

OpenMP e a Metodologia Proposta . . . .

Comparação Entre a Plataforma de Processamento MPI e a Metodologia Proposta . . . . . . 90

Cenário $2 \ldots \ldots$. . . . . . . . . . . . 93

Cenário $3 \ldots \ldots \ldots$. . . . . . . . . . . . 97

5.3.5 Considerações Finais Sobre os Resultados e Análises . . . . . 98

6 Estudo de Caso: Modelagem de Distribuição de Espécies 103

6.1 Modelagem de Distribuição de Espécies em R . . . . . . . . . . . . 103

6.1.1 Aplicação da Metodologia Proposta na Plataforma BIOMOD2 107

6.1.1.1 Estrutura da Aplicação Paralela BIOMOD2 . . . . 107

6.1.2 Resultados Obtidos a Partir da Implementação da Metodologia Proposta na Predição de Espécies. . . . . . . . . . . . . . . 108

6.2 Computação Paralela versus Computação Distribuída . . . . . . . . . 113

7 Conclusões

7.1 Contribuições . . . . . . . . . . . . . . . . . . . . 117 
7.2 Trabalhos Futuros . . . . . . . . . . . . . . . . . . 118

Referências

Apêndice A - Código do Exemplo de Implementação da Metodologia em Computadores Multicores

Apêndice B - Código do Exemplo de Implementação da Metodologia em Sistemas Distribuídos

Apêndice C - Código do Exemplo de Implementação da Metodologia em R e para a Biodiversidade. 


\section{LISTA DE ILUSTRAÇÕES}

1 Tempo de execução para os valores i e j da função f. . . . . . . . . . . 28

2 Processamento sequencial de laços aninhados. . . . . . . . . . . . 29

3 Processamento paralelo do laço mais externo (laço i). . . . . . . . . . 29

4 Processamento paralelo do laço mais interno (laço j). . . . . . . . 30

5 Processamento paralelo do laço linearizado. . . . . . . . . . . 31

6 Processamento paralelo com a quantidade ideal de recursos e distribuição de carga adequada. . . . . . . . . . . . . . . . 32

$7 \quad$ Fases da metodologia. . . . . . . . . . . . . . . . 47

$8 \quad$ Exemplos de Task. . . . . . . . . . . . . . . . . . . . 49

9 Exemplo de implementação de task em C. . . . . . . . . . . . . . . 49

10 Exemplo de implementação de task em R. . . . . . . . . . . . . . 50

11 Exemplo de implementação de task em R na aplicação de Biodiversidade. 50

12 Exemplo de vector_task. . . . . . . . . . . . . 51

13 Exemplo de implementação de vector_task em C . . . . . . . . . . 51

14 Exemplo de implementação de vector_task em R e para a aplicação da Biodiversidade. . . . . . . . . . . . . . . . . . 51

15 Exemplo de chamada da ferramenta de cálculo do valor inicial do número ideal de recursos na plataforma $\mathrm{C} \ldots \ldots . \ldots 53$

16 Exemplo de chamada da ferramenta de cálculo do valor inicial do número ideal de recursos de processamento em $R$. . . . . . . . . . . 53 
17 Exemplo de chamada da ferramenta de cálculo do valor inicial do número ideal de recursos de processamento em $R$ para a aplicação da Biodiversidade. ...................... 53

18 Exemplo de chamada da ferramenta de escalonamento em C. . . . . . 54

19 Exemplo de chamada da ferramenta de escalonamento em $R$. . . . . 55

20 Exemplo de chamada da ferramenta de escalonamento em $R$ para a aplicação da Biodiversidade. . . . . . . . . . . . . . . 55

21 Fluxo das Atividades da Fase de Execução da Aplicação. . . . . . . . 63

22 Exemplo de vector_task_list. . . . . . . . . . . . . . 66

23 Estratégia de escalonamento aplicada na ferramenta. . . . . . . . . 67

24 Tabela com os tempos de execução das iterações do laço linearizado Cenário 1. . . . . . . . . . . . . . . . . . 72

25 Tempos do processamento paralelo e sequencial - Cenário 1 - Cluster. 73

26 Tempo teórico de execução de cada recurso de processamento - Cenário 1 - Cluster. . . . . . . . . . . . . . . 75

27 Balanceamento de carga entre os recursos de processamento - Cenário 1 - Cluster. . . . . . . . . . . . . . . . 76

28 Speedup - Cenário 1 - Cluster. . . . . . . . . . . . . . . . 77

29 Tabela com os tempos de execução das iterações do laço linearizado Cenário 2. . . . . . . . . . . . . . . . . . 78

30 Tempos das execução paralela e sequencial - Cenário 2 - Cluster. . . . 79

31 Tempo teórico de execução paralela das 125 iterações - Cenário 2. . . 80

32 Execução da aplicação com balanceamento de carga - Cenário 2 - Cluster. 81 
33 Speedups - Cenário 2 - Cluster . . . . . . . . . . . . . 82

34 Tempos das iterações do laço linearizado - Cenário $3 \ldots 83$

35 Tempos da execução paralela e sequencial - Cenário 3 - Cluster. . . . 84

36 Tempo teórico da execução de cada iteração do laço linearizado - Ce-

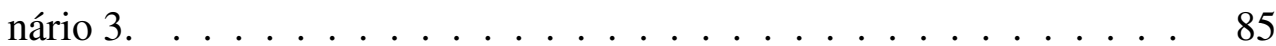

37 Execução da aplicação com balanceamento de carga - Cenário 3 - Cluster. 85

38 Speedups - Cenário 3 - Cluster . . . . . . . . . . . . . . 86

39 Tempos de iteração de laços aninhados - Cenário 1 - Tabela 1. . . . . 87

40 Tempo de processamento - Cenário: Comparação entre os algoritmos de escalonamento do OpenMP e Metodologia - Tabela - Ambiente Paralelo. ...................... . . 88

41 Tempo de processamento - Cenário: Comparação entre os algoritmos de escalonamento do OpenMP e Metodologia - Gráfico - Ambiente Paralelo. ...................... 88

$42 \quad$ Speedups - Ambiente Paralelo. . . . . . . . . . . . . . . . . . 89

43 Tempo de processamento - Cenário - 1- Tabela - Cluster. . . . . . . . 91

44 Tempo de processamento - Cenário 1 - Gráfico - Cluster. . . . . . . . 91

45 Speedup - Cenário - 1 - Cluster. . . . . . . . . . . . . . . . . 92

46 Tempos de execução das iterações do laço mais interno - Cenário 2 : Comparação entre Metodologia proposta com OpenMP e MPI - Modelagem. . . . . . . . . . . . . . . . . 93

47 Tempo de processamento - Cenário 2 - Tabela - Ambiente Paralelo Modelagem. . . . . . . . . . . . . . . . . . . . . . . . 94 
48 Tempo de processamento - Cenário 2 - Gráfico - Ambiente Paralelo Modelagem. . . . . . . . . . . . . . . . . . . . . . 94

49 Tempo de processamento - Cenário 2 - Tabela - Cluster - Modelagem. 95

50 Tempo de processamento - Cenário 2 - Gráfico - Cluster - Modelagem. 95

51 Distribuição de tarefas no algoritmo Estático. . . . . . . . . . . . . . 96

52 Distribuição de tarefas no algoritmo Self Schedule. . . . . . . . . . . 97

53 Tempo de processamento. . . . . . . . . . . . . . . . 98

54 Um exemplo de predição. . . . . . . . . . . . . . . . . . . . . . . 104

55 Exemplo de Task na fase de modelagem. . . . . . . . . . . . . . . 107

56 Tempo de execução sequencial e paralelo da fase de modelagem. . . . 110

57 Tempo de projeção sequencial e paralela. . . . . . . . . . . . . 111

58 Tempo de execução do processo de predição. . . . . . . . . . . . . . 111

59 Balanceamento de carga na fase de modelagem. . . . . . . . . . . . 112

60 Tempos teóricos de execução de todas as tarefas na fase de modelagem. 113

61 Computação Paralela versus Computação Distribuída. . . . . . . . . . . 114 


\section{INTRODUÇÃO}

Atualmente, Computação Paralela e Distribuída tem sido essencial para se obter um melhor desempenho no processamento de aplicações que demandam alto poder computacional. Em aplicações biológicas, por exemplo, geralmente é necessário analisar milhões de amostras experimentais, que muitas vezes, consomem horas ou até mesmo dias de processamento. Aplicações com este perfil, frequentemente utilizam laços de repetições aninhados no processamento de dados e muitas vezes, executam computações heterogêneas dentro dos mesmos (HAJIESKANDAR; LOTFI, 2010). O processamento de aplicações com este perfil requer ferramentas capazes de manipular grandes quantidades de dados, como também, boas estratégias de processamento, a fim de realizar o processamento de forma rápida e eficiente.

Diversas aplicações cientificas contêm laços aninhados em suas estruturas (RIAKIOTAKIS; TSANAKAS, 2005; TEICH J.; TANASE; HANNIG, 2014). A modelagem de distribuição de espécies é um exemplo de tais aplicações. Esta aplicação permite entender como fatores ambientais, tais como, conservação de espécies raras ou ameaçadas de extinção, reintrodução de espécies, perda de biodiversidade, impactos das mudanças climáticas e outros, influenciam na distribuição geográfica de espécies (GIANNINI C.; SIQUEIRA, 2012). O processo de geração de modelos de distribuição de espécie combina diversas variáveis ambientais e projeta um cenário que identifica as regiões potencialmente apropriadas para a ocorrência das espécies, criando um mapa de distribuição potencial (CANDELA L.; CASTELLI; SINIBALDI, 2016). A modelagem de distribuição de espécies possui diversas fases, sendo suas principais: as fases de modelagem e proje- 
ção. Existem diversas técnicas de modelagem de distribuição de espécies. Na técnica considerada neste trabalho como estudo de caso, na fase de modelagem são processados 10 diferentes algoritmos de modelagem dentro de laços aninhados. Já na fase de projeção, todos os modelos gerados na fase anterior, são projetados. Na fase de modelagem, os modelos são criados através de laços aninhados, sendo os algoritmos de modelagem executados no laço mais interno. Cada modelo consome um tempo diferente de processamento, resultando em diferentes tempos de execução para cada iteração do laço aninhado.

Aplicações científicas que geram e analisam grandes quantidades de dados, podem ser executadas em tempos muito longos. O uso de técnicas de paralelização podem melhorar o desempenho da execução de tais aplicações (NICOLAU A.; CAMMAROTA; VEIDENBAUM, 2012; RAVISHANKAR M.; EISENLOHR; SADAYAPPAN, 2012). Uma possível solução para diminuir o tempo de processamento é a substituição de laços, incluindo laços aninhados, por laços paralelos. Laços paralelos são laços onde suas $n$ iterações são compartilhadas e processadas por $p$. processados.

Realizar apenas uma paralelização pode não ser suficiente para melhorar o desempenho da aplicação e garantir um bom uso dos recursos de processamento. As iterações dos laços aninhados podem conter tempos de execução diferentes, e isso gera uma heterogeneidade no tempo de processamento das mesmas. O desbalanceamento de carga causado pela heterogeneidade dos tempos de execução das iterações de um laço aninhado causa ociosidade no processamento, resultando em um baixo desempenho e não garante um bom uso dos recursos de processamento. Algumas estratégias foram propostas para resolver esse problema. Todavia, boa parte dos trabalhos encontrados na literatura se preocupam em apresentar soluções para a paralelização de laços em ambientes heterogêneos.

Há também, trabalhos que apresentam soluções para a paralelização de laços aninhados buscando melhorar o balanceamento de carga de trabalho no processamento. 
Os algoritmos de escalonamento dinâmico lidam melhor com o balanceamento de carga no processamento se comparados com os algoritmos de escalonamento estático. Todavia, dependendo dos valores das cargas pode ocorrer do algoritmo de escalonamento estático realizar um balanceamento de carga melhor que o dinâmico. No escalonamento dinâmico,como o apresentado em (KEJARIWA A.; NICOLAU; POLYCHRONOPOULOS, 2008; NICOLAU A.; VEIDENBAUM, 2009; POLYCHRONOPOULOS, 1988), o balanceamento de carga depende dos tempos de execução de cada iteração, podendo ocorrer um desbalanceamento em alguns casos.

A hipótese considerada neste trabalho envolve o desempenho de aplicações que contêm laços perfeitamente aninhados com processamentos heterogêneos. A hipótese diz que é possível melhorar o desempenho de tais aplicações, utilizando uma quantia de recursos limitada a um número ideal; através de uma estratégia de paralelização adequada e a redução da ociosidade no processamento.

Considerando esta hipótese, este trabalho visa apresentar uma metodologia para paralelizar laços perfeitamente aninhados que envolvem iterações com computações heterogêneas, incluindo laços simples sem aninhamento. Também são apresentadas ferramentas desenvolvidas para auxiliar alguns procedimentos da metodologia proposta.

As iterações de um laço podem contém tempos de execução diferentes, considerando que um laço pode processar computações heterogêneas dentro de seus laços. Uma aplicação pode contém laços aninhados com computações heterogêneas. Na estratégia de paralelização proposta nesta tese, o código da aplicação é modificado nos pontos em que se apresentam laços que envolvem iterações com computações heterogêneas. Essa modificação permite extrair o máximo de paralelismo da aplicação.

A estratégia de paralelização implementada na metodologia proposta realiza uma alocação de recursos dinamicamente e promove a paralelização individual de cada ocorrência de laços perfeitamente aninhados com computação heterogênea, presentes 
na aplicação. Na estratégia de paralelização, cada ocorrência de laço aninhado presente na aplicação é linearizada, obtendo um único laço que é paralelizado em seguida. No caso de laços únicos, não é necessário essa etapa de linearização. Devido à presença de partes executadas sequencialmente e também, como cada ocorrência de laço aninhado demanda um número ideal de recursos computacionais específico, a alocação dos recursos de processamento é realizada no momento da sua utilização, portanto, dinamicamente.

Para melhorar o desempenho e diminuir a ociosidade entre os processadores na execução de um laço linearizado e paralelizado é necessário definir a quantidade ideal de recursos de processamento e realizar um escalonamento de tarefas adequado. A metodologia proposta define o número ideal de recursos de processamento e também, realiza um escalonamento de tarefa adequado.

O cálculo do número de recursos de processamento visa definir o número ideal de recursos a ser utilizado no processamento, a partir do qual não se teria uma melhora de desempenho no processamento. Para cada ocorrência de laço aninhado é calculada uma quantidade ideal de recursos.

A estratégia de escalonamento para a distribuição das iterações aos recursos computacionais visa balancear a carga de trabalho entre tais recursos, a fim de, diminuir a ociosidade. Esta distribuição tem como base o tempo de execução de cada iteração do laço linearizado.

\subsection{Objetivo}

O objetivo deste trabalho consiste em apresentar uma metodologia para paralelizar laços perfeitamente aninhados sem dependência de dados e com processamento heterogêneo para sistemas distribuídos e paralelos. Esta metodologia pode ser aplicada em aplicações que utilizam o paradigma de programação procedimental. É considerado 
também, que os laços da aplicação são laços contadores, como por exemplo laços do tipo for. Este trabalho também apresenta duas ferramentas desenvolvidas para auxiliar dois procedimentos da metodologia proposta. A primeira ferramenta é responsável por determinar o número ideal de recursos de processamento que são utilizados no processamento, a segunda é responsável por realizar um escalonamento adequado das iterações dos laços.

O objetivo desta metodologia de paralelização é, além de proporcionar a redução do tempo de processamento, prover o uso adequado dos recursos de processamento, minimizando a ociosidade no processamento.

\subsection{Justificativa e Motivação}

Habitualmente, aplicações científicas utilizam laços aninhados para processar seus dados. Estes laços, muitas vezes, contêm computações heterogêneas que implicam em uma heterogeneidade de tempo de execução nas iterações do laço aninhado, afetando o desempenho da aplicação. Realizar a paralelização em um dos níveis do alinhamento pode limitar o paralelismo e havendo a heterogeneidade mencionada, não é possível realizar um bom balanceamento de carga de trabalho entre os processadores, deixando alguns ociosos e outros, sobrecarregados. Um mau balanceamento de carga entre os recursos de processamento pode afetar o desempenho da aplicação (NICOLAU A.; VEIDENBAUM, 2009).

Na literatura, há diversos trabalhos sobre paralelização de laços. Todavia, as estratégias de paralelização utilizadas nestes trabalhos, não têm enfoque na criação de uma metodologia de paralelização que diminua o tempo de processamento e diminua a ociosidade no processamento causada pela heterogeneidade dos tempos de execução das iterações dos laços aninhados. Boa parte dos trabalhos encontrados na literatura se preocupam com ambientes de processamento heterogêneos. Por exemplo, em (HUANG 
C.; W.; CHEN, 2015) é apresentado um estudo sobre como melhorar o balanceamento de carga de trabalho na paralelização de laços utilizando a técnica de escalonamento Self Schedule em um ambiente de processamento composto por recursos heterogêneos. Já em (YAN Y.; LIU; UMAR, 2017) é apresentada uma interface de programação que automatiza a distribuição de computações, laços paralelos, e dados para recursos heterogêneos tais como, GPU, CPUs e MICs. Em (CIORBA M.; ANDRONIKOS; PAPAKONSTANTINOU, 2006) é apresentada uma técnica para o problema de escalonamento de laços aninhados com dependência de iterações para Clusters composto por máquinas heterogêneas. Existem trabalhos que apresentam soluções que buscam realizar um balanceamento de carga no processamento de laços aninhados Um exemplo desses trabalhos é o (KEJARIWA A.; NICOLAU; POLYCHRONOPOULOS, 2008), que apresenta uma solução para processar laços com computações heterogêneas buscando realizar um balanceamento de carga no processamento. Todavia, este trabalho é aplicado somente para computadores Multicores, já a solução apresentada neste trabalho é aplicada tanto para computadores Multicores, como para Clusters de computadores.

A heterogeneidade dos tempos de execução das iterações dos laços aninhados demanda uma paralelização adequada visando a uma distribuição de carga homogênea entre os recursos computacionais para reduzir a ociosidade e melhorar o desempenho da aplicação. Este fato motivou neste trabalho, a criação de uma metodologia de paralelização de laços perfeitamente aninhados com processamento heterogêneo, que além de paralelizar os laços, realize um escalonamento das iterações do laço, a fim de garantir um bom balanceamento de carga e resultando em uma boa utilização dos recursos de processamento.

Resultados experimentais apresentados no Capítulo 5 mostram que, ao aplicar a metodologia de paralelização proposta, é possível diminuir o tempo de processamento de aplicações que contêm laços aninhados e melhorar o uso dos recursos computacionais envolvidos no processamento; através da diminuição da ociosidade no processa- 
mento.

\subsection{Contribuições}

A principal contribuição deste trabalho é, com o uso da metodologia proposta, melhorar a eficiência de aplicações que contêm laços perfeitamente aninhados com processamento heterogêneo, através do aumento de desempenho e redução da ociosidade dos recursos de processamento. Este trabalho também provê ferramentas aplicadas na implementação da paralelização, buscando facilitar a codificação. A metodologia aqui proposta pode ser implementada e processada por um computador Multicore, um Cluster real ou virtual alocado na nuvem. No caso de um Cluster virtual alocado na nuvem, a metodologia proposta pode refletir em um menor custo na alocação de máquinas virtuais. As máquinas virtuais devem ser ativadas de forma a não ultrapassar o número de recursos definido pela metodologia.

\subsection{Metodologia de Desenvolvimento Desta Tese}

Para propor e desenvolver a metodologia proposta foram realizados os seguintes procedimentos:

1. Revisão bibliográfica.

2. Definição do problema.

3. Pesquisa de trabalhos relacionados.

4. Estudo sobre a modelagem de distribuição de espécies.

5. Estudo sobre a ferramenta R.

6. Estudo sobre a plataforma BIOMOD2. 
7. Desenvolvimento da metodologia proposta nesse trabalho.

8. Aplicação da metodologia proposta no estudo de caso considerado.

9. Realização de testes experimentais.

10. Criação de uma aplicação sintética para aplicar a metodologia.

11. Realização de testes experimentais.

Considerando a hipótese apresentada, o primeiro passo adotado foi realizar uma revisão bibliográfica para conhecer e estudar as estratégias de paralelizações já propostas na literatura. Nesta revisão bibliográfica, foram estudados diversos artigos. Ao se estudar os trabalhos encontrados na literatura, é possível perceber que as estratégias de paralelização utilizadas nestes trabalhos, não têm enfoque na criação de uma metodologia de paralelização que diminua o tempo de processamento e diminua a ociosidade no processamento causada pela heterogeneidade dos tempos de execução das iterações dos laços aninhados. A heterogeneidade dos tempos de execução das iterações do laço aninhado causa um desbalanceamento de carga de trabalho entre processadores, resultando em uma ociosidade no processamento. Isso afeta o desempenho e não garante uma utilização dos recursos de processamento de forma ótima. A observação deste fato criou uma motivação para criar uma metodologia de paralelização de laços perfeitamente aninhados com processamento heterogêneo que, além de diminuir o tempo de processamento da aplicação, permite diminuir a ociosidade no processamento da aplicação, como também, provê um bom uso dos recursos de processamento.

O próximo passo realizado foi estudar a aplicação de modelagem de distribuição de espécies, que é adotada como estudo de caso neste trabalho. Para melhor entendimento sobre a geração de modelos de distribuição de espécies, foram utilizadas como fonte de estudos as referências (PHILLIPS; R., 2006; IWASHITA, 2007; GIANNINI C.; SIQUEIRA, 2012). Também foi possível contar com o apoio do biólogo André Luiz Acosta para 
entender sobre os procedimentos e ferramentas utilizadas na análise de modelos de distribuição de espécies.

Atualmente estão disponíveis diversas ferramentas para a geração de modelos de distribuição de espécies. No estudo de caso realizado neste trabalho, é utilizada a plataforma BIOMOD2. BIOMOD2 é uma plataforma computacional que disponibiliza funções que permitem realizar predições de distribuição de espécies. Tais funções permitem o tratamento de uma série de incertezas metodológicas em modelos e permite também, a avaliação da relação espécie-ambiente (THUILLER W.; LAFOURCADE; ARAUJO, 2009). A plataforma BIOMOD2 é executada no ambiente R. Para entender o correto funcionamento da plataforma BIOMOD2 e da ferramenta $\mathrm{R}$, foram adotadas como fontes de estudo as referências (R FOUNDATION FOR STATISTICAL COMPUTING, 2008; THUILLER W.; LAFOURCADE; ARAUJO, 2009).

A metodologia proposta foi implementada na ferramenta BIOMOD2. Foram realizados testes experimentais com a implementação da metodologia na plataforma BIOMOD2. Os resultados e análises obtidos nos experimentos foram publicados no artigo (LUZ C.; SATO; MIDORIKAWA, 2017).

Outras formas de avaliação da metodologia foram realizadas. Foram criadas aplicações sintéticas com a aplicação da metodologia proposta. Foram realizados testes e análises, executados em um computador Multicore e um Cluster de computadores real que são apresentados no Capitulo 5, tais resultados mostram o impacto da metodologia proposta no desempenho das aplicações sintéticas e no estudo de caso apresentado neste trabalho.

\subsection{Organização do Texto}

Este trabalho está organizado em sete capítulos.

O primeiro capítulo apresenta o problema abordado neste trabalho, bem como, a 
justificativa e motivação, o objetivo e as suas contribuições.

O Capítulo 2 apresenta alguns conceitos sobre processamento paralelo de laços aninhados para melhor entendimento da contextualização do problema e da proposta apresentada.

Já o Capítulo 3 apresenta algumas soluções encontradas na literatura que apresentam aspectos semelhantes e divergentes com a metodologia proposta.

No Capítulo 4 é apresentada a metodologia proposta neste trabalho.

Resultados experimentais são apresentados no Capítulo 5.

O Capítulo 6 apresenta os resultados obtidos no estudo de caso considerado neste trabalho, e por fim, conclusões são apresentadas no Capítulo 7. 


\section{CONCEITOS}

Para facilitar o entendimento deste trabalho, este capítulo apresenta alguns conceitos básicos de programação paralela, tais conceitos, são apresentados nas próximas seções.

\subsection{Laços Aninhados}

Laços são estruturas que têm como objetivo repetir a execução de um conjunto de instruções por um determinado número de vezes (SAIM A.; MELLAH; MACHMOUM, 2016). Cada repetição do laço é chamada de iteração (SAIM A.; MELLAH; MACHMOUM, 2016; JOHN; GHOSH, 2016). Cada linguagem de programação tem uma forma diferente de implementar uma estrutura de repetição. As mais comuns são; while, for e do-while.

Um laço pode processar computações homogêneas ou computações heterogêneas. No processamento de computações homogêneas, as iterações do laço processam uma mesma instrução. Em contrapartida, no processamento de computações heterogêneas para cada iteração do laço pode ser processada uma instrução diferente.

Existem diversas aplicações que em suas estruturas, utilizam laços perfeitamente aninhados. Quando um laço (for, while, etc) é declarado dentro de outro laço, são formados laços aninhados. Laços aninhados podem processar computações homogêneas ou computações heterogêneas. O algoritmo abaixo ilustra um exemplo de laço aninhado com computação heterogênea. 


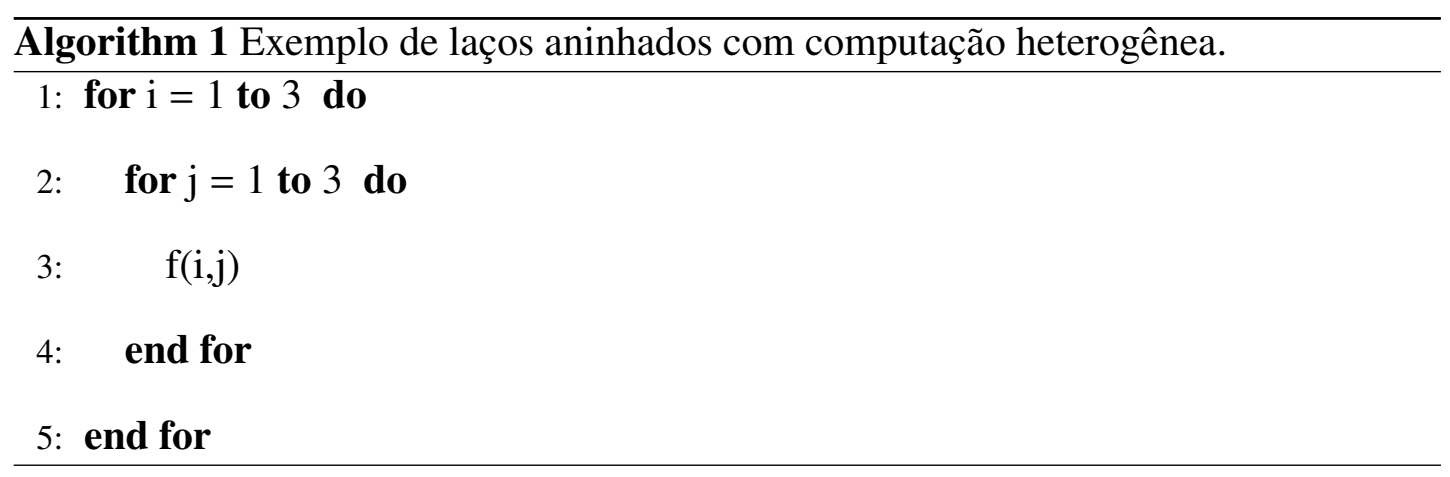

Neste algoritmo, para cada valor de $i$ e $j$ a função $f$ executa uma tarefa diferente. A Figura 1 apresenta uma tabela com o tempo de processamento de cada execução da função $f$.

Figura 1: Tempo de execução para os valores i e j da função f.

\begin{tabular}{|c|c|}
\hline Tarefa & Tempo de Execução (Min) \\
\hline $\mathrm{f}(1,1)$ & 3 \\
\hline $\mathrm{f}(1,2)$ & 9 \\
\hline $\mathrm{f}(1,3)$ & 2 \\
\hline $\mathrm{f}(2,1)$ & 5 \\
\hline $\mathrm{f}(2,2)$ & 1 \\
\hline $\mathrm{f}(2,3)$ & 4 \\
\hline $\mathrm{f}(3,1)$ & 1 \\
\hline $\mathrm{f}(3,2)$ & 7 \\
\hline $\mathrm{f}(3,3)$ & 10 \\
\hline
\end{tabular}

A Figura 2 ilustra o processamento sequencial das execuções de $f$, ou seja, o processamento sequencial do laço aninhado considerado. 
Figura 2: Processamento sequencial de laços aninhados.

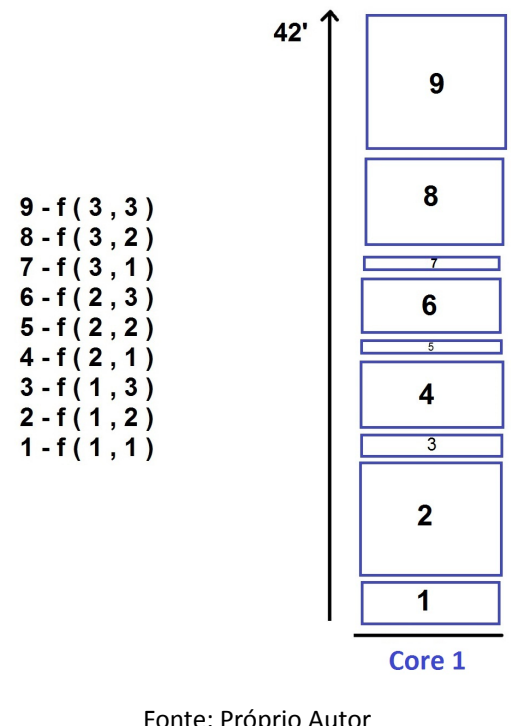

No Algoritmo 1 é possível aplicar 3 estratégias de paralelização. A primeira estratégia consiste em paralelizar o laço da linha 1. A Figura 3 ilustra o processamento paralelo desta estratégia de paralelização.

Figura 3: Processamento paralelo do laço mais externo (laço i).

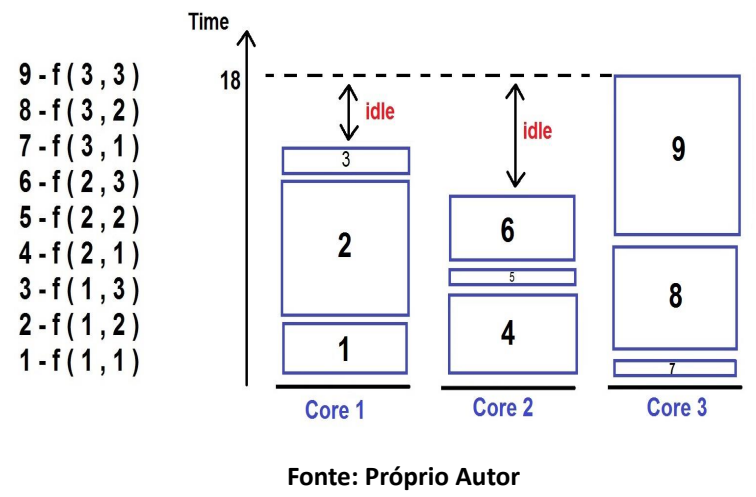

O processamento paralelo permite compartilhar tarefas entre 2 ou mais recursos de processamento (CHIN C.; LAI; CHIU, 2008). Na paralelização do laço mais externo, as execuções da função $\mathrm{f}$ foram compartilhadas entre 3 recursos. Com isso, o tempo de execução do laço aninhado apresentados no Algoritmo 1, passou de 42 minutos para 18 minutos. 
A segunda estratégia de paralelização consiste em paralelizar o laço da linha 2. A Figura 4 ilustra este processamento.

Figura 4: Processamento paralelo do laço mais interno (laço j).

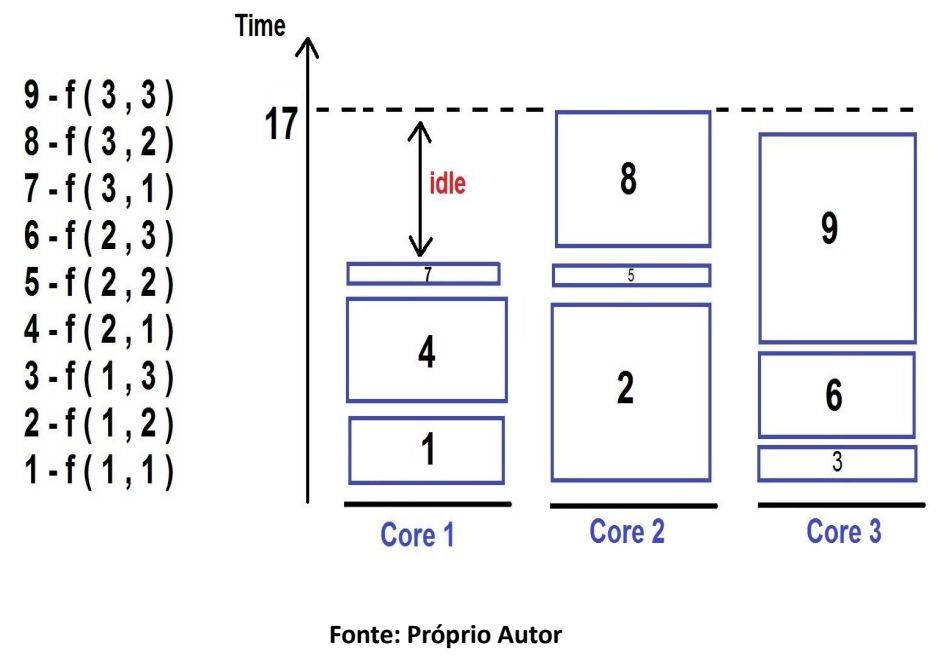

Neste processamento, também são utilizados 3 recursos de processamento, onde, o tempo de processamento passou de 42 minutos para 17 minutos.

A terceira estratégia de paralelização consiste na utilização da técnica de Linearização seguida de uma paralelização. A técnica de linearização permite linearizar os laços aninhados para obter um único laço. O Algoritmo 2 ilustra o único laço obtido com a técnica de linearização.

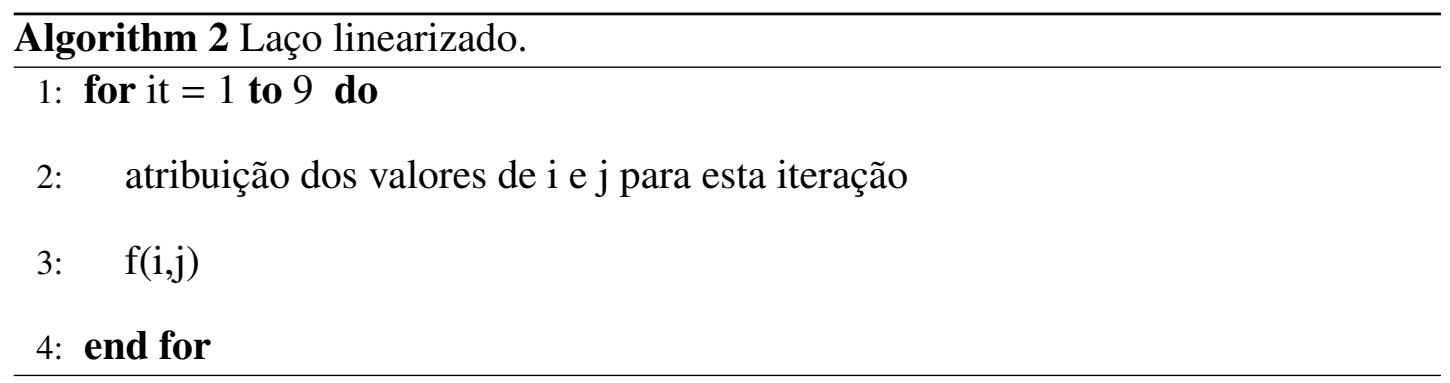

A Figura 5 ilustra o processamento paralelo do único laço obtido. 
Figura 5: Processamento paralelo do laço linearizado.

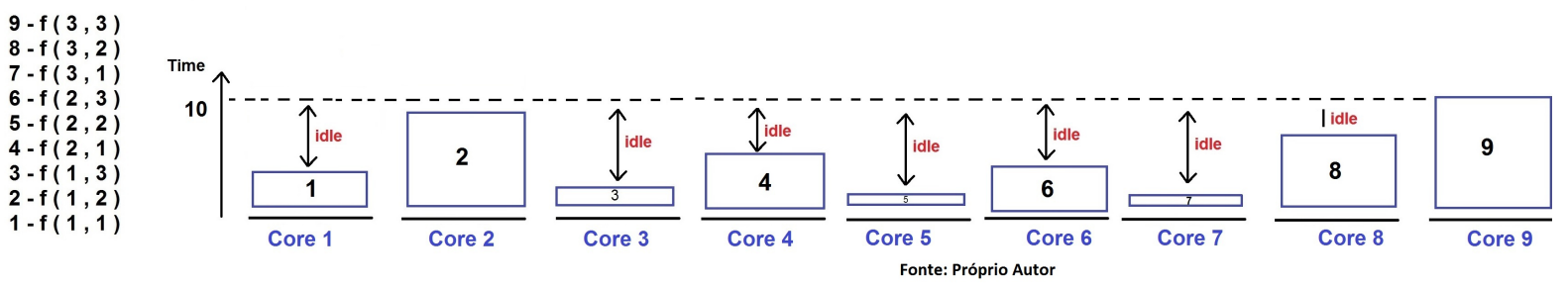

Na execução paralela do único laço são utilizados 9 recursos de processamento. Comparando o processamento sequencial com o processamento paralelo, o tempo de processamento diminuiu de 42 minutos para 10 minutos.

No processamento paralelo, quando as tarefas são heterogêneas, como é o caso das execuções da função $f$, há uma Ociosidade entre os processadores. Observe a Figura 5, o recurso de processamento 1 processa uma execução da função $f$ que leva 3 minutos, enquanto que, o recurso 9 processa uma execução que leva 10 minutos. O recurso 1 irá terminar o seu processamento primeiro que o recurso 9, ficando 7 minutos ocioso, sem nenhuma tarefa para processar. No processamento paralelo, o ideal é que as tarefas sejam atribuídas para os processadores de forma justa e equilibrada, de forma a diminuir a ociosidade entre os processadores e realizando um Balanceamento de Carga de Trabalho. O Balanceamento de Carga permite balancear as cargas de trabalhos entre os processadores, de forma que, todos tenham uma carga de trabalho justa e igual (CARINO.; BANICESCU, 2005).

No exemplo demonstrado neste capítulo, a execução da função $f$ que consome maior tempo de processamento é a $f(3,3)$ que consome 10 minutos de processamento. Dessa forma, mesmo se a quantidade de recurso for igual à quantidade de tarefa, não será possível obter um tempo de processamento menor que 10 minutos. Todavia, ainda é possível realizar uma otimização no uso dos recursos de processamento, de forma que, não haja ociosidade entre os recursos de processamento e também, que não haja uma subutilização dos mesmos. É possível, utilizar uma quantia de recursos 
ideal, onde, os recursos de processamento não fiquem ociosos e não haja uma subutilização dos mesmos. Observe a Figura 6. O tempo mínimo de processamento (10 minutos) foi alcançado com 5 recursos e todos os recursos terminam o processamento em tempos parecidos.

Figura 6: Processamento paralelo com a quantidade ideal de recursos e distribuição de
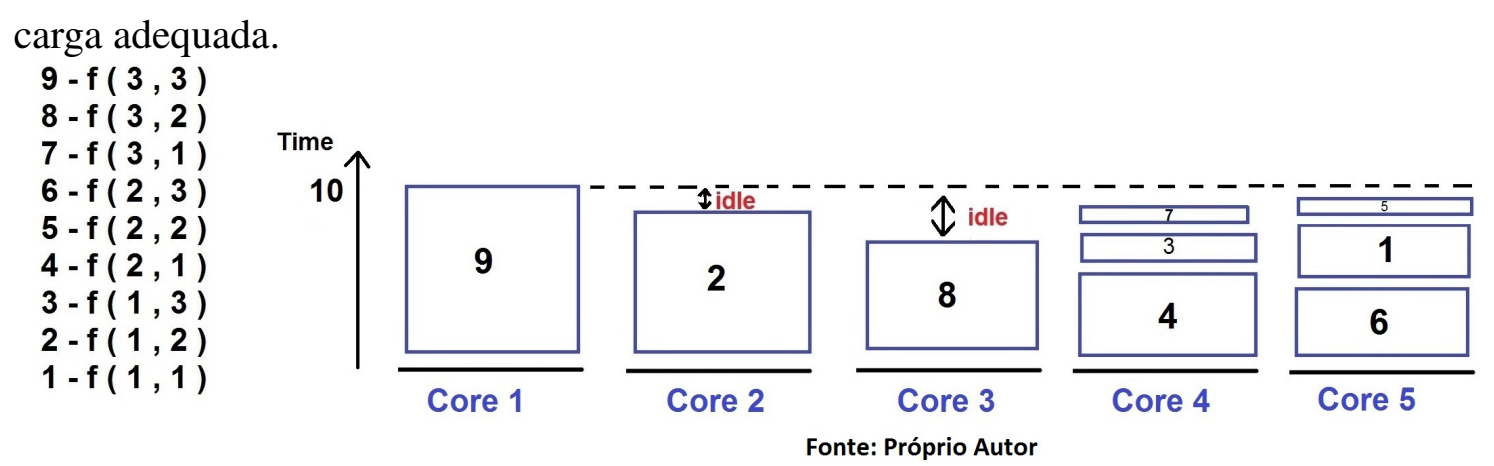

\subsection{Modelos de programação paralela.}

Nesta seção, são apresentados alguns modelos de programação paralela encontrados na literatura.

Um modelo de programação encontrado na literatura é o modelo de programação com memória distribuída. Este modelo consiste em distribuir o processamento entre os computadores presentes em um Cluster. Um Cluster é um aglomerado de computadores conectados por uma rede. Cada computador presente no Cluster é chamado de nó. Neste modelo cada nó possui sua memória local. A comunicação é realizada através de trocas de mensagens.

Outro modelo de programação consiste no modelo de Memória Compartilhada. Neste modelo a comunicação entre as tarefas é realizada através do compartilhamento de espaços de memória. A comunicação é realizada através de uma região de memória compartilhada. Este modelo possui fácil programação. 


\subsection{Escalonamento}

Problemas que envolvem escalonamento ocorrem em diversas áreas. De um modo geral, o problema de escalonamento é definido como se segue. Dados y recursos e $z$ tarefas é preciso alocar os $y$ recursos para as $z$ tarefas, respeitando uma série de restrições pré-estabelecidas, a fim de alcançar um objetivo final (TANENBAUM, 2010; BECK, 2000).

Escalonamento aparece em diversas áreas e de formas variadas. Para um melhor entendimento sobre o conceito de escalonamento, é necessário o entendimento dos seguintes termos:

- Recursos: podem ser entendidos como computadores, dispositivos, aparelhos, máquinas e entre outros.

- Tarefa: pode ser vista como um conjunto de operações que juntas, completam uma rotina.

- Escalonador: é o componente responsável por gerenciar os recursos e escalonar as tarefas para os mesmos. O escalonador é responsável por fornecer a solução de escalonamento das tarefas para os recursos disponíveis.

- Escalonamento: O termo "Escalonamento" caracteriza o processo de alocação de recursos às tarefas como um todo. Uma solução de escalonamento mostra como o problema de alocação de recursos às tarefas pode ser resolvido. As tarefas podem ser escalonadas dinamicamente, em tempo real, ou estaticamente, antes de começar a execução da aplicação.

\subsubsection{Técnicas de Escalonamento de Tarefas}

Um escalonamento de tarefas pode ser classificado em dois grupos: Escalonamento Estático e Escalonamento Dinâmico. Essa classificação baseia-se nas regras 
de escalonamento quanto à consideração do estado atual da aplicação. Como por exemplo, no escalonamento estático não são consideradas as alterações do estado atual da aplicação (TANENBAUM, 2010; S. W.; CHUNG; SHIAN, 2005). Dessa forma, as tarefas são alocadas antes da execução da aplicação e a execução é feita em função do escalonamento estabelecido. $\mathrm{O}$ escalonamento dinâmico detecta alterações no estado atual da aplicação e gerencia os recursos com base nas informações atuais da aplicação (TANENBAUM, 2010; S. W.; CHUNG; SHIAN, 2005). As tarefas são alocadas em tempo de execução, considerando as informações e condições da aplicação.

Na literatura, os algoritmos de escalonamento dinâmicos mais comuns são:

- FIFO: no algoritmo de escalonamento FIFO (First In First Out) as tarefas são colocadas em uma fila ordenada por ordem de chegada. Em FIFO o escalonamento é feito obedecendo ao instante de chegada de cada tarefa, ou seja, a tarefa que ocupa o primeiro lugar na fila será a próxima a ser escalonada para o recurso. A tarefa escalonada recebe o uso do recurso até a sua finalização. Quando uma tarefa que estava em execução é finalizada, a próxima tarefa que se encontra na fila é então, escalonada para utilizar o recurso (TANENBAUM, 2010).

- HPF: o escalonamento HPF (Highest Priority First), também chamado de escalonamento por prioridades é uma variante do escalonamento FIFO. Em HPF as tarefas em espera pelo recurso são organizadas em uma fila obedecendo a sua prioridade. Na fila, as posições são ocupadas por tarefas em ordem decrescente de prioridade. Com isso, a função de seleção para o escalonamento, favorece as tarefas consideradas mais importantes (TANENBAUM, 2010).

- SJF: o algoritmo de escalonamento SJF (Shortest Job First) é um caso especial do HPF, onde o escalonamento é realizado em função do tempo de execução das tarefas. As tarefas em espera pelos recursos são organizadas em uma fila obedecendo a seu tempo de execução. As tarefas com menores tempos de execução 
são colocadas na frente da fila (TANENBAUM, 2010).

- HRN: escalonamento HRN (Highest Response-Ratio Next) é uma versão mais eficiente do escalonamento SJF. Em HRN é realizado um balanceamento entre a duração da tarefa e seu tempo de espera, de forma a compensar a espera excessiva de tarefas de maior duração (TANENBAUM, 2010).

\subsubsection{Técnicas de Escalonamento de Iterações de Laço Paralelo}

Existem diversas técnicas de escalonamento de iterações de laço paralelo na literatura. Neste trabalho, são utilizadas as técnicas de escalonamento de iterações estático e dinâmico (Self-Scheduling e Guided).

A técnica de escalonamento estático consiste em atribuir as iterações do laço paralelo em tempo de compilação. Desta forma, antes do processamento começar cada recurso de processamento já sabe quais iterações do laço paralelo terá que processar (POLYCHRONOPOULOS, 1988).

Na técnica de escalonamento dinâmico, as iterações do laço paralelizado são atribuídas para os recursos em tempo de processamento. Assim, o recurso somente sabe quais iterações terá que processar na hora da execução. A técnica de escalonamento dinâmico Self-Scheduling é usada principalmente para lidar com o balanceamento de cargas. Durante o Self-Scheduling o processador ocioso busca a próxima tarefa ou um bloco de tarefas de tamanho definido pelo usuário em um pool de tarefas compartilhadas. Um processo (processo mestre) fica responsável por enviar tarefas para os outros processos (processos escravos). Quando um escravo termina de processar a sua tarefa ou o seu bloco, ele envia uma mensagem para o nó mestre avisando que terminou a execução e logo em seguida, o nó mestre envia outra tarefa ou bloco de tarefa para este escravo (POLYCHRONOPOULOS, 1988).

Na técnica de escalonamento Guided a atribuição de iterações é realizada em blo- 
cos dinamicamente. O tamanho de bloco é calculado dinamicamente e varia ao longo das atribuições durante a execução. A idéia principal desta técnica é iniciar o processamento das iterações do laço atribuindo quantias de iterações cujo tamanho começa com $\frac{n}{p}$ e continua a diminuir até que todas as iterações estejam atribuídas. Em $\frac{n}{p}, n$ é a quantidade de iterações do laço paralelo e $p$ é a quantidade de recurso de processamento (POLYCHRONOPOULOS, 1988). 


\section{TRABALHOS RELACIONADOS}

Neste capítulo são apresentados alguns trabalhos encontrados na literatura que se relacionam com a metodologia proposta. Tais trabalhos são descritos nas próximas seções.

\subsection{Melhoria no Balanceamento de Carga Usando Self Schedule em Intel Xeon Phi}

Atualmente, coprocessadores, tais como; GPU e Xeon Phi são boas alternativas para processar aplicações que necessitam de um alto poder computacional. Em (HUANG C.; W.; CHEN, 2015) é apresentado um estudo sobre como melhorar o balanceamento de carga de trabalho na paralelização de laços utilizando a técnica de escalonamento Self Schedule em um ambiente de processamento composto por recursos heterogêneos. Em (HUANG C.; W.; CHEN, 2015), os experimentos foram realizados com a técnica de escalonamento Self Schedule e executados em dois diferentes coprocessadores Xeon Phi e dois processadores Xeon. Nos experimentos realizados, foram observadas as características que melhoram o balanceamento de carga entre os recursos heterogêneos. Os experimentos foram executados em uma máquina com 2 processadores Intel Xeon E5-2650, 1 Intel Xeon Phi 5110P e 1 Intel Xeon Phi 7120 e foi utilizada a linguagem OpenMP (DAGUM; MENON, 1998). 


\subsection{HOMP: Distribuição Automatizada de Laços Para- lelos em Sistemas de Aceleradores Altamente Para- lelos}

Ambientes de processamento heterogêneos, tais como, ambientes compostos por CPUs, GPUs e Xeon Phi oferecem ganho de desempenho no processamento de aplicações. Para usar vários recursos de processamento heterogêneos em conjunto, é necessário realizar esforços para alcançar um bom desempenho (YAN Y.; LIU; UMAR, 2017). Em (YAN Y.; LIU; UMAR, 2017) é apresentada uma interface de programação chamada HOMP, que automatiza a distribuição das iterações dos laços paralelos para os recursos heterogêneos tais como, GPU, CPUs e MICs. Nesta interface, foi explorado o uso da linguagem de programação paralela OpenMP para permitir que os usuários desenvolvam aplicações paralelas que automaticamente e simultaneamente utilizem todos os diferentes recursos de processamento disponíveis. Esta automatização melhora a adaptação dos códigos paralelos para os diversos e diferentes recursos computacionais presentes em um único computador.

\subsection{Escalonamento de Laços com Dependência de Ite- rações em Cluster Heterogêneo}

No processamento paralelo, quando há dependência de dados ou de iteração, o algoritmo de escalonamento tende a ficar mais específico. A presença de dependências de iterações implica em um grau de dificuldade adicional e torna o escalonamento mais restrito. Em (CIORBA M.; ANDRONIKOS; PAPAKONSTANTINOU, 2006) é apresentada uma técnica para o problema de escalonamento de laços aninhados com dependência de iterações para Clusters compostos por máquinas heterogêneas. Os experimentos realizados neste artigo foram executados em um Cluster composto por máquinas heterogêneas. 


\subsection{Eficiência no Escalonamento de Laços Aninhados Paralelos em Sistemas Multicores}

Habitualmente, o tempo de execução de laços paralelos representa boa parte do tempo total de execução da aplicação paralela (NICOLAU A.; VEIDENBAUM, 2009). Por esta razão, os autores de (NICOLAU A.; VEIDENBAUM, 2009) apresentam uma solução para melhorar a eficiência do escalonamento de laços perfeitamente e imperfeitamente aninhados em computadores multicores. Neste artigo é apresentada uma técnica que realiza o escalonamento das iterações do laço aninhado de modo a manter o cache coerente.

\subsection{Escalonamento Dinâmico de Laços Aninhados com Dependência em Cluster Heterogêneo}

Nos últimos anos, algoritmos de escalonamento estático têm sido propostos para paralelizar laços com dependências para Cluster composto por máquinas heterogêneas (RIAKIOTAKIS; TSANAKAS, 2005). No entanto, a heterogeneidade do Cluster exige uma solução dinâmica para os problemas de balanceamento e escalonamento. Algoritmos de escalonamento dinâmico também têm sido propostos, entretanto, todos eles lidam com laços paralelos e sem dependências (RIAKIOTAKIS; TSANAKAS, 2005). Em (RIAKIOTAKIS; TSANAKAS, 2005), é apresentado um algoritmo de escalonamento dinâmico para escalonar tarefas com dependências de dados em Cluster composto por máquinas heterogêneas. $\mathrm{O}$ algoritmo proposto neste artigo pode ser aplicado para ambientes de processamento homogêneos ou heterogêneos. Em (RIAKIOTAKIS; TSANAKAS, 2005) os autores relatam que os resultados obtidos revelam que algoritmos de balanceamento de carga dinâmicos são mais adequados para o escalonamento de laços aninhados com dependência em Cluster composto por máquinas heterogêneas ou homogêneas. 


\subsection{Melhoria no Escalonamento de Tarefas Dependen- tes para Aplicações em Grid}

Em (MACHTANS E.; SATO; DEPPMAN, 2009) é apresentada uma técnica para melhorar o escalonamento de tarefas dependentes para aplicações em Grid. Neste artigo são discutidas as ineficiências de algumas técnicas de transferência de arquivos, e é proposta uma heurística para o escalonamento de tarefas dependentes e independentes que chegam em tempo real para serem processadas pelo Grid. Em suma, o artigo (MACHTANS E.; SATO; DEPPMAN, 2009) apresenta duas contribuições, a primeira contribuição é a criação de uma heurística chamada de Description of the Best File-Transfer Time Heuristic (BFTT) para realizar transferência de arquivos de dados de um recurso para outro em Grid. A segunda contribuição é o desenvolvimento de um algoritmo de escalonamento chamado Maestro que escalona tarefas dependentes e independentes.

Considerar e atenuar o problema de tempo gasto na transferência de arquivos de dados de um recurso para outro no Grid é de importância fundamental para a otimização do tempo de execução total da aplicação. A técnica heurística BFTT foi proposta em (MACHTANS E.; SATO; DEPPMAN, 2009) com dois objetivos principais. O primeiro objetivo é de reduzir o tempo gasto na transferência de arquivos de dados entre os diferentes recursos no Grid. O segundo objetivo é garantir um bom desempenho e bom equilíbrio de carga de trabalho entre os recursos do Grid.

\subsection{Um Algoritmo Heurístico para Paralelização de Laços Aninhados}

Computação paralela é uma solução eficiente para melhorar o desempenho de aplicações. A fase de escalonamento de tarefa é um estágio da computação paralela e distribuída. Em (HAJIESKANDAR; LOTFI, 2010) é apresentado um algoritmo heurístico para escalonar as iterações dos laços aninhados. Neste artigo, desenvolve-se uma 
abordagem baseada em cromossomos bipartidos. Os resultados experimentais apresentados neste artigo mostram que, a solução heurística apresentada, oferece um melhor desempenho que outras soluções alternativas da literatura.

\subsection{Laços Coalescing: Uma técnica de compilação para a transformação de espaços iterativos não uniforme}

Laços paralelos é uma boa alternativa para melhorar o desempenho de aplicações. Em (KEJARIWA A.; NICOLAU; POLYCHRONOPOULOS, 2008) é apresentada uma técnica de compilação para paralelizar laços aninhados. A solução apresentada nesse artigo utiliza uma técnica chamada Coalesce. Dado um laço aninhado, esta técnica obtém um único laço. A solução apresentada em (KEJARIWA A.; NICOLAU; POLYCHRONOPOULOS, 2008) é aplicada somente para computadores Multicores. Para balancear a carga de trabalho no processamento, a solução apresentada neste artigo utiliza o algoritmo de escalonamento GSS. Em (KEJARIWA A.; NICOLAU; POLYCHRONOPOULOS, 2008) é considerado que as iterações do laço aninhados contém tempos de execução heterogêneos.

\subsection{Considerações Sobre as Propostas Apresentadas}

Os trabalhos descritos neste capítulo apresentam alguns aspectos semelhantes e outros divergentes com a metodologia aqui proposta. Esta seção destina-se a apresentar considerações sobre estes trabalhos com a metodologia aqui proposta.

Os trabalhos apresentados em (RIAKIOTAKIS; TSANAKAS, 2005; CIORBA M.; ANDRONIKOS; PAPAKONSTANTINOU, 2006; YAN Y.; LIU; UMAR, 2017; HUANG C.; W.; CHEN, 2015) trazem soluções para a paralelização de laço, todavia, focando na paralelização de laços em ambiente de processamento composto por recursos heterogêneos. Já os trabalhos apresentados em (NICOLAU A.; VEIDENBAUM, 2009; MACHTANS E.; SATO; 
DEPPMAN, 2009; HAJIESKANDAR; LOTFI, 2010) focam na criação de algoritmos para paralelizar as iterações do laço. Este trabalho apresenta uma metodologia para a paralelização de laços perfeitamente aninhados com processamento heterogêneo. Implementando a metodologia proposta, é possível melhorar a eficiência de aplicações que contêm laços perfeitamente aninhados com processamento heterogêneo, através do aumento de desempenho e redução da ociosidade dos recursos de processamento. Aspectos que não são considerados nos demais trabalhos.

O trabalho apresentado em (KEJARIWA A.; NICOLAU; POLYCHRONOPOULOS, 2008) apresenta aspectos semelhantes ao trabalho aqui apresentado. Em (KEJARIWA A.; NICOLAU; POLYCHRONOPOULOS, 2008) é apresentada uma solução para paralelizar laços aninhados. Problema que também é considerado nesta tese. Todavia, esta tese apresenta uma solução paralela para computadores Multicores e Clusters, a solução apresentada em (KEJARIWA A.; NICOLAU; POLYCHRONOPOULOS, 2008) é aplicada somente para computadores Multicores. Na tese apresentada neste trabalho, é criado um algoritmo de escalonamento onde a atribuição de tarefas se baseia em uma distribuição específica, onde, as tarefas de maior tempo de execução, são atribuídas para os recursos que contém a menor carga de trabalho. O algoritmo utilizado nesta tese permite realizar um balanceamento de carga no processamento, impactando em uma baixa ociosidade no processamento Já em (KEJARIWA A.; NICOLAU; POLYCHRONOPOULOS, 2008) é utilizado o algoritmo o algoritmo dinâmico GSS para balancear a carga de trabalho no processamento. Em (KEJARIWA A.; NICOLAU; POLYCHRONOPOULOS, 2008) é considerado que as iterações do laço aninhados contém tempo de execução heterogêneo, aspecto que também é considerado neste trabalho. 


\section{METODOLOGIA E FERRAMENTAS PARA PARALELIZAÇÃO DE LAÇOS PERFEITAMENTE ANINHADOS COM PROCESSAMENTO HETEROGÊNEO.}

Aplicações podem apresentar laços perfeitamente aninhados que demandam um alto poder de processamento. Tais laços podem processar computações heterogêneas. Uma solução para reduzir o tempo de execução desta classe de aplicações é a paralelização destes laços. A heterogeneidade dos tempos de execução de computações heterogêneas presentes nas iterações de tais laços demanda uma paralelização adequada visando a uma distribuição de carga homogênea entre os recursos computacionais para reduzir a ociosidade de tais recursos. Esta heterogeneidade implica em um número ideal de recursos computacionais, a partir do qual, o seu aumento não impactaria no ganho de desempenho, uma vez que, o tempo mínimo possível é o tempo de execução da tarefa que consome o maior tempo de processamento.

A metodologia aqui proposta consiste em executar uma série de procedimentos para paralelizar laços perfeitamente aninhados com computações heterogêneas em ambientes paralelos e distribuídos. Alguns procedimentos são apoiados por ferramentas desenvolvidas para auxiliá-los.

O objetivo desta metodologia de paralelização é, além de proporcionar a redução do tempo de processamento, é prover o uso adequado dos recursos de processamento, minimizando a ociosidade. A redução da ociosidade no processamento é realizada através de uma estratégia de escalonamento e do cálculo do número ideal de recursos 
de processamentos que deverão ser utilizados no processamento paralelo.

Para um melhor entendimento da metodologia e das ferramentas propostas, nos exemplos apresentados neste capítulo é considerado um laço aninhado de 3 níveis $(i, j, k)$. Este laço aninhado é ilustrado no Algoritmo 3.

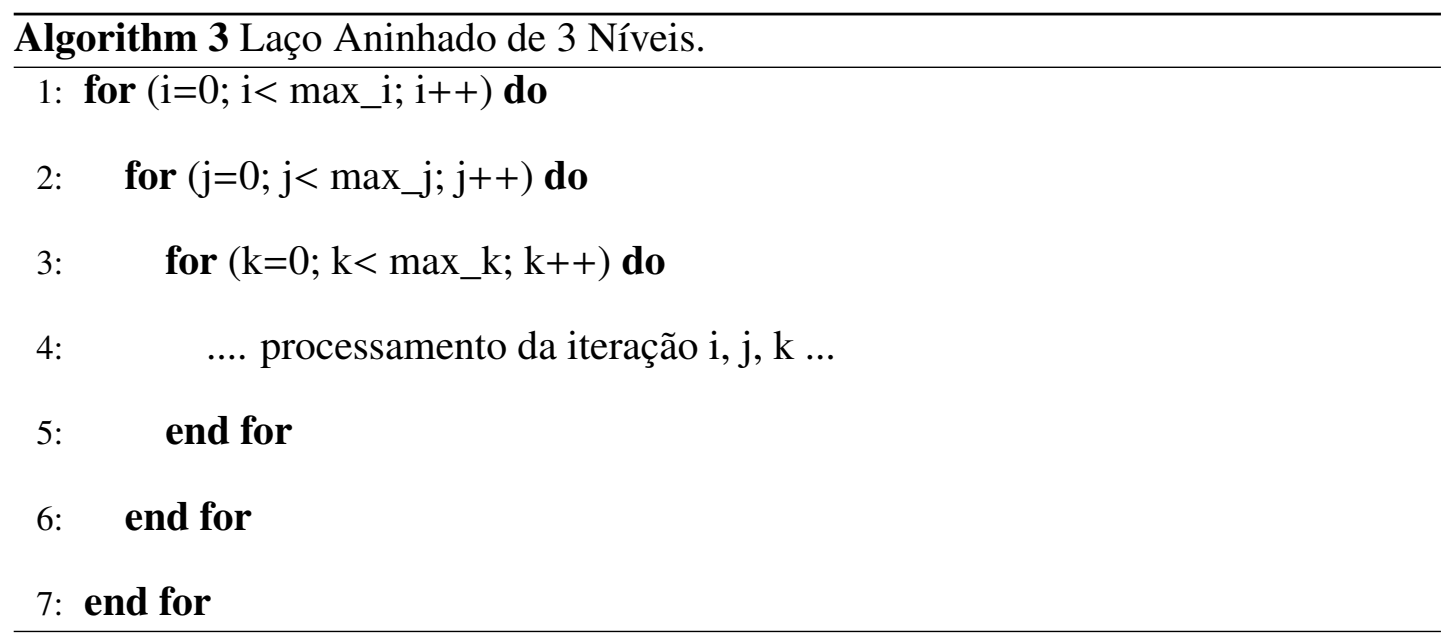

\subsection{Estratégia de Paralelização da Aplicação}

Uma aplicação pode apresentar múltiplas ocorrências de laços perfeitamente aninhados com computações heterogêneas. Devido à presença de partes executadas sequencialmente e também como cada ocorrência de laço aninhado demanda um número ideal de recursos computacionais específico, a alocação dos recursos de processamento é realizada no momento da sua utilização, portanto, dinamicamente. A estratégia de paralelização aqui apresentada realiza a alocação de recursos dinamicamente e promove a paralelização individual de cada ocorrência de laços perfeitamente aninhados com computação heterogênea, presente na aplicação.

Uma solução de paralelização de laços aninhados consiste em paralelizar o laço mais externo. Esta solução promove um grau de paralelismo limitado ao número de iterações. Por exemplo, para um total de 10 iterações o número máximo de recursos a serem utilizados é 10, limitando o ganho de desempenho possível para 10. Outra solução possível consiste em paralelizar o laço mais interno. Esta solução além de resultar 
em um limite de grau de paralelismo, impacta no desempenho devido à sincronização necessária no final da execução deste laço. Uma solução, adotada na estratégia aqui proposta, é transformar os laços aninhados em um único laço, ou seja, aplicar uma linearização dos laços, o que elimina os limites de graus de paralelismo mencionados e não implica em custos de sincronizações, e a seguir, paralelizá-lo.

Para melhorar o desempenho e diminuir a ociosidade entre os processadores na execução de um laço linearizado e paralelizado é necessário definir a quantidade ideal de recursos de processamento e realizar um escalonamento de tarefas adequado. $\mathrm{O}$ cálculo do número de recursos de processamento visa definir o número ideal de recursos a ser utilizado no processamento, a partir do qual não se teria uma melhora de desempenho no processamento. Para cada ocorrência de laço aninhado é calculada uma quantidade ideal de recursos específica. O número de recursos computacionais a serem utilizados na execução de cada ocorrência de laços aninhados deve ser o mínimo entre o número calculado e o número informado pelo usuário, caso seja especificado.

A estratégia de escalonamento para a distribuição das iterações aos recursos computacionais visa balancear a carga de trabalho entre tais recursos, a fim de, diminuir a ociosidade. Esta distribuição tem como base o tempo de execução de cada iteração do laço linearizado.

A metodologia aqui proposta pode ser implementada e processada em sistemas paralelos e distribuídos, tais como, computadores multicores e sistemas distribuídos, tais como, Clusters físicos ou virtuais alocados na nuvem. No caso de computação em nuvem, a metodologia proposta pode refletir em um menor custo na alocação de máquinas virtuais. As máquinas virtuais são ativadas de acordo com a quantidade de recursos estabelecida pela metodologia.

A estratégia de paralelização se aplica tanto a laços únicos como a laços perfeitamente aninhados. Também é considerado que não existe dependência de dados entre as iterações dos laços. 


\subsection{Descrição da Metodologia}

A metodologia proposta para a paralelização de laços perfeitamente aninhados presentes na aplicação é composta pelas seguintes atividades:

\section{Criação do Arquivo de Tempos Iniciais}

Nesta atividade é criado o arquivo que contém os tempos de execução das iterações dos laços aninhados.

\section{Linearização.}

A atividade de Linearização consiste em linearizar os laços aninhados e transformá-los em um único laço.

\section{Preparação da Paralelização do Código da Aplicação.}

Nesta atividade é realizada a preparação do código da aplicação para o processamento paralelo.

\section{Leitura dos Tempos.}

Esta atividade consiste em ler os tempos de execução das iterações dos laços aninhados lidos e montar um vetor de tempos.

\section{Cálculo do Valor Inicial do Número Ideal de Recursos de Processamento.}

Esta atividade consiste em calcular o valor inicial do número ideal de recursos de processamento.

\section{Escalonamento das Iterações do Laço Linearizado.}

Esta atividade consiste em escalonar as iterações do laço paralelizado para os recursos computacionais. Nesta atividade é também realizado um refinamento do número ideal de recursos de processamento.

\section{Processamento Paralelo.}

Nesta atividade o processamento paralelo da aplicação é realizado. As iterações 
do laço paralelizado são processadas nesta atividade.

\section{Coleta de Tempos.}

O tempo de execução de cada iteração é coletado durante a execução da aplicação e armazenado em um arquivo de histórico.

A metodologia proposta é constituída de duas fases:

- Paralelização da Aplicação;

- Execução da aplicação.

Na fase de preparação da aplicação paralelizada são realizadas todas as atividades necessárias para preparar a aplicação para a execução paralela. Nesta fase, para cada ocorrência de laços aninhados são realizadas as atividades 1,2 e 3 . Já na fase de execução da aplicação são realizadas todas as atividades para processar a aplicação paralelizada, ou seja, as atividades 4, 5, 6, 7 e 8 .

A Figura 7 ilustra as duas fases da metodologia.

Figura 7: Fases da metodologia.

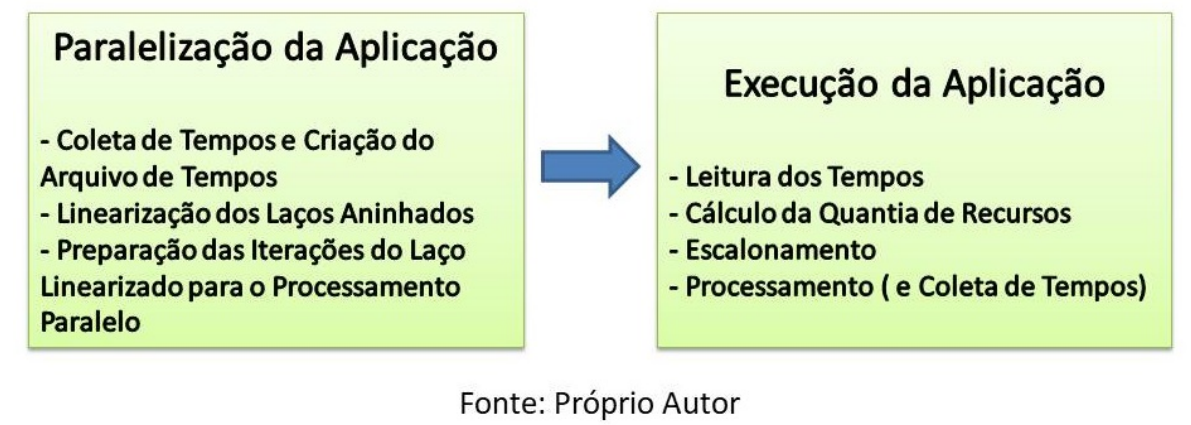

\subsection{Preparação da Aplicação Paralelizada}

A preparação da aplicação paralelizada consiste em realizar atividades para preparar a aplicação para o processamento. Nesta fase, o código paralelo da aplicação é criado. 


\subsubsection{Criação do Arquivo de Tempos Iniciais}

Algumas atividades presentes na metodologia necessitam dos tempos de execução das iterações dos laços perfeitamente aninhados. Estes tempos são coletados durante a execução da aplicação e armazenados em um arquivo de histórico. Devido ao fato destes tempos serem coletados em tempo de execução, na fase de preparação da aplicação se faz necessária a criação do arquivo contendo tempos iniciais. Estes tempos são utilizados pelas demais atividades da metodologia na primeira execução da aplicação. A partir da segunda, os tempos são lidos do arquivo de histórico. Neste arquivo de histórico, são mantidos os tempos coletados mais recentemente, por exemplo, os últimos 10 tempos de execução.

Uma solução para se obter os tempos iniciais consiste em executar a aplicação de forma sequencial uma vez e coletar os tempos de execução das iterações dos laços aninhados. Outra solução seria apenas estipular os valores dos tempos iniciais. Poderia, neste caso, adotar tempos calculados com base no custo de cada execução do laço mais interno. Por exemplo, no caso da aplicação aqui utilizada como estudo de caso, foram coletados os tempos de execução de cada algoritmo de modelagem que são executados no laço mais interno dos laços aninhados.

\subsubsection{Linearização}

A atividade de linearização consiste em linearizar os laços aninhados, transformando-os em um único laço. A solução de linearização elimina o problema do limite no grau de paralelismo e os custos decorrentes das sincronizações.

Cada ocorrência de laços aninhados, que não contém dependência de dados, presente na aplicação, é linearizada. As informações de cada iteração dos laços aninhados são armazenadas em estruturas chamadas task. Considerando um laço aninhado de 3 níveis $(i, j, k)$, a Figura 8 ilustra uma task para armazenar informações de uma iteração 
de um laço aninhado.

A estrutura task armazena os valores de cada iteração do laço aninhado.

Figura 8: Exemplos de Task.

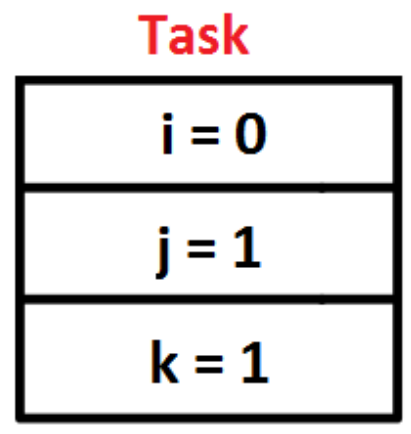

Fonte: Próprio Autor

Opcionalmente, pode ser inserido na task um ou mais campos com informações necessárias na execução do corpo do laço. A seguir são apresentados exemplos de implementação de task em algumas plataformas. Em alguns exemplos, a estrutura task contém um vetor chamado de vet_iter. Cada nível do laço aninhado $(i, j, k, \ldots)$ é correspondente a um elemento de vet_iter. Considerando um laço aninhado de 3 níveis, o tamanho de vet_iter é 3.

A Figura 9 ilustra um exemplo de implementação de task na plataforma C. Na plaraforma $\mathrm{C}$, vet_iter é um ponteiro de inteiros.

Figura 9: Exemplo de implementação de task em C.

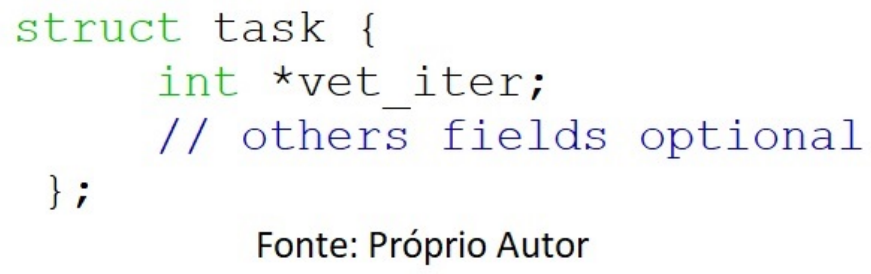

A Figura 10 mostra um exemplo de implementação de task na plataforma R. 
Figura 10: Exemplo de implementação de task em R.

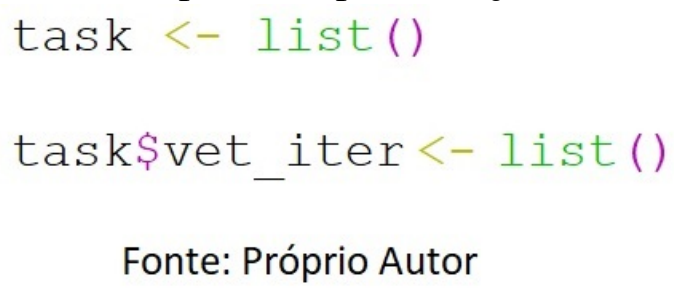

Fonte: Próprio Autor

A Figura 11 mostra um exemplo de implementação de task na plataforma R para a aplicação de Biodiversidade utilizada como estudo de caso neste trabalho. Nesta ilustração, os campos pa, run e model são equivalentes aos campos i, j e k da ilustração de task apresentada na Figura 8. A fase de modelagem é executada por um laço aninhado de 3 níveis, que são as PA, Runs e modelos (mais detalhes em Capítulo 6). O campo mod.prep.dat é um campo criado adicionalmente para passar dados adicionais para o processamento.

Figura 11: Exemplo de implementação de task em R na aplicação de Biodiversidade.

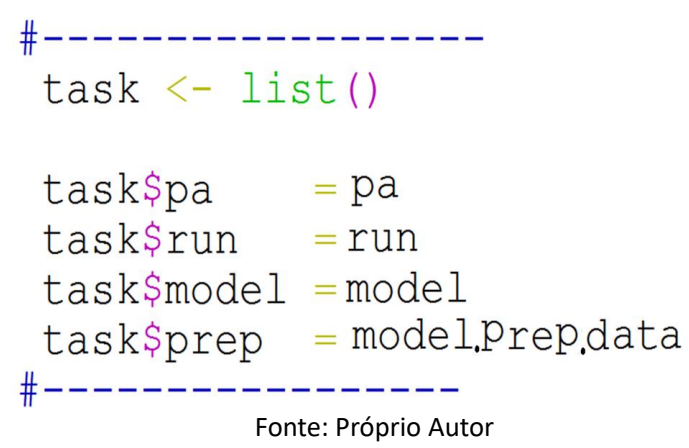

Para a aplicação de biodiversidade considerada como estudo de caso neste trabalho, não houve a necessidade de criar o vet_iter, porque no processo de modelagem, somente é utilizado um laço aninhado de 3 níveis, logo, como a quantidade de níveis do laço é conhecida, não há a necessidade de criar o vet_iter, podendo criar os campos na própria estrutura task.

Cada task é um elemento de um vetor chamado task_vector. A Figura 12 ilustra um exemplo de vector_task. Neste exemplo, é considerado um vector_task 
capaz de armazenar 27 tasks. Para cada recurso de processamento é criado um vetor, onde, cada elemento é uma estrutura task obtida de task_vector. Para cada ocorrência de laço aninhado apresentada na aplicação, é criado um vector_task.

Figura 12: Exemplo de vector_task.

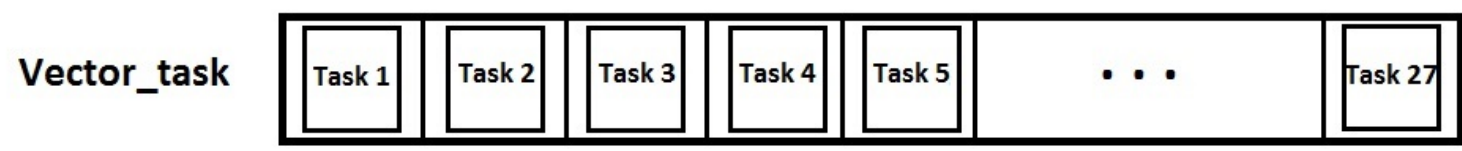

Fonte: Próprio Autor

A Figura 13 mostra um exemplo de implementação de vector_task em C.

Figura 13: Exemplo de implementação de vector_task em C.

struct task *task vector $=($ struct task *) malloc $((n) *$ sizeof (struct task)) ;

Fonte: Próprio Autor

A Figura 14 mostra um exemplo de implementação de vector_task em R e para a aplicação da Biodiversidade utilizada como estudo de caso neste trabalho.

Figura 14: Exemplo de implementação de vector_task em $\mathrm{R}$ e para a aplicação da Biodiversidade.

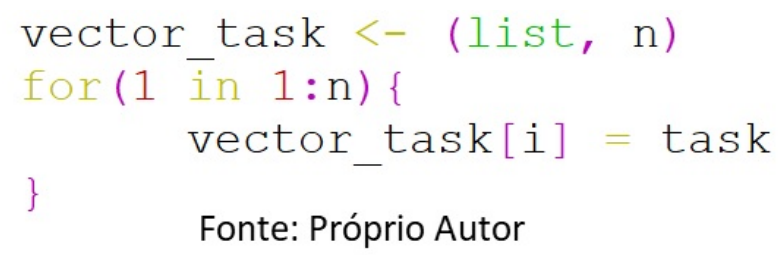

Fonte: Próprio Autor

O vector_task possui as informações das iterações de todo o laço aninhado. Dessa forma, para processar as iterações do laço aninhado, basta processar o vector_task em um único laço. Em cada iteração do laço linearizado é obtido o 
elemento de vector_task correspondente, ou seja, para cada iteração do laço linearizado é um obtida uma task de vector_task. Com a task correspondente, é possível obter os valores das iterações do laço aninhado $(i, j, k \ldots)$ que corresponde à iteração do laço aninhado em questão. As tasks e o vector_task são criados na ferramenta de escalonamento, não sendo necessário o usuário se preocupar com estas criações.

\subsubsection{Preparação da Paralelização do Código da Aplicação}

Nesta atividade é realizada a preparação do código para o processamento paralelo. As atividades de Cálculo do Número ideal de Recursos de Processamento, Escalonamento e Processamento são aplicadas no código da aplicação. Esta preparação é realizada para cada ocorrência de laços perfeitamente aninhados na aplicação.

A seguir, são apresentados exemplos de implementações das atividades realizadas pela metodologia em algumas linguagens e plataformas de processamento. Após linearizar um laço perfeitamente aninhado e obter um único laço, é necessário calcular o número ideal de recursos de processamento. Foi desenvolvida uma ferramenta que realiza este cálculo e retorna um número preliminar do número ideal de recursos de processamento. Este valor é obtido através de um cálculo matemático apresentado na Seção 4.4.2. Este número é refinado na atividade de escalonamento, mais detalhes são dados na Seção 4.4.2.

$\mathrm{Na}$ implementação desta atividade basta apenas realizar uma chamada da ferramenta de cálculo do valor inicial do número ideal de recursos de processamento. A Figura 15 ilustra a chamada desta ferramenta na plataforma C. Nesta ilustração, é passado como parâmetro o vetor de tempos e a sua quantidade de elementos. Por exemplo, considerando um laço aninhado de 3 níveis, é passado como parâmetro o valo máximo de $i, j, k$, conforme na ilustração. 
Figura 15: Exemplo de chamada da ferramenta de cálculo do valor inicial do número ideal de recursos na plataforma $\mathrm{C}$.

// Get resouces number

int resources_number $=$ calc_resources_number (time_vet, max_i * max_j * max_k) ; Fonte: Próprio Autor

A Figura 16 mostra como é chamada a ferramenta de cálculo do valor inicial do número ideal de recursos no ambiente $R$.

Figura 16: Exemplo de chamada da ferramenta de cálculo do valor inicial do número ideal de recursos de processamento em $R$.

number_resource $=$.number_resource_tool (vector_time, max_i $*$ max_j $*$ max_k )

Fonte: Próprio Autor

A Figura 17 mostra como é chamada a ferramenta de cálculo do valor inicial do número ideal de recursos no ambiente $R$ para a aplicação da Biodiversidade utilizada como estudo de caso neste trabalho.

Figura 17: Exemplo de chamada da ferramenta de cálculo do valor inicial do número ideal de recursos de processamento em $R$ para a aplicação da Biodiversidade. number_resource $=$.number_resource_tool (vector_time, pa $\star$ run $*$ model) Fonte: Próprio Autor

Após executar a atividade de cálculo do valor inicial do número ideal de recursos, é necessário executar a atividade de escalonamento. Também foi desenvolvida uma ferramenta de escalonamento para auxiliar esta atividade. A execução desta atividade consiste na chamada desta ferramenta. A estratégia de escalonamento implementada 
nesta ferramenta é apresentada na Seção 4.4.3. A Figura 18 ilustra a chamada para a ferramenta de escalonamento na linguagem C. A ferramenta de escalonamento recebe como parâmetro, o vetor de tempos, o valor inicial do número ideal de recursos de processamento, a quantidade de níveis do laço aninhado (por exemplo para um laço aninhado de $i, j, k$ é passado o número 3) e o vetor vector_int_amount_per_level. Cada elemento de vector_int_amount_per_level representa um nível do laço aninhado e armazena o seu valor máximo. Por exemplo, para um laço aninhado de $i$ até 5, $j$ até 3 e $k$ até 4, o tamanho de vector_int_amount_per_level é 3, sendo que, a primeira posição armazena o valor 5, a segunda posição o valor 3 e última posição o valor 4. A ferramenta de escalonamento retorna listas de tarefas para cada recurso.

Neste exemplo, após chamar a ferramenta de escalonamento, task_list_per_core será uma estrutura que contém listas de tarefas para cada recurso de processamento. Uma task_list_per_core contém os campos task_list que armazena uma lista de task e o campo task_amount que armazena a quantidade de tasks atribuída para o recurso.

Figura 18: Exemplo de chamada da ferramenta de escalonamento em C.

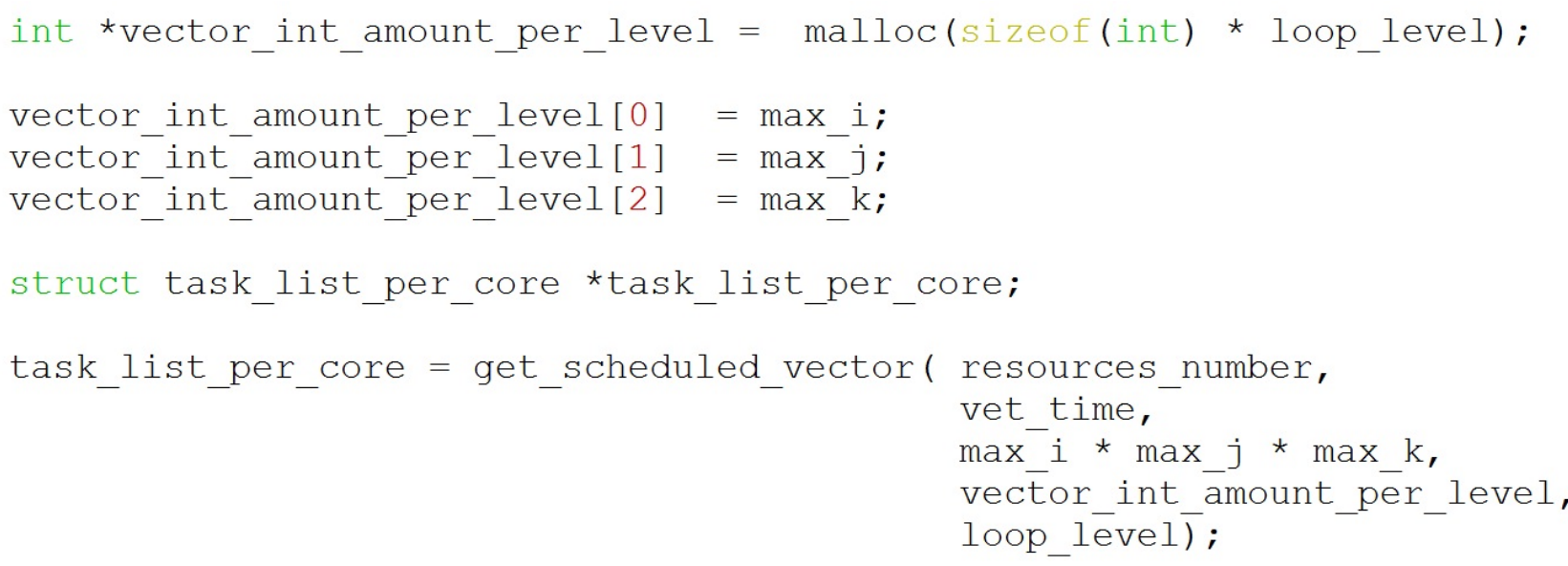

Fonte: Próprio Autor

A Figura 19 mostra um exemplo de chamada da ferramenta de escalonamento em $R$. 
Figura 19: Exemplo de chamada da ferramenta de escalonamento em $R$.

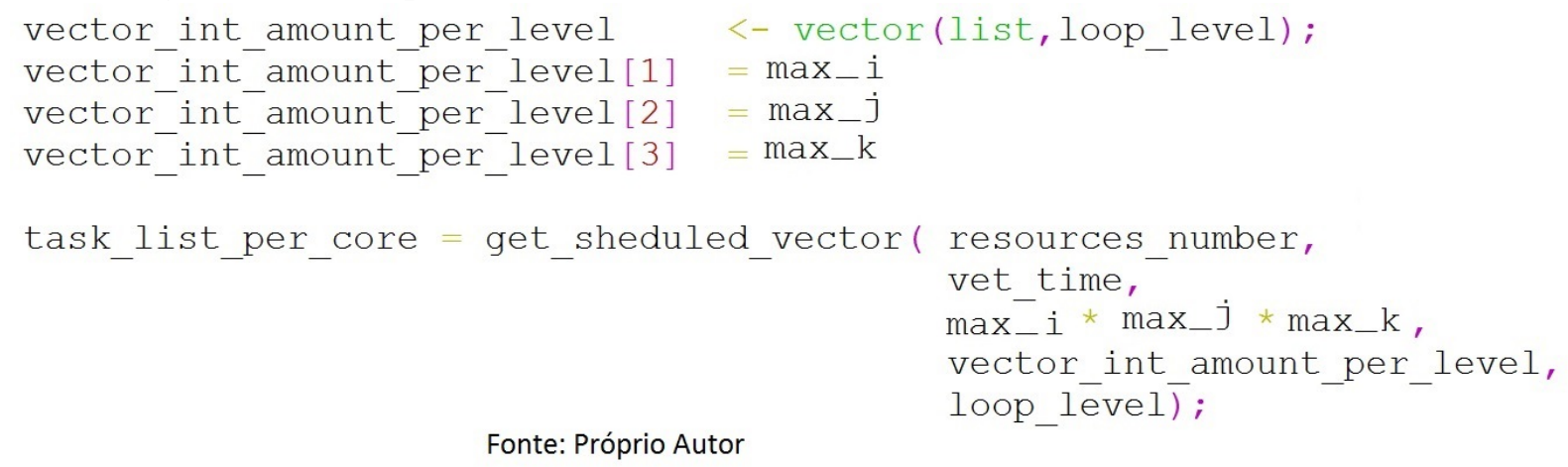

Já a Figura 20 ilustra um exemplo de chamada da ferramenta de escalonamento em $R$ para a aplicação da biodiversidade. Para a biodiversidade não foi necessário criar o vetor vector_int_amount_per_level.

Figura 20: Exemplo de chamada da ferramenta de escalonamento em $R$ para a aplicação da Biodiversidade.

$\begin{aligned} \text { task_list_per_core }=\text { get_sheduled_vector } & \text { resources_number, } \\ & \text { vet_time, } \\ & \text { pa } \star \text { run } \star \text { model, } \\ & \text { ); }\end{aligned}$

Fonte: Próprio Autor

Considere o laço aninhado apresentado no Algoritmo 3. A implementação da paralelização no código da aplicação segue o paradigma de programação de cada plataforma de processamento paralelo. Por exemplo, na plataforma de processamento paralelo openMP (DAGUM; MENON, 1998) é necessário especificar a quantidade de threads usando a cláusula num_threads. Em openMP uma região paralela é criada pela diretiva \#pragrama omp for. A seguir é apresentado um exemplo de código paralelizado com a implementação da metodologia proposta.

\#include <stdio.h>

2 \#include <stdlib.h> 
3 \#include <omp.h>

4 \#include "tool_3.h"

5 \#define max_i 3

\#define $\max _{-} j 3$

\#define max_k 3

\#define loop_level 3

int main(int argc, char *argv[]) \{

int $i, j, k$, resources_number;

// creation of the vector_int_amount_per_level

int *vector_int_amount_per_level $=$ malloc $(\operatorname{sizeof}($ int $)$

* loop_level);

vector_int_amount_per_level $[\theta]=\max _{-} i$;

vector_int_amount_per_level $[1]=\max _{-} j$;

vector_int_amount_per_level[2] = max_k;

// Reading the execution times of iteration

int $*$ vet_time $=$ readTime $\left(\max _{-} i * \max _{-} j * \max \_k\right)$;

// get resource number

resources_number = calc_resources_number(vet_time, $\left.\max _{-} i * \max _{-} j * \max _{-} k\right)$

// Get scheduled vector

struct task_list_per_core *list_resources =

get_scheduled_vector(resources_number, vet_time, max_i *

$\max _{-} j *$ max_k, vector_int_amount_per_level, loop_level);

\#pragma omp parallel num_threads(resources_number) private(i,

j) shared(list_resources)

\{

\#pragma omp for

for $(a=0 ; a<$ resources_number $; a++)\{$ 


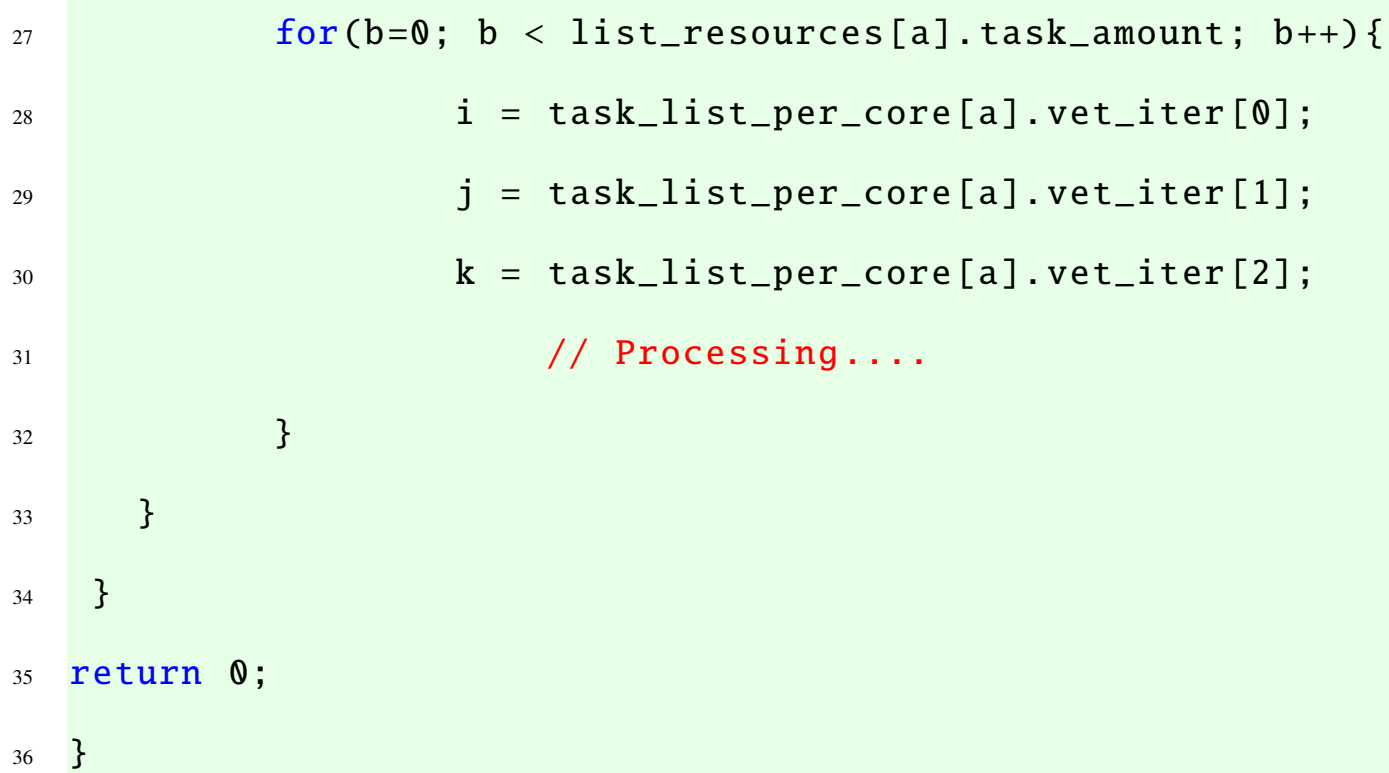

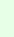

Neste exemplo de código, entre as linhas $\begin{array}{lllll}12 & \text { a } & 15 & \text { o }\end{array}$ vector_int_amount_per_level é criado. Na linha 17, o vetor de tempo é criado. A ferramenta de cálculo do número ideal de recursos de processamento é chamada na linha 19. A ferramenta de escalonamento de iterações é chamada na linha 21. Entre as linhas 23 a 34 o processamento paralelo é então realizado.

Para ambientes distribuídos, tais como, Clusters reais ou virtuais, a codificação da aplicação paralela requer um passo a mais. Em Clusters é necessário enviar os dados para cada máquina antes do processamento. Utilizando a plataforma de processamento distribuído MPI, o envio de dados pode ser realizado pela função MPI_SEND. São enviadas listas contendo dados sobre as iterações do laço paralelizado para cada máquina. Após o recebimento, cada máquina processa as iterações do laço paralelizado que lhe foi atribuída. Na plataforma MPI, após codificar todas as atividades da metodologia, o código da aplicação deverá ficar semelhante ao código apresentado a seguir.

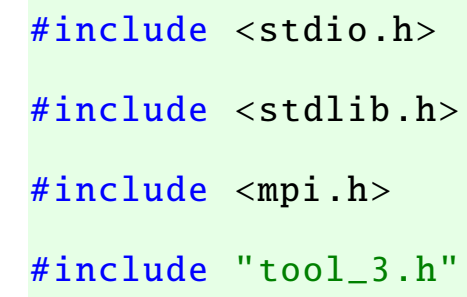




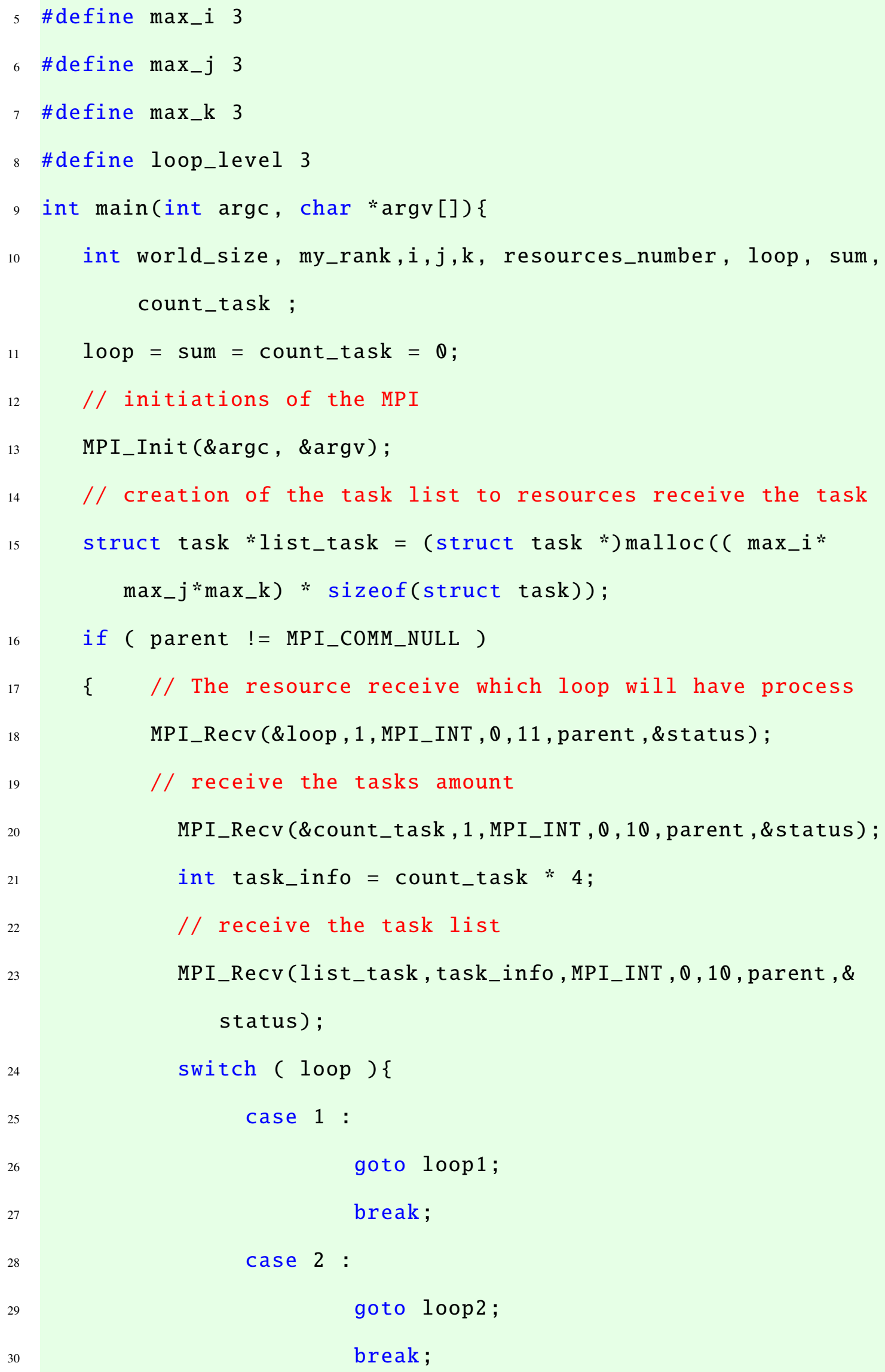




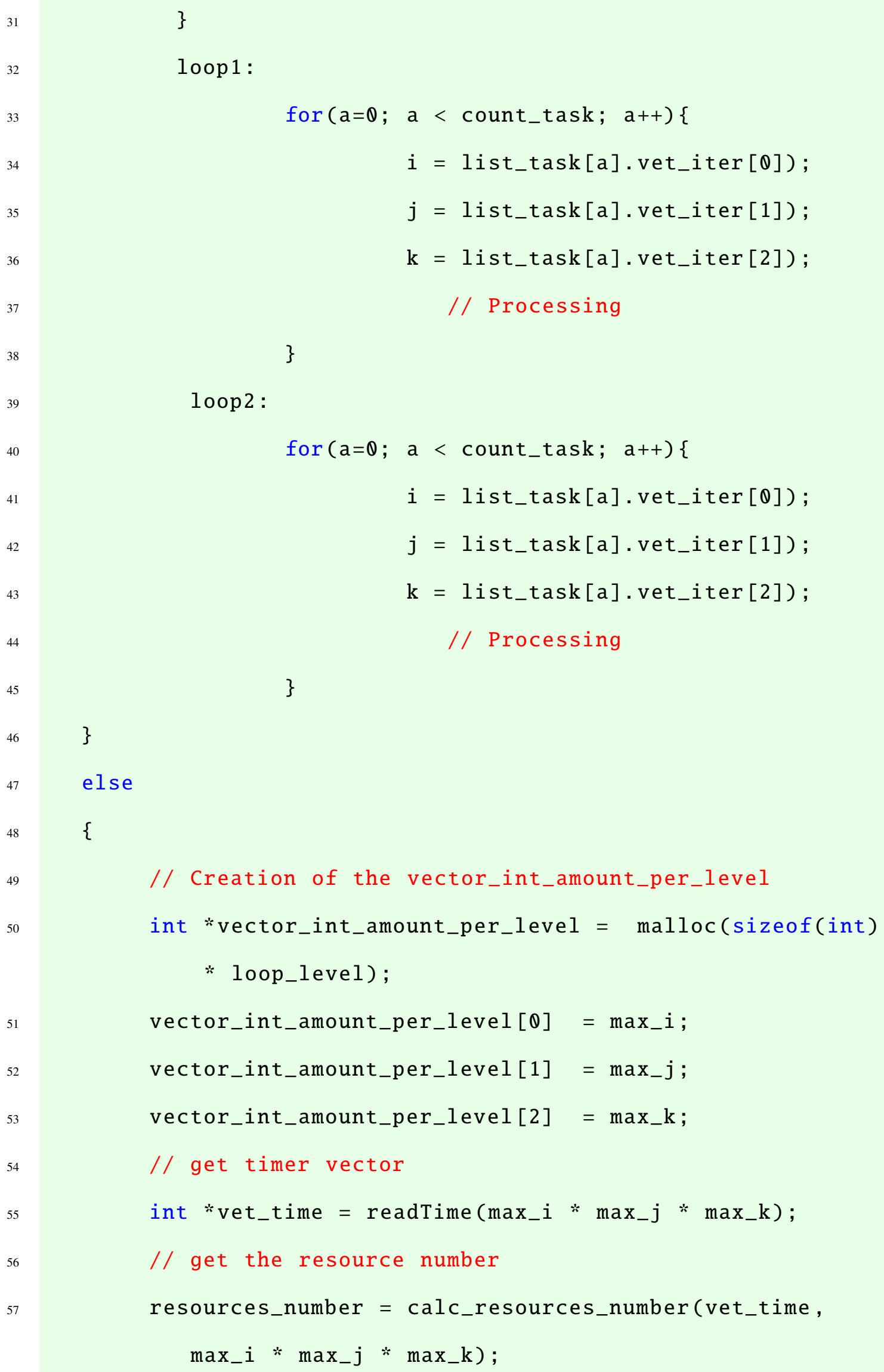



77 MPI_Finalize(); \}

\}

\}

\section{西}

// Get scheduled vector

struct task_list_per_core *task_list_per_core $=$ get_scheduled_vector(resources_number, vet_time, max_i * $\max _{-} j *$ max_k, vector_int_amount_per_level, loop_level);

// spawn the process

MPI_Info_set( info, "add-hostfile", "hostfile.txt"); MPI_Comm_spawn("teste" ,MPI_ARGV_NULL, resources_number -1, info, 0, MPI_COMM_SELF , \&everyone 1, MPI_ERRCODES_IGNORE) ; // send the value loop to children int value_loop $=1$; for $(i=0 ; i<$ resources_number $-1 ; i++)\{$ MPI_Send (\&value_loop,1,MPI_INT , i, 11, everyone 1) // send the datas amount to children for $(i=0 ; i<$ resources_number $-1 ; i++)\{$ MPI_Send(\&task_list_per_core[i].task_amount , 1,MPI_INT , i , 10 , everyone 1 ) ;

// send the datas loop to children for $(i=0 ; i<$ resources_number $-1 ; i++)\{$ MPI_Send (task_list_per_core[i].list_task, C list_resources[i].task_amount *3), MPI_INT, i, 10, everyone1);

//The processe 0 execute the task list 
Neste exemplo de código, na linha 15 é criada uma estutura task_list que armazena as listas de tarefas dos recursos de processamento. Entre as linhas 18 a 23, os processos escravos recebem as listas de tarefas para processar. Entre as linhas 24 a 46 os processos escravos processam suas listas de tarefas. Entre as linhas 50 a 53 o vector_int_amount_per_level é criado. Na linha 55, o vetor de tempo é obtido. A ferramenta de cálculo do número ideal de recursos de processamento é chamada na linha 57. A ferramenta de escalonamento de iterações é chamada na linha 59. Neste código é utilizado a função MPI_Comm_spawn para criar os processos. O MPI_Comm_spawn é chamado na linha 60. Entre as linhas 64 a 74 o processamento mestre envia os dados para os processos escravos. Por fim, o processo mestre executa a sua lista de tarefas.

Na plataforma $\mathrm{R}$ o processamento paralelo pode ser implementado com a utilização do pacote Snowfall. No Snowfall o paralelismo é realizado através da função sfLapply. Esta função recebe como parâmetro o vetor de dados para cada recurso e a função que cada recurso irá processar. Adicionalmente, pode ser passados outros parâmetros na função sflapply. Caso a plataforma escolhida seja R, o código da aplicação paralelizada deverá ficar semelhante ao exemplo mostrado a seguir. Este exemplo é o código da aplicação utilizada como estudo de caso neste trabalho.

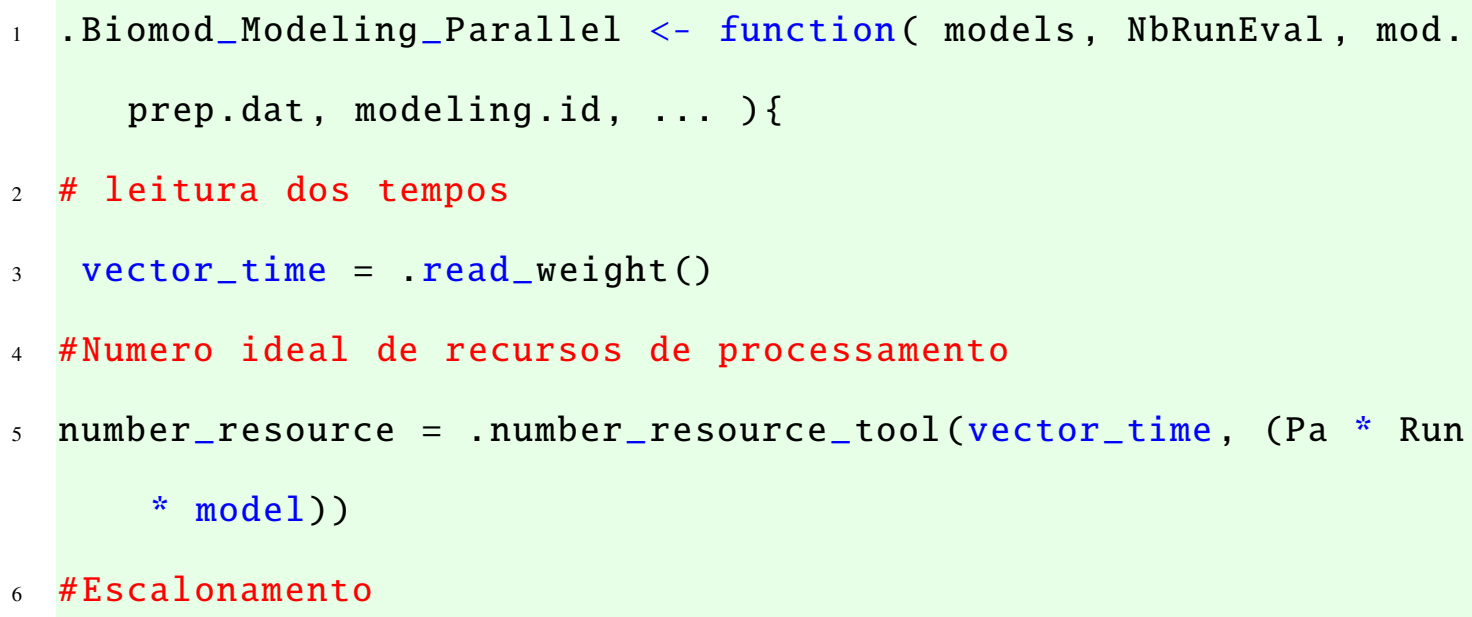




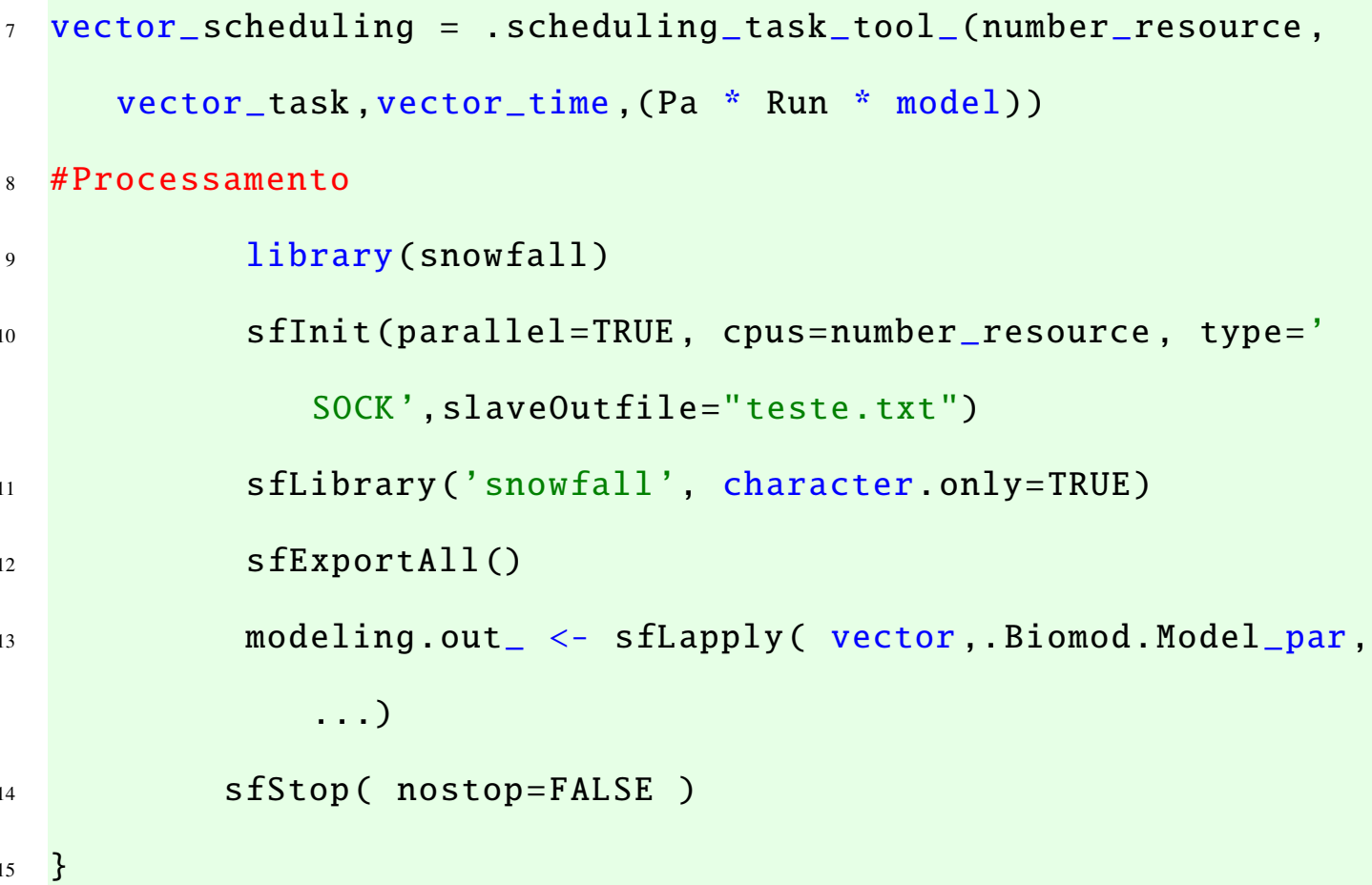

Neste código, na linha 5 é realizada uma chamada para a ferramenta de cálculo do valor inicial do número ideal de recurso de processamento. A ferramenta de escalonamento é chamada na linha 7. Entre as linhas 9 a 15 o processamento paralelo é então realizado. O processamento paralelo é realizado pela função sfLapply. Nesta função o primeiro parâmetro é a lista de tarefas que cada recurso deve processar. Já o segundo parâmetro é a função que cada recurso executa no processamento, os demais parâmetros são dados adicionais necessários para o processamento.

\subsection{Execução da Aplicação}

Na fase de Execução da Aplicação são executadas todas as atividades para processar a aplicação paralelizada. Nesta fase, são realizadas atividades como: leitura dos tempos de execução, cálculo do número ideal de recursos de processamento, escalonamento, processamento e coleta de tempos.

A Figura 21 ilustra o fluxo das atividades da fase de Execução da aplicação. 
Figura 21: Fluxo das Atividades da Fase de Execução da Aplicação.

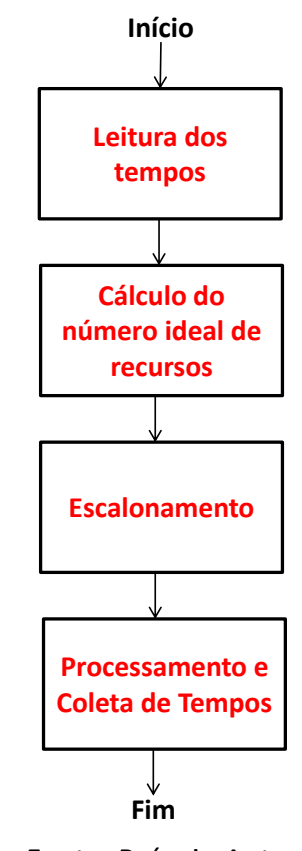

Fonte: Próprio Autor

\subsubsection{Leitura dos Tempos}

Esta atividade consiste em ler os tempos de execução das iterações do laço linearizado e montar o vetor de tempos. Para cada ocorrência de laço linearizado é criado um arquivo de histórico. O arquivo de histórico contém os tempos de execução de cada iteração de um laço linearizado.

Nesta atividade, os tempos de execução das iterações do laço linearizado são lidos e armazenados no vetor de tempos chamado de vet_time. A leitura do arquivo de histórico consiste em ler os 10 últimos registros de cada iteração e calcular o valor médio dos mesmos. Cada elemento de vet_time representa o tempo médio de uma iteração do laço linearizado. Logo, se a quantidade de iterações do laço linearizado for $n$, o tamanho de vet_time é $n$. Após a leitura e a criação do vetor de tempo, o vet_time é passado para as demais atividades da metodologia. 


\subsubsection{Cálculo do Valor Inicial do Número Ideal de Recursos de Processamento}

Nesta atividade é calculado o valor inicial do número ideal de recursos computacionais a ser utilizado no processamento. Este valor é obtido através de um cálculo matemático descrito nesta seção. Este valor é refinado na atividade de escalonamento. No cálculo realizado para obter o valor inicial do número ideal de recursos de processamento, os tempos de execução das iterações do laço linearizado são somados e o resultado dividido pelo tempo de execução da tarefa que mais consome tempo de processamento. Devido ao fato do processamento de uma iteração do laço linearizado não poder ser quebrada, este número calculado pode ser inferior ao número ideal e por isso deve ser refinado na atividade de escalonamento. Para cada ocorrência de laço aninhado é calculado o número ideal de recursos.

Esta atividade realiza três passos para calcular o número ideal de recursos de processamento, tais passos, são descritos a seguir:

1. realiza a soma dos pesos das tarefas, ou seja, a soma do tempo de execução de todas as iterações do laço linearizado.

2. divide a soma obtida pelo maior peso entre os pesos de todas as iterações.

3. arredonda o resultado da divisão obtida no passo anterior para o teto do número fracionário obtido.

O valor inicial do número ideal de recursos de processamento pode ser obtido a partir do cálculo:

$$
p=\left\lceil\frac{\sum_{i=1}^{n} \text { vet_time }_{i}}{\text { max }(\text { vet_time })}\right\rceil
$$

Onde, $p$ é o número inicial de recursos de processamento e timeVector é o vetor 
que contêm os tempos de execução das iterações do laço linearizado. timeVector é obtido a partir da leitura dos tempos registrados no histórico.

Para auxiliar esta atividade, foi desenvolvida uma ferramenta que realizada o cálculo matemático apresentado nesta seção.

\subsubsection{Escalonamento}

$\mathrm{Na}$ atividade de escalonamento as iterações do laço linearizado são atribuídas para os recursos de processamento. Esta atividade também é responsável por refinar o valor do número ideal de recursos de processamento. O refinamento é realizado através da adição de recursos no número inicial calculado pela atividade anterior. A adição ocorre até que o tempo mínimo de processamento seja alcançado. Esta atividade é realizada para cada ocorrência de laço aninhado presente na aplicação.

Cada iteração do laço linearizado possui um tempo diferente de processamento. Assim, uma simples atribuição das iterações entre os recursos de processamento implica em um desbalanceamento de carga, deixando alguns recursos de processamento sobrecarregados e outros ociosos. A estratégia de escalonamento visa balancear a carga de trabalho entre os recursos computacionais, permitindo atribuir uma quantidade de iteração igualitária e justa para os recursos computacionais, diminuindo a ociosidade dos recursos e melhorando o desempenho da aplicação.

Para iniciar o escalonamento, a estratégia aqui apresentada recebe o valor inicial do número ideal de recursos de processamento calculado pela atividade anterior, e também, o vetor de task, o task_vector. Na execução do escalonamento é criado um vetor vector_task_list, onde, cada elemento deste vetor, representa uma lista de tarefa para cada recurso. Inicialmente, o tamanho de vector_task_list é definido pelo número de recursos. A Figura 22 ilustra um exemplo de vector_task_list. 
Figura 22: Exemplo de vector_task_list.

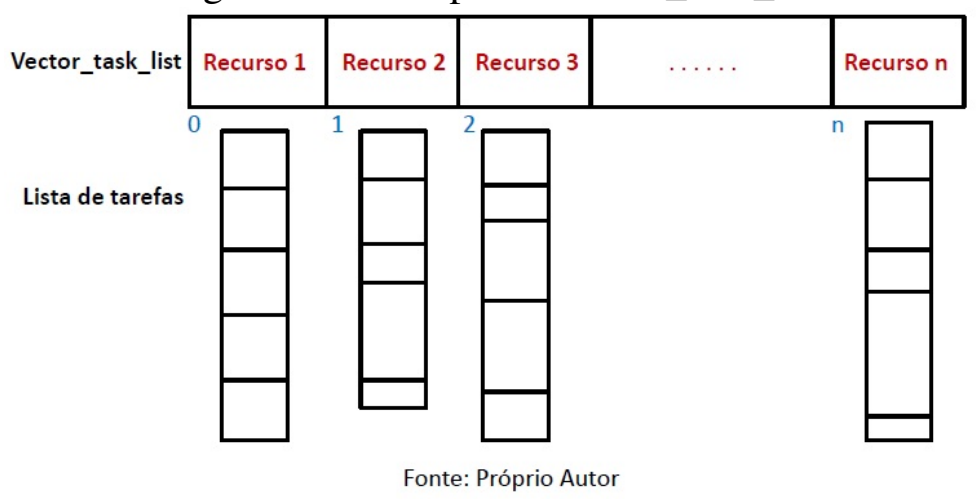

No escalonamento realizado, a atribuição de tarefas se baseia em uma distribuição específica, onde, as tarefas de maior tempo de execução, são atribuídas para os recursos que contém a menor carga de trabalho. Os elementos de vector_task são ordenados de forma decrescente de peso. Cada elemento de vector_task é atribuído para as listas de tarefas de vector_task_list. Dessa forma, cada task de vector_task é atribuída em ordem decrescente de peso para as listas de tarefas dos recursos de processamento.

Quando todos os elementos de vector_task forem atribuídos para as listas de tarefas, é verificado se o tempo mínimo de processamento foi alcançado. O tempo mínimo de processamento é definido como sendo $\max (v e t$ time). Se o tempo mínimo de processamento não foi alcançado, é somado 1 ao número de recursos, o tamanho de vector_task_list é aumentado em uma unidade e o escalonamento é realizado novamente. A atribuição de tarefas somente será finalizada quando o tempo mínimo de processamento for alcançado ou o número de recursos, for igual ao número especificado pelo usuário, como ilustrado na Figura 23. 
Figura 23: Estratégia de escalonamento aplicada na ferramenta.

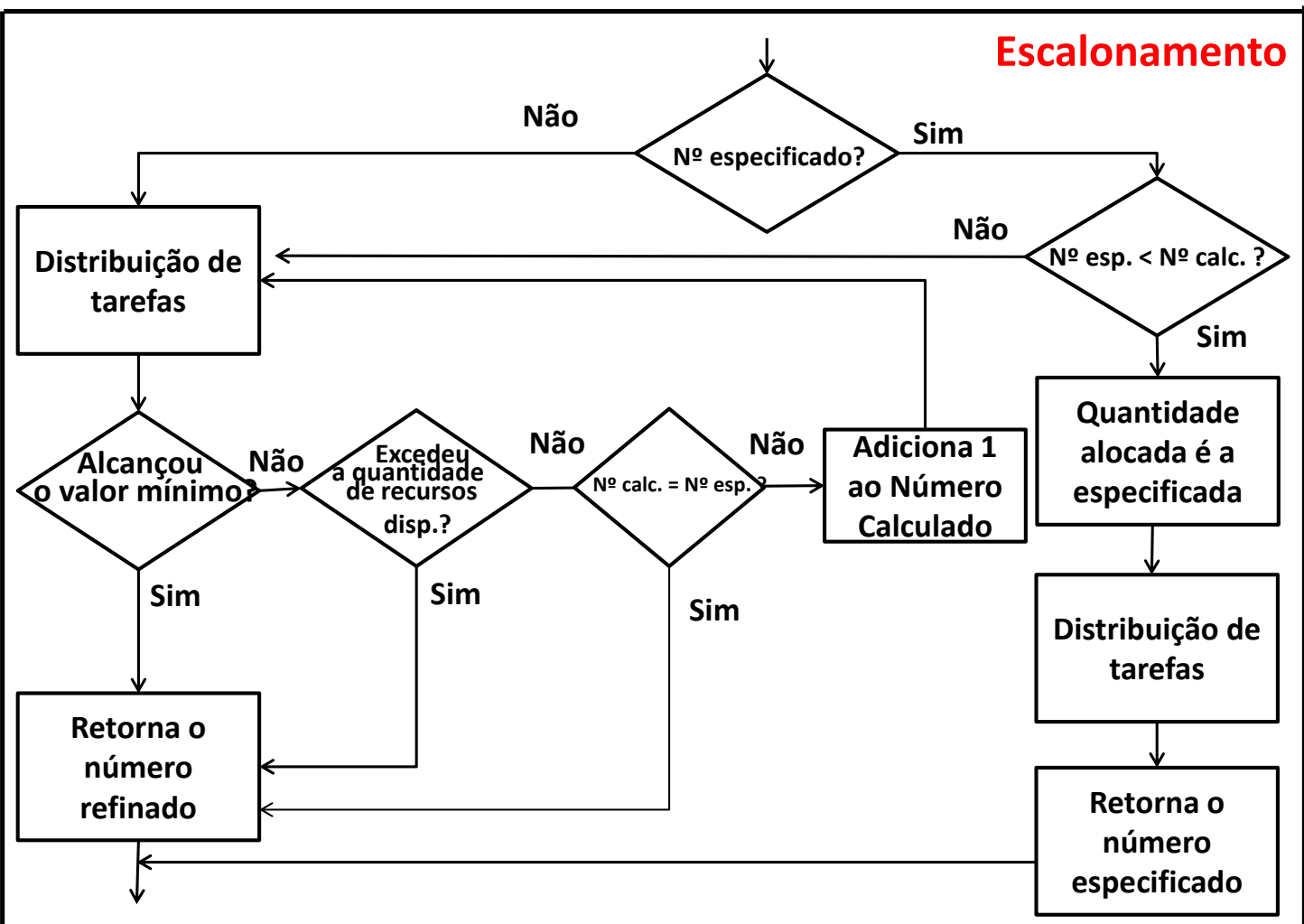

Fonte: Próprio Autor

Para auxiliar esta atividade, foi desenvolvida uma ferramenta que realiza o escalamento aqui proposto. Nesta atividade é realizada uma chamada para a ferramenta de escalonamento, que retorna uma estrutura contendo uma lista de tarefas para cada recurso de processamento.

\subsubsection{Processamento}

Após ativar os recursos de processamento e obter o escalonamento das iterações do laço paralelizado, o próximo passo é enviar as iterações do laço paralelizado aos recursos de processamento. Cada recurso de processamento irá executar um conjunto de iterações, especificado na sua respectiva lista de iterações recebida.

A metodologia aqui proposta pode ser implementada e processada em sistemas 
paralelos e distribuídos, tais como, computadores multicores e, sistemas distribuídos composto por Clusters reais ou virtuais alocados na nuvem. 


\section{IMPLEMENTAÇÕES, RESULTADOS E ANÁLISES}

Neste capítulo, são apresentadas algumas implementações de paralelização com a aplicação da metodologia. Resultados e análises experimentais destas implementações são apresentados neste capítulo, mostrando o impacto do uso da metodologia aqui proposta. A hipótese considerada neste trabalho diz que é possível melhorar o desempenho de aplicações que contêm laços aninhados com processamento heterogêneo, utilizando uma quantia de recursos limitada a um número ideal; através de uma estratégia de paralelização adequada e da redução da ociosidade de recursos de processamento. Os resultados experimentais apresentados neste capítulo demonstram a viabilidade da hipótese considerada.

Nos experimentos realizados, foram desenvolvidas aplicações sintéticas, utilizando a linguagem C. O objetivo do desenvolvimento destas aplicações é processálas e analisar os desempenhos obtidos. Nesta análise, é considerada uma aplicação, onde o processamento é realizado sequencialmente, e uma aplicação paralela com implementações para computadores Multicore e para Clusters de computadores. As implementações paralelas foram desenvolvidas baseadas na metodologia proposta, implementando-se todas as atividades da metodologia.

Neste capítulo, em alguns momentos são utilizados os termos "aplicação paralela" e "aplicação sequencial". O termo aplicação paralela se refere à aplicação paralela com a implementação da metodologia proposta. As aplicações paralelas foram desenvolvidas utilizando as plataformas de processamento $M P I$ e OpenMP. O termo aplicação 
sequencial se refere à aplicação onde o processamento ocorre sequencialmente e foi desenvolvida na linguagem $\mathrm{C}$.

Visando comparar a eficiência e o desempenho da metodologia proposta com outras soluções paralelas e distribuídas, foram desenvolvidas aplicações paralelas, onde, outras estratégias de escalonamentos foram implementadas. O objetivo deste experimento é comparar o desempenho e a eficiência do algoritmo de escalonamento implementado na metodologia, com outros algoritmos de escalonamento encontrados na literatura, tais como, os algoritmos estáticos e dinâmicos.

\subsection{Metodologia de Teste e Análise}

Nesta seção é descrita a organização dos testes e análises utilizadas na avaliação da metodologia proposta.

Para avaliar a metodologia proposta, utilizando-se a aplicação sintética, cenários de testes foram definidos. O objetivo de estabelecer determinados cenários de testes é analisar o comportamento da aplicação em diversas situações, visando avaliar a paralelização com a implementação da metodologia proposta. Os cenários de testes são apresentados com mais detalhes na Seção 5.3. Para cada cenário de teste, foram considerados laços perfeitamente aninhados de 3 níveis $(i, j, k)$. Todos os experimentos foram executados 10 vezes e no final, foi obtido um tempo médio de execução que é considerado e apresentado nos gráficos como sendo o tempo de execução de cada experimento.

\subsection{Ambientes de Execução}

Os experimentos realizados neste trabalho foram executados em dois ambientes de processamento. O primeiro é um ambiente paralelo e é composto de um computador Multicore. Esse computador possui dois processadores Intel Xeon CPU E52650 de 
2.00GHz, 16 GB de RAM e executa um sistema operacional Linux na distribuição CentOS e na versão 6.7. Cada processador Intel Xeon CPU E52650 contém 8 núcleos, totalizando 16 núcleos de processamento no ambiente paralelo.

O segundo ambiente é distribuído e é composto por um Cluster que possui cinco máquinas conectadas por uma rede Gigabit Ethernet. Cada máquina (nó) contém um processador Intel Core i7-3770 quad-core de 3.40GHz, 16 GB de memória RAM e sistema operacional Linux na distribuição openSUSE v.13.2. Cada máquina do Cluster possui um processador i7 com 4 núcleos de processamento, dessa forma, o ambiente de processamento distribuído disponibiliza 20 núcleos de processamento. O Cluster foi configurado com os serviços NIS (Network Information Service) e NFS (Network File System).

\subsection{Avaliação da Proposta}

Para avaliar a metodologia de paralelização proposta neste trabalho, foram definidos alguns experimentos que têm como objetivo avaliar o comportamento da execução das aplicações sintéticas desenvolvidas. Os experimentos realizados têm como objetivo realizar análises quanto:

1. à escalabilidade da aplicação.

2. à ociosidade dos recursos de processamento.

3. à heterogeneidade das iterações do laço aninhado que interfere no desempenho da aplicação.

4. à quantidade ideal de recursos de processamento que permite não haver ociosidade dos mesmos.

5. a soluções que utilizam programação paralela e distribuída, tais como openMP $e$ MPI. 


\subsubsection{Caso de Teste 1}

O primeiro caso de teste é definido por um laço perfeitamente aninhado composto por 3 laços $(i, j, k)$. O laço $i$, varia de 0 a 2 , o $j$ de 0 a 2 e o $k$ varia de 0 a 3 . Linearizando este laço perfeitamente aninhado, obtém-se um único laço com 36 iterações. $\mathrm{O}$ tempo de cada iteração é estipulado aleatoriamente com a função random da linguagem C. Os valores de tempos foram estipulados em uma faixa de 0 a 300 segundos. $\mathrm{O}$ objetivo deste experimento é analisar como a execução da aplicação paralela, desenvolvida utilizando-se a metodologia proposta, e a sequencial se comportam em relação aos aspectos: 1, 2, 3 e 4, em situações que os tempos de execução das iterações do laço são heterogêneos dentro de uma faixa de valores de 0 a 300 segundos. Cada iteração do laço linearizado corresponde a uma tarefa. A Figura 24 mostra os valores do tempo de execução de cada iteração estipulada neste experimento, estes valores estão especificados em segundos.

Figura 24: Tabela com os tempos de execução das iterações do laço linearizado Cenário 1.

\begin{tabular}{|l|c|c|c|}
\hline Tarefas & Tempo(Segundos) & Tarefas & Tempo(Segundos) \\
\hline Tarefa 1 & 5 & Tarefa 19 & 174 \\
\hline Tarefa 2 & 50 & Tarefa 20 & 182 \\
\hline Tarefa 3 & 12 & Tarefa 21 & 58 \\
\hline Tarefa 4 & 37 & Tarefa 22 & 192 \\
\hline Tarefa 5 & 1 & Tarefa 23 & 228 \\
\hline Tarefa 6 & 25 & Tarefa 24 & 268 \\
\hline Tarefa 7 & 182 & Tarefa 25 & 115 \\
\hline Tarefa 8 & 216 & Tarefa 26 & 156 \\
\hline Tarefa 9 & 227 & Tarefa 27 & 32 \\
\hline Tarefa 10 & 296 & Tarefa 28 & 4 \\
\hline Tarefa 11 & 157 & Tarefa 29 & 135 \\
\hline Tarefa 12 & 13 & Tarefa 30 & 77 \\
\hline Tarefa 13 & 248 & Tarefa 31 & 106 \\
\hline Tarefa 14 & 195 & Tarefa 32 & 75 \\
\hline Tarefa 15 & 80 & Tarefa 33 & 245 \\
\hline Tarefa 16 & 21 & Tarefa 34 & 20 \\
\hline Tarefa 17 & 117 & Tarefa 35 & 20 \\
\hline Tarefa 18 & 215 & Tarefa 36 & 165 \\
\hline & & Fonte: Próprio Autor & \\
\hline
\end{tabular}




\subsubsection{Resultados e Análises - Cenário 1}

Nesta seção são apresentados os resultados obtidos nos experimentos realizados com a aplicação sintética no cenário de teste 1 . Os resultados experimentais apresentados nesta seção foram executados no ambiente distribuído, na plataforma de processamento $M P I$.

\section{Escalabilidade e Desempenho - Cenário 1}

A Figura 25 exibe um gráfico onde, os tempos de execução da aplicação paralela e sequencial são apresentados. Neste experimento, o desvio padrão variou de 0,2 a 0,7.

Figura 25: Tempos do processamento paralelo e sequencial - Cenário 1 - Cluster.

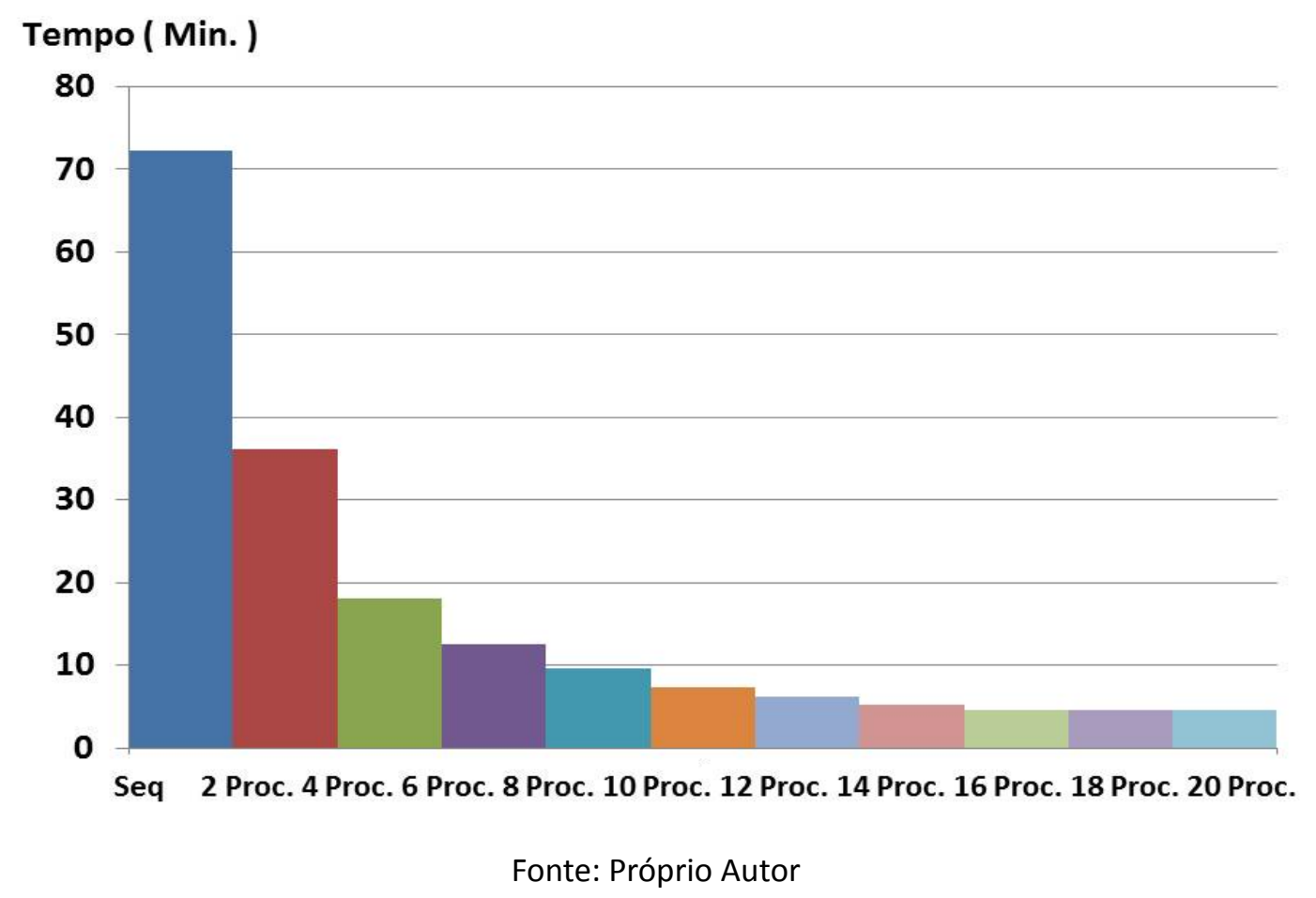

Para este cenário, a metodologia definiu que 16 é a quantidade ideal de recursos capaz de processar todas as tarefas no tempo mínimo possível, ou seja, o tempo da 
tarefa mais longa. No gráfico apresentado na Figura 25 é possível concluir que 16 realmente é o número ideal de recursos. Ao passar a quantidade de 16 recursos, o tempo de processamento da aplicação se manteve estável, ou seja, mesmo se adicionar mais recursos de processamento, não é possível obter um tempo menor que 5 minutos, que corresponde aproximadamente ao tempo da tarefa mais longa.

\section{Ociosidade dos Recursos de Processamento - Cenário 1.}

No processamento paralelo é ideal que todos os recursos executem tarefas com o mesmo tempo de execução ou com pelo menos tempos aproximados, para que todos comecem e terminem o processamento simultaneamente. Entretanto, quando as tarefas contêm tempos de execução heterogêneos, dependendo da paralelização e distribuição das tarefas, cada recurso pode terminar em um tempo diferente, causando ociosidade dos recursos de processamento.

Para paralelizar o laço linearizado seriam necessários 36 recursos para processar simultaneamente todas as tarefas e obter o tempo mínimo de processamento (tempo da maior tarefa, 296 segundos). O gráfico apresentado na Figura 26, mostra os tempos teóricos de execução gastos pelos 36 recursos de processamento. 
Figura 26: Tempo teórico de execução de cada recurso de processamento - Cenário 1 Cluster.

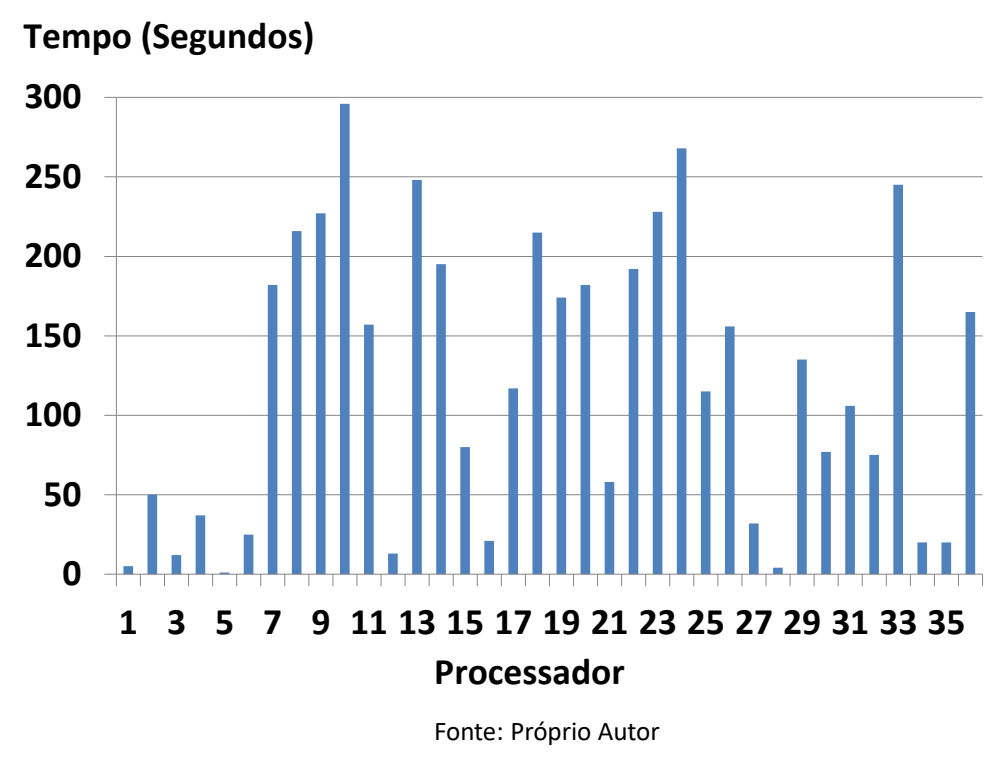

Neste gráfico, é possível perceber a ociosidade dos processadores. Esta ociosidade é causada pela heterogeneidade dos tempos de execução das iterações do laço linearizado. Por exemplo, observe o tempo de execução dos processadores 1 e 10 . O processador 10 leva 296 segundos para processar a tarefa 10, ao passo que, o processador 1 leva 5 segundos para processar a tarefa 1 . A tarefa 10 é a tarefa de maior tempo. O processamento paralelo só irá finalizar, quando essa tarefa for terminada, ficando ociosos os demais processadores. Neste caso, o processador 1 ficará 291 segundos ocioso até que o processador 10 termine de executar a sua tarefa.

Para este cenário, a metodologia definiu que 16 é o número ideal de recursos de processamento. Ao realizar um escalamento adequado, proporcionando o balanceamento da carga de trabalho entre os recursos e, consequentemente, reduz a sua ociosidade. O gráfico apresentado na Figura 27 apresenta o balanceamento de carga entre os recursos e uma baixa ociosidade, comparativamente à apresentada no gráfico da Figura 26. 
Figura 27: Balanceamento de carga entre os recursos de processamento - Cenário 1 Cluster.

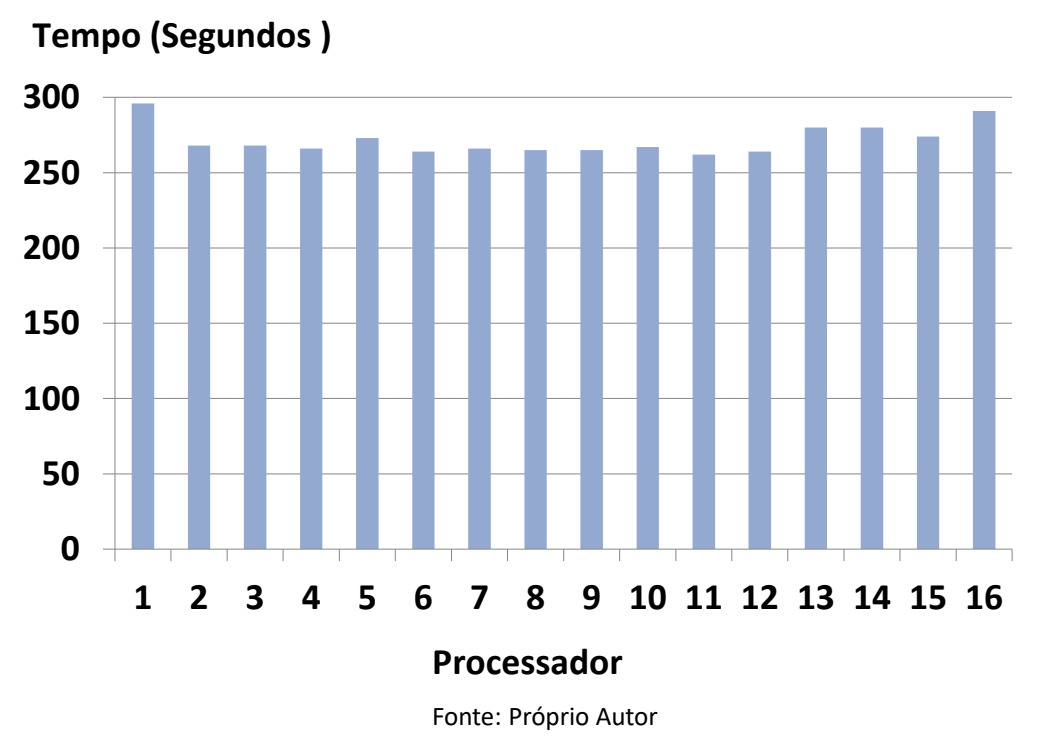

\section{Heterogeneidade x Desempenho - Cenário 1}

Observando o gráfico apresentado na Figura 26, é possível perceber o quanto a heterogeneidade interfere no processamento. A ociosidade causada pela heterogeneidade das tarefas não permite, dependendo da estratégia adotada, aproveitar adequadamente $100 \%$ dos processadores. Ao passo que alguns processadores ainda estão em execução, outros podem estar ociosos.

\section{Speedup - Cenário 1}

O gráfico apresentado na Figura 28 mostra os Speedups obtidos no processamento da aplicação paralela para este cenário de teste. O Speedup permite mensurar, o quanto o processamento paralelo foi mais rápido do que o processamento sequencial. O Speedup é calculado pela divisão do tempo sequencial pelo paralelo, com isso, é possível dizer quantas vezes o processamento paralelo foi mais rápido que o sequencial (POLYCHRONOPOULOS, 1988). 
Figura 28: Speedup - Cenário 1 - Cluster.

\section{Speedup}

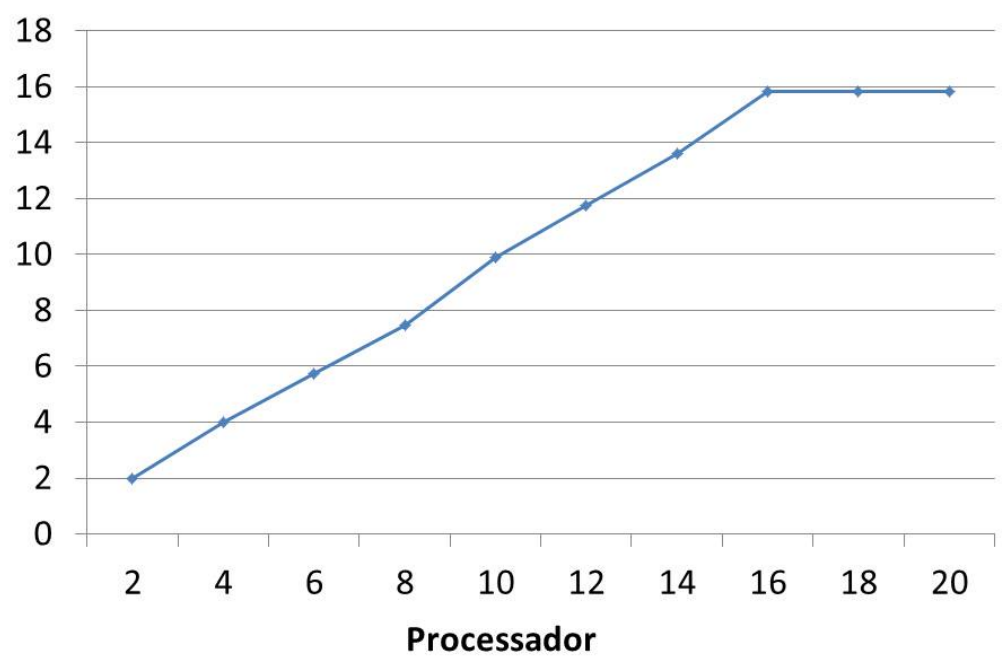

Fonte: Próprio Autor

Neste gráfico, é possível perceber que o Speedup maior foi com 16 recursos de processamento. No processamento paralelo, é buscado alcançar um Speedup linear. Todavia, muitas vezes, isto não é atingido, porque as aplicações podem possuir trocas de mensagens, trechos com dependência de dados e dependendo da estratégia de escalonamento adotada, alguns recursos de processamento podem ficar ociosos. Neste cenário, nota-se que o Speedup linear foi atingido, devido a uma quantidade mínima de troca de mensagens, a ausência de dependência de dados e principalmente ao escalonamento das tarefas, que se mostra adequado. Outro aspecto interessante para se observar, é o fato do Speedup estagnar em 16, mesmo aumentando o número de recursos de processamento. Este aspecto mostra mais uma vez, a eficiência da metodologia em calcular o número ideal de recursos de processamento.

\subsubsection{Caso de Teste 2}

O segundo caso de teste foi realizado com um laço perfeitamente aninhado composto por 3 laços $(i, j, k)$. Os valores de $i, j, k$ variam de 0 a 5 . Linearizando este laço obtém-se um único laço com 125 iterações. Neste experimento é analisado como 
a execução da aplicação paralela se comporta quando há duas iterações com o tempo de execução muito elevado. Dessa forma, o tempo de execução de 123 iterações foi estipulado com valores aleatórios de 0 a 100, o tempo de execução das outras duas iterações foi especificado com os valores de 500 e 450 segundos. A tabela apresentada na Figura 29 mostra os valores de tempo de execução de cada tarefa em segundos.

Figura 29: Tabela com os tempos de execução das iterações do laço linearizado Cenário 2.

\begin{tabular}{|c|c|c|c|c|c|c|c|c|c|c|c|}
\hline Tarefas & Segundos & Tarefas & Segundos & Tarefas & Segundos & Tarefas & Segundos & Tarefas & Segundos & Tarefas & Segundos \\
\hline Tarefa 1 & 500 & Tarefa 22 & 74 & Tarefa 43 & 37 & Tarefa 64 & 99 & Tarefa 85 & 35 & Tarefa 106 & 60 \\
\hline Tarefa 2 & 450 & Tarefa 23 & 99 & Tarefa 44 & 38 & Tarefa 65 & 28 & Tarefa 86 & 23 & Tarefa 107 & 36 \\
\hline Tarefa 3 & 25 & Tarefa 24 & 69 & Tarefa 45 & 85 & Tarefa 66 & 46 & Tarefa 87 & 90 & Tarefa 108 & 84 \\
\hline Tarefa 4 & 64 & Tarefa 25 & 9 & Tarefa 46 & 65 & Tarefa 67 & 86 & Tarefa 88 & 4 & Tarefa 109 & 37 \\
\hline Tarefa 5 & 33 & Tarefa 26 & 51 & Tarefa 47 & 45 & Tarefa 68 & 52 & Tarefa 89 & 43 & Tarefa 110 & 33 \\
\hline Tarefa 6 & 18 & Tarefa 27 & 82 & Tarefa 48 & 90 & Tarefa 69 & 12 & Tarefa 90 & 66 & Tarefa 111 & 54 \\
\hline Tarefa 7 & 35 & Tarefa 28 & 40 & Tarefa 49 & 64 & Tarefa 70 & 8 & Tarefa 91 & 30 & Tarefa 112 & 17 \\
\hline Tarefa 8 & 94 & Tarefa 29 & 5 & Tarefa 50 & 57 & Tarefa 71 & 20 & Tarefa 92 & 31 & Tarefa 113 & 52 \\
\hline Tarefa 9 & 100 & Tarefa 30 & 69 & Tarefa 51 & 52 & Tarefa 72 & 29 & Tarefa 93 & 14 & Tarefa 114 & 90 \\
\hline Tarefa 10 & 20 & Tarefa 31 & 74 & Tarefa 52 & 18 & Tarefa 73 & 100 & Tarefa 94 & 28 & Tarefa 115 & 22 \\
\hline Tarefa 11 & 78 & Tarefa 32 & 73 & Tarefa 53 & 67 & Tarefa 74 & 18 & Tarefa 95 & 58 & Tarefa 116 & 86 \\
\hline Tarefa 12 & 21 & Tarefa 33 & 40 & Tarefa 54 & 25 & Tarefa 75 & 67 & Tarefa 96 & 60 & Tarefa 117 & 12 \\
\hline Tarefa 13 & 93 & Tarefa 34 & 50 & Tarefa 55 & 68 & Tarefa 76 & 37 & Tarefa 97 & 13 & Tarefa 118 & 64 \\
\hline Tarefa 14 & 19 & Tarefa 35 & 88 & Tarefa 56 & 87 & Tarefa 77 & 35 & Tarefa 98 & 61 & Tarefa 119 & 89 \\
\hline Tarefa 15 & 7 & Tarefa 36 & 24 & Tarefa 57 & 85 & Tarefa 78 & 63 & Tarefa 99 & 23 & Tarefa 120 & 6 \\
\hline Tarefa 16 & 5 & Tarefa 37 & 67 & Tarefa 58 & 70 & Tarefa 79 & 26 & Tarefa 100 & 72 & Tarefa 121 & 29 \\
\hline Tarefa 17 & 47 & Tarefa 38 & 22 & Tarefa 59 & 68 & Tarefa 80 & 98 & Tarefa 101 & 33 & Tarefa 122 & 70 \\
\hline Tarefa 18 & 61 & Tarefa 39 & 17 & Tarefa 60 & 24 & Tarefa 81 & 19 & Tarefa 102 & 4 & Tarefa 123 & 36 \\
\hline Tarefa 19 & 63 & Tarefa 40 & 66 & Tarefa 61 & 74 & Tarefa 82 & 29 & Tarefa 103 & 24 & Tarefa 124 & 42 \\
\hline Tarefa 20 & 55 & Tarefa 41 & 93 & Tarefa 62 & 37 & Tarefa 83 & 67 & Tarefa 104 & 50 & Tarefa 125 & 97 \\
\hline Tarefa 21 & 11 & Tarefa 42 & 47 & Tarefa 63 & 97 & Tarefa 84 & 6 & Tarefa 105 & 22 & & \\
\hline
\end{tabular}

\subsubsection{Resultados e Análises - Cenário 2}

Nesta seção são apresentados os resultados obtidos nos experimentos realizados com as aplicações sintéticas paralela e sequencial no cenário de teste 2. Os resultados experimentais apresentados nesta seção foram executados no ambiente distribuído, na plataforma de processamento MPI. 


\section{Escalabilidade e Desempenho - Cenário 2.}

O gráfico apresentado na Figura 30 mostra os tempos de execução do processamento paralelo e sequencial executados no ambiente distribuído, no Cluster. Neste experimento, o desvio padrão variou de 0,1 a 0,6 .

Figura 30: Tempos das execução paralela e sequencial - Cenário 2 - Cluster.

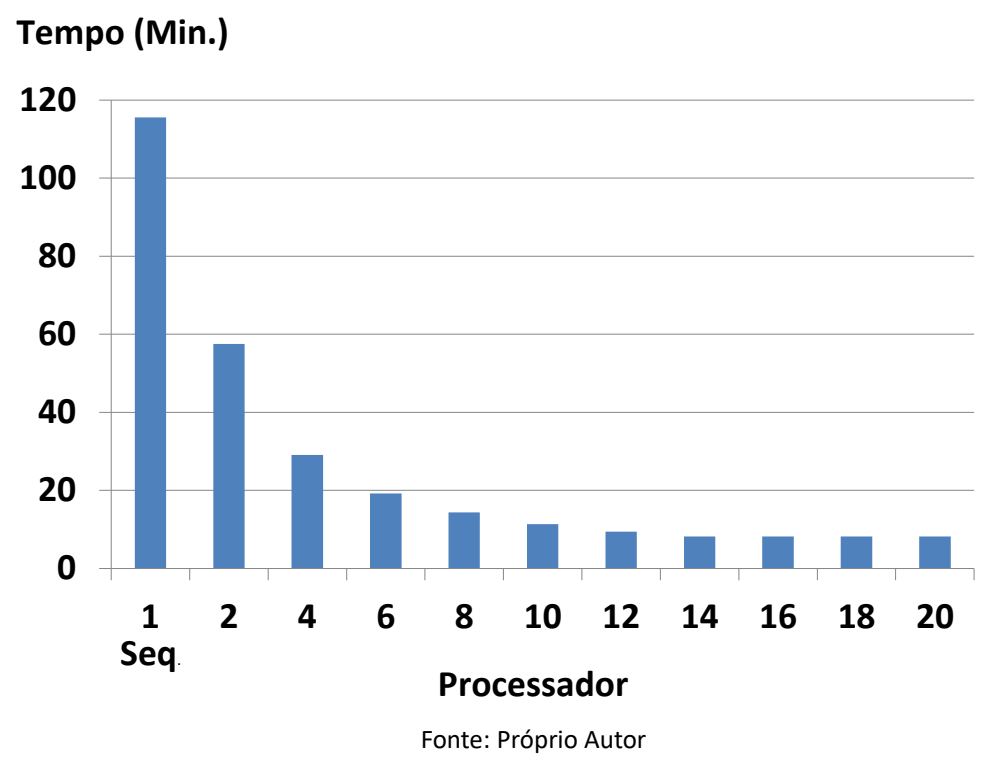

Nos experimentos realizados para neste cenário, é possível perceber que no processamento paralelo, a aplicação se mostrou escalável. Na medida em que a quantidade de recursos de processamento aumenta, o tempo de execução diminui linearmente. $\mathrm{O}$ comportamento da execução da aplicação é similar ao do cenário de teste 1 .

Para este cenário, a metodologia definiu que 14 é a quantidade ideal de recursos de processamento. Observando o gráfico apresentado na Figura 30, é possível concluir que 14 recursos de processamento é a quantia ideal de recursos para alcançar o tempo mínimo de processamento. Ao adicionar mais recurso de processamento, não é mais possível diminuir o tempo de processamento.

Ociosidade dos Recursos de Processamento - Cenário 2. 
Após linearizar o laço aninhado considerado neste caso de teste, é obtido um único laço com 125 iterações. O gráfico apresentado na Figura 31 mostra o tempo teórico de execução do processamento paralelo do laço único obtido. Neste gráfico é possível perceber que a ociosidade entre os recursos de processamento aumentou, devido ao cenário adotado.

Figura 31: Tempo teórico de execução paralela das 125 iterações - Cenário 2.

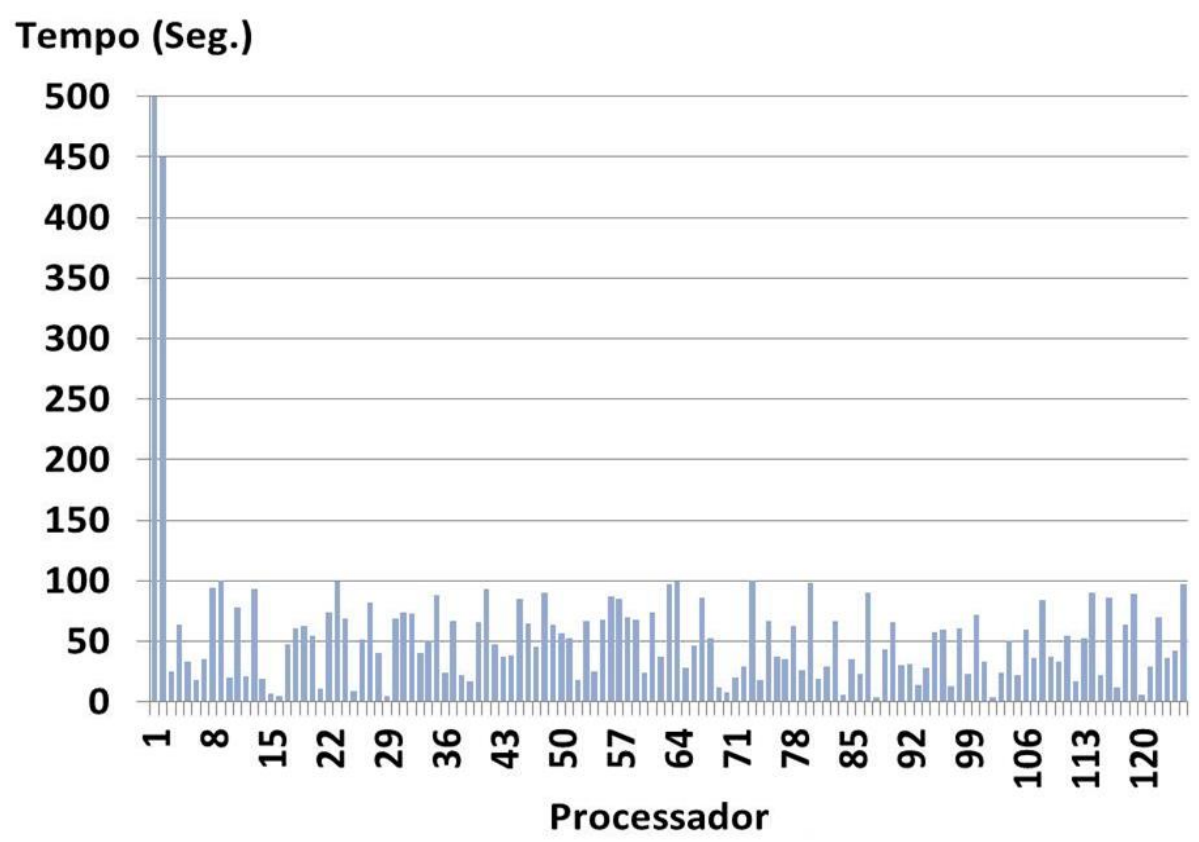

Fonte: Próprio Autor

Neste experimento, é possível concluir que duas tarefas com tempo de execução muito elevado, se comparadas com o tempo de execução das outras tarefas, tem uma influência significativa no desempenho da aplicação. No gráfico apresentado na Figura 31 é possível perceber que enquanto o processadores 1 e 2 processam suas tarefas até o final, os demais processadores ficam ociosos até o término do processamento. Observando o gráfico é possível concluir também que, quanto maior a diferença entre os tempos das tarefas, maior é a ociosidade. Apenas a linearização seguida de uma paralelização não é suficiente para melhorar o desempenho da aplicação. É necessária uma estratégia de escalonamento apropriada. 
O gráfico apresentado na Figura 32 mostra o balanceamento de carga. Para este cenário, a metodologia definiu que 14 é a quantia ideal de recursos de processamento para que, seja alcançado o tempo mínimo de processamento e sem ociosidade no processamento. Observando o gráfico apresentado na Figura 32 é possível perceber que o objetivo de diminuir a ociosidade no processamento foi atingido. Neste experimento, a ociosidade no processamento é quase nula. Neste cenário de teste, o comportamento da execução da aplicação é similar ao cenário de teste 1.

Figura 32: Execução da aplicação com balanceamento de carga - Cenário 2 - Cluster.

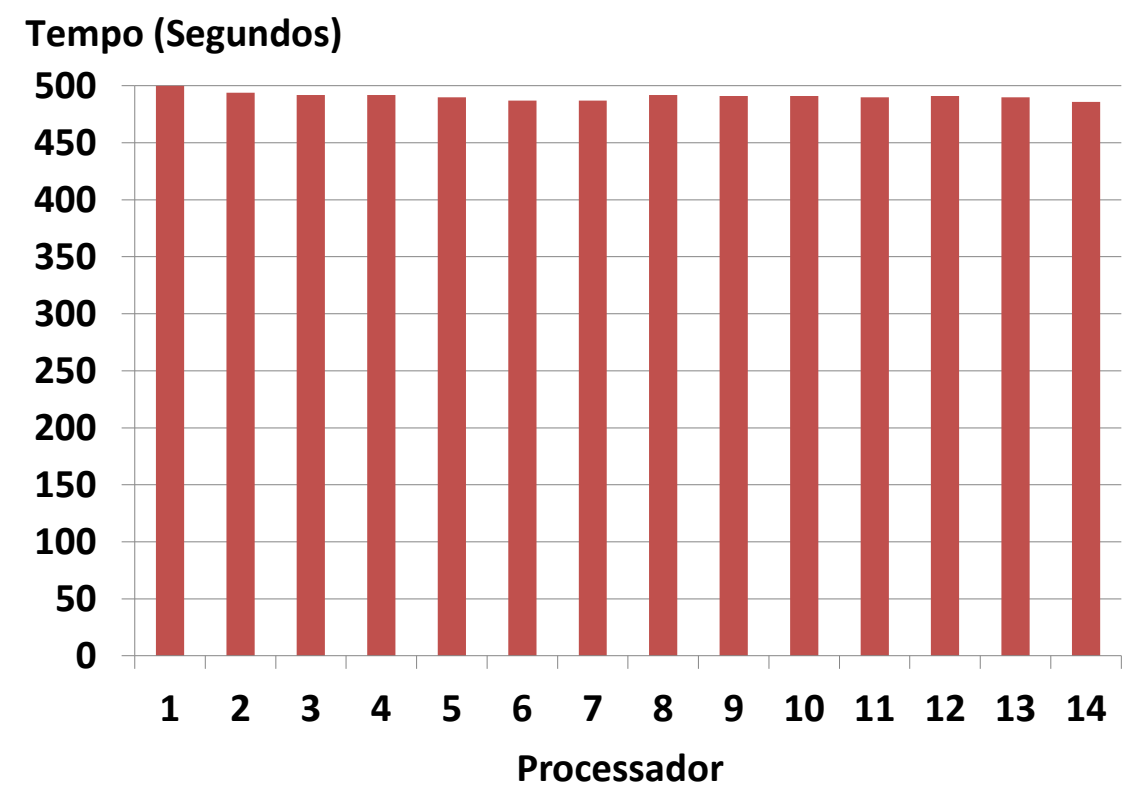

Fonte: Próprio Autor

\section{Speedup - Cenário 2}

Os Speedups obtidos nos experimentos realizados neste cenário de teste são exibidos no gráfico apresentado na Figura 33. Neste gráfico é possível perceber que o maior Speedup foi obtido com 14 recursos e mesmo, adicionando mais recursos de processamento não é possível obter um Speedup superior. Dessa forma, é possível concluir que 14 recursos de processamento realmente é a quantidade ideal de recursos computacionais para este cenário. Este fato, mais uma vez, mostra a eficiência da metodologia em calcular o número ideal de recursos de processamento e realizar um escalonamento de 
iterações adequado, resultando em um bom desempenho e na diminuição da ociosidade no processamento.

Figura 33: Speedups - Cenário 2 - Cluster.

\section{Speedup}

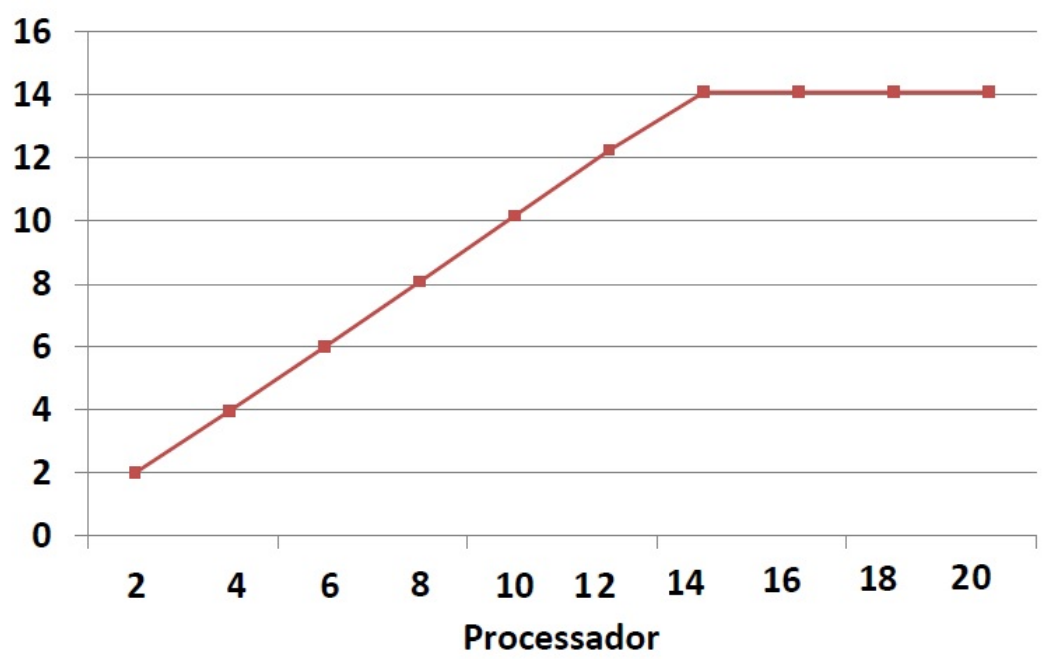

Fonte: Próprio Autor

\subsubsection{Caso de Teste 3}

O terceiro caso de teste é definido com um laço perfeitamente aninhado composto por 3 laços $(i, j, k)$. O laço $i$, varia de 0 a 4 , o $j$ de 0 a 4 e o $k$ varia de 0 a 5 . Linearizando este laço aninhado obtém-se um único laço com 80 iterações. Para este cenário, os valores de tempo de execução foram estipulados aleatoriamente, sendo 76 tarefas com valores de tempos de execução entre 0 a 300, e 4 tarefas com os valores de $850,800,500$ e 450 . O objetivo deste experimento é analisar como as execuções da aplicação se comportam quando há 4 tarefas com tempos elevados em relação às demais. O tempo de cada iteração é apresentado na tabela da Figura 34. 
Figura 34: Tempos das iterações do laço linearizado - Cenário 3

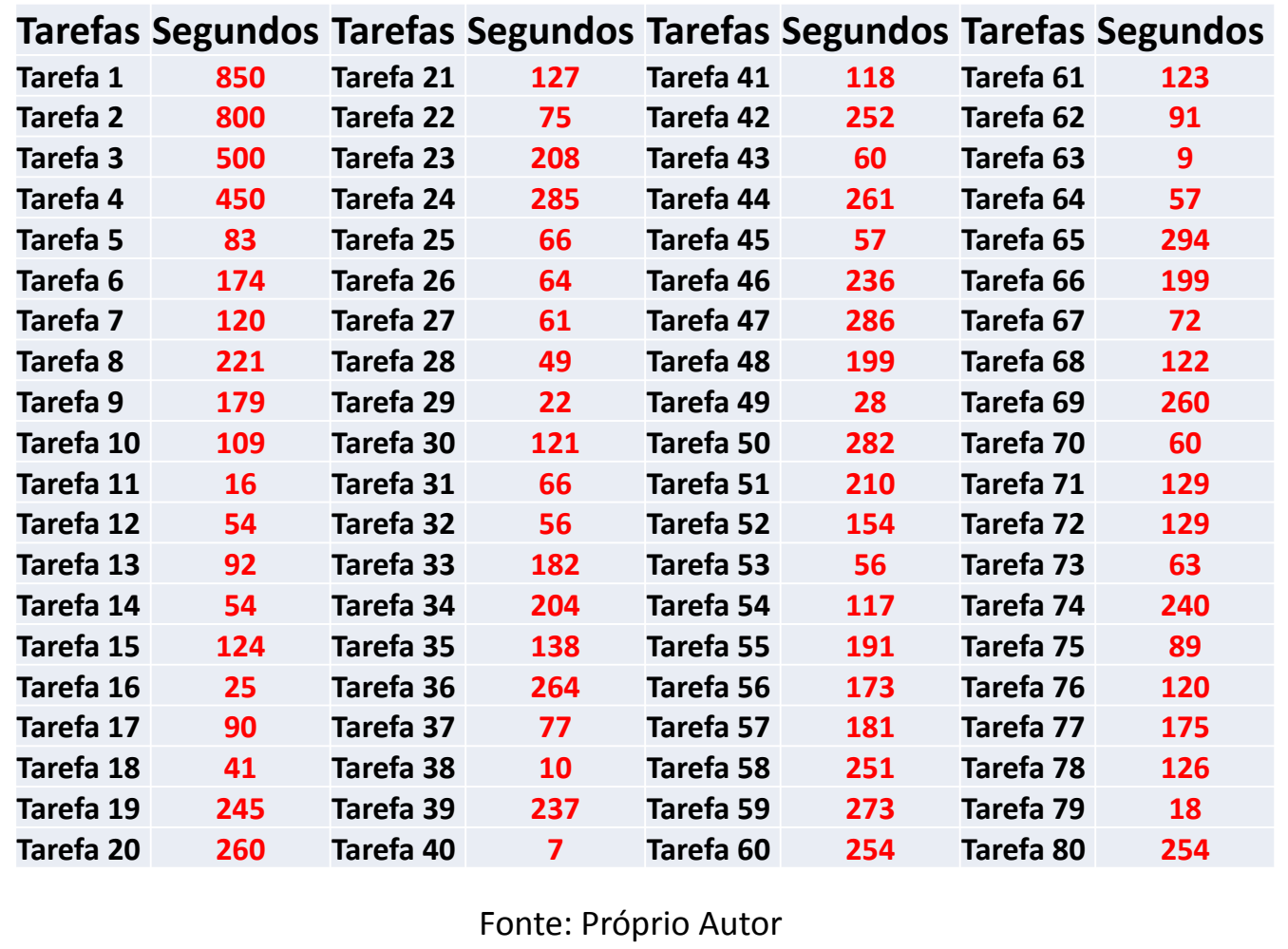

\subsubsection{Resultados e Análises - Cenário 3}

Nesta seção são apresentados os resultados obtidos nos experimentos realizados com as aplicações sintéticas no cenário de teste 3. Os resultados experimentais apresentados nesta seção foram executados no ambiente distribuído, na plataforma de processamento MPI.

\section{Escalabilidade e Desempenho - Cenário 3}

O gráfico apresentado na Figura 35, exibe os tempos das execuções paralela e sequencial para este cenário. Neste experimento, o desvio padrão variou de 0,2 a 0,7 . 
Figura 35: Tempos da execução paralela e sequencial - Cenário 3 - Cluster.

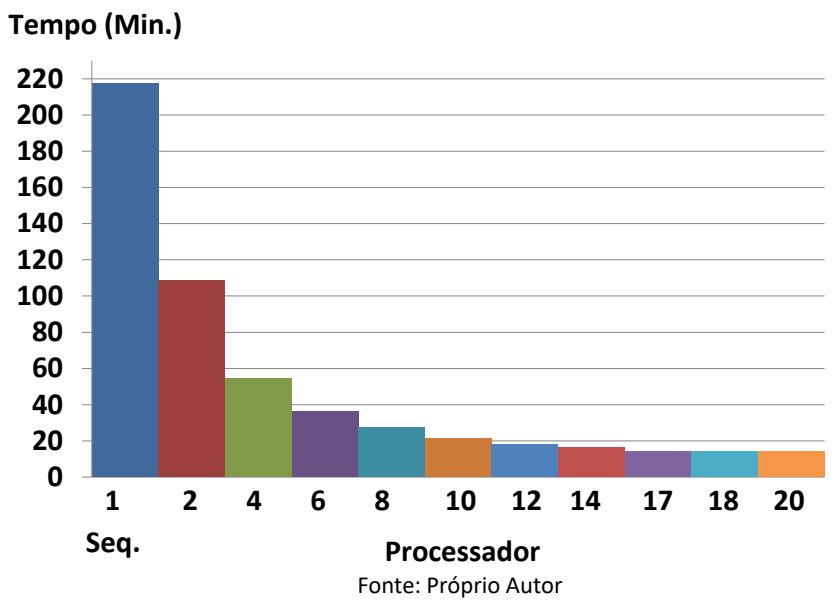

Para este cenário de teste, foi possível perceber que, mais uma vez, a aplicação se mostrou escalável. O tempo de processamento paralelo diminui proporcionalmente. Neste experimento, o comportamento da execução da aplicação sintética, se mostrou similar aos casos de testes 1 e 2 .

\section{Ociosidade dos Recursos de Processamento - Cenário 3 .}

Neste cenário de teste, a ociosidade entre os recursos de processamento aumentou significativamente. Observando o gráfico apresentado na Figura 36 é possível concluir que a heterogeneidade interfere no desempenho da aplicação. Neste cenário houve uma ociosidade significativa porque as tarefas são totalmente heterogêneas e também há tarefas com tempo de execução muito elevado com relação às demais. Como já concluído no cenário de teste 2 , quando o tempo de execução das tarefas possuem diferenças significativas de valores, a ociosidade aumenta consideravelmente.

A Figura 36 mostra o tempo teórico de execução das 80 tarefas. Neste cenário, são consideradas 4 tarefas com tempo de execução elevado e 76 tarefas com valores aleatórios relativamente baixos. Enquanto os 4 processadores ainda estão executando suas tarefas, outros já terminaram a sua execução. Com isso, a ociosidade aumenta 
consideravelmente.

Figura 36: Tempo teórico da execução de cada iteração do laço linearizado - Cenário 3.

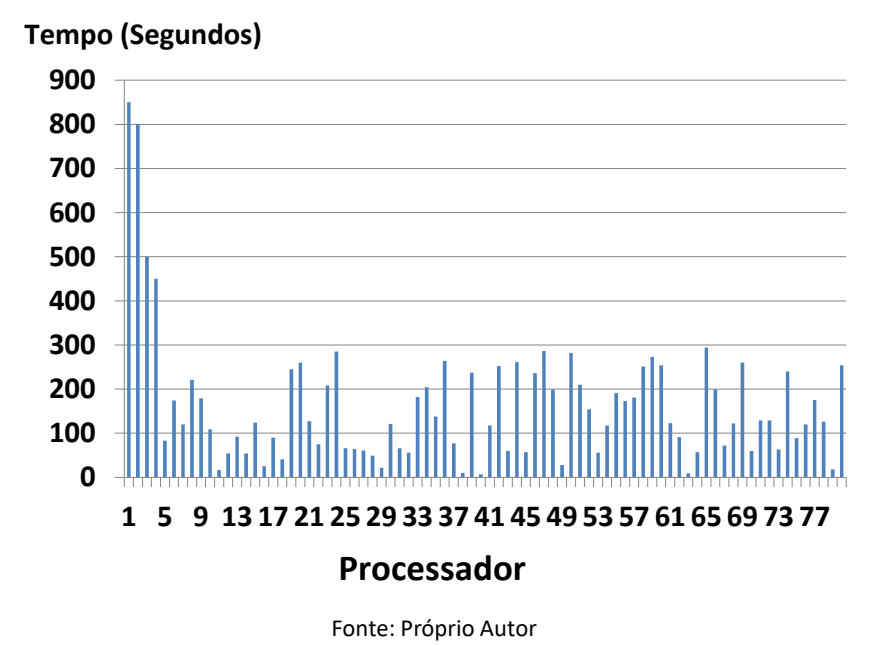

Na Figura 37 é apresentado um gráfico onde, é mostrado o tempo de execução de cada processador. Neste gráfico é possível perceber que foi realizado um bom balanceamento de carga entre os recursos. Para esta execução a metodologia definiu que 17 recursos é a quantidade ideal para processar a aplicação e alcançar o tempo mínimo de processamento com a menor ociosidade possível.

Figura 37: Execução da aplicação com balanceamento de carga - Cenário 3 - Cluster.

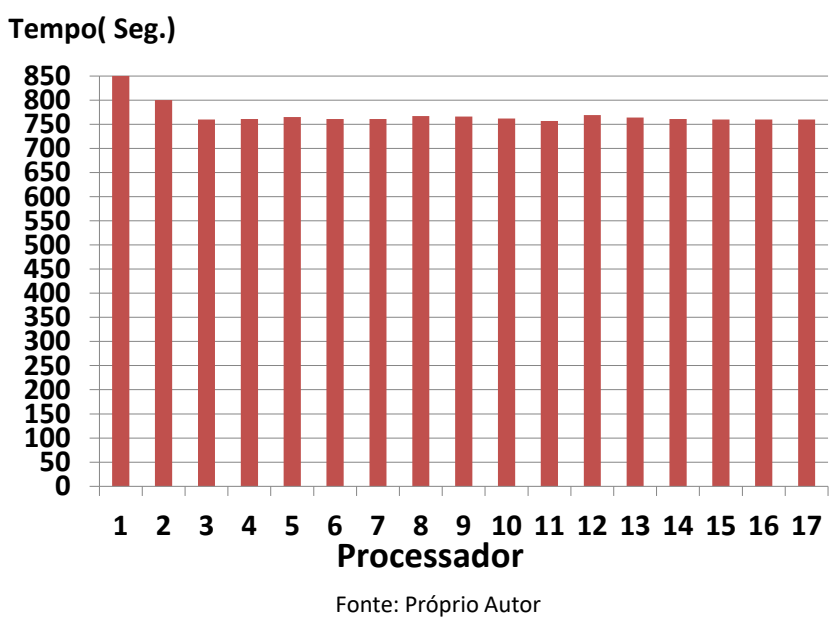

No gráfico acima é possível perceber que com a definição do número ideal de re- 
cursos de processamento e um escalonamento adequado, é possível melhorar o desempenho da aplicação e diminuir a ociosidade. Um escalonamento adequado resulta em um bom balanceamento de carga entre os recursos e permite melhorar o desempenho da aplicação.

\section{Speedup - Cenário 3}

A Figura 38 mostra os Speedups obtido neste cenário.

Figura 38: Speedups - Cenário 3 - Cluster.

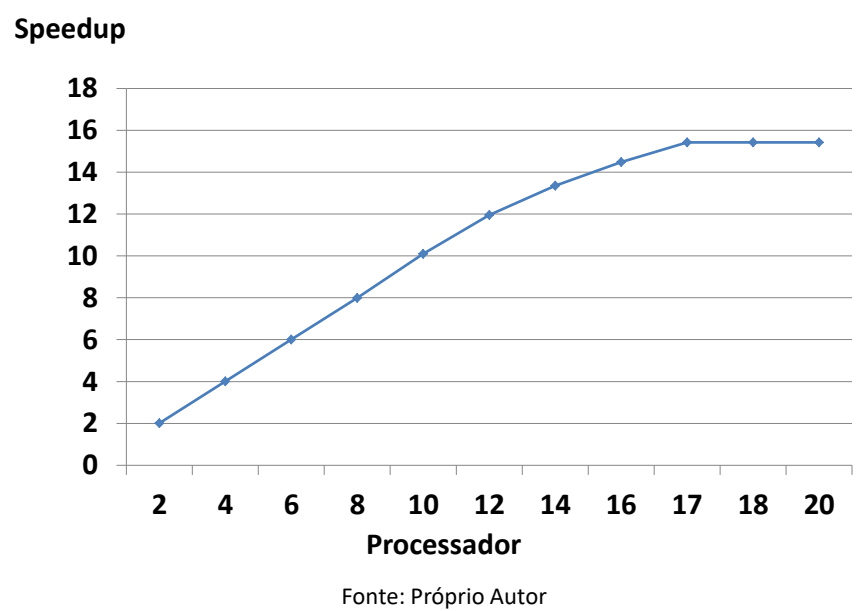

Neste cenário de teste também foi possível obter um Speedup linear. O maior Speedup obtido foi com 17 recursos de processamento. O comportamento da execução da aplicação se mostrou similar aos casos de testes 1 e 2 .

\subsubsection{Comparação Entre a Metodologia Proposta com Plata- formas de Processamento Paralelos e Distribuídos}

Nesta seção, são apresentados resultados experimentais comparando a metodologia proposta com OpenMP e MPI. Nestes experimentos são considerados laços linearizados. Nos experimentos realizados com MPI foram implementados os algoritmos estático e Self Schedule. Já nos experimentos realizados com OpenMP foram implementados os algoritmos estático, Self Schedule e Guided. 


\subsubsection{Cenário 1}

Neste cenários, os tempos apresentados na Figura 39 foram adotados como tempos de execução de iterações de laço linearizado.

Figura 39: Tempos de iteração de laços aninhados - Cenário 1 - Tabela 1.

$\begin{array}{ll}\text { Tarefas } & \text { Segundos } \\ \text { Tarefa 1 } & 2 \\ \text { Tarefa 2 } & 10 \\ \text { Tarefa 3 } & 3 \\ \text { Tarefa 4 } & 30 \\ \text { Tarefa 5 } & 1 \\ \text { Tarefa 6 } & 20 \\ \text { Tarefa 7 } & 50 \\ \text { Tarefa 8 } & 110 \\ \text { Tarefa 9 } & 3 \\ \text { Tarefa 10 } & 450 \\ & \text { Fonte: Próprio Autor }\end{array}$

Neste experimento são considerados laços de 100, 1.000 e 2.000 iterações. Para isso, a quantidade de valores apresentados na Figura 39, foi multiplicada por 10, 100 e 200. Dessa forma, os valores se repetem 10, 100 e 200.

\section{Comparação Entre a Plataforma de Processamento OpenMP e a Metodologia}

Proposta . O objetivo deste experimento é comparar o desempenho obtido no processamento do laço linearizado utilizando as diretivas schedule (static), (dynamic) , (guided) com o desempenho obtido utilizando o algoritmo de escalonamento implementado na metodologia.

Foram desenvolvidas 4 aplicações sintéticas. Na primeira aplicação, todas as atividades da metodologia foram implementadas, na segunda, foi implementado o algoritmo estático, na terceira o algoritmo Self Shedule foi implementado e na quarta, o algoritmo Guided foi implementado. Todos os experimentos apresentados nesta seção foram executados no ambiente de processamento paralelo, ou seja, em uma máquina Multicore. Esta máquina possui 2 processadores Xeon com 8 núcleos de processa- 
mento, totalizando 16 núcleos de processamento. Neste experimento foram criadas 16 threads em cada aplicação paralela.

A Figura 40 apresenta uma tabela com os tempos de execução obtidos no processamento.

Figura 40: Tempo de processamento - Cenário: Comparação entre os algoritmos de escalonamento do OpenMP e Metodologia - Tabela - Ambiente Paralelo.

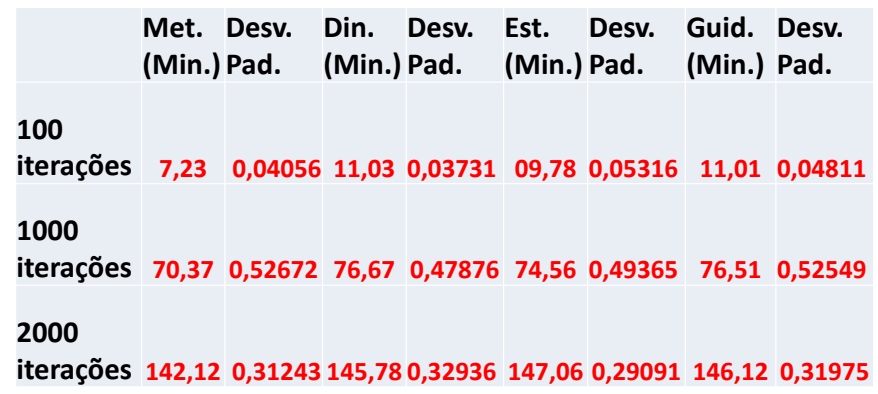

Fonte: Próprio Autor

A Figura 41 apresenta os mesmos tempos graficamente.

Figura 41: Tempo de processamento - Cenário: Comparação entre os algoritmos de escalonamento do OpenMP e Metodologia - Gráfico - Ambiente Paralelo.

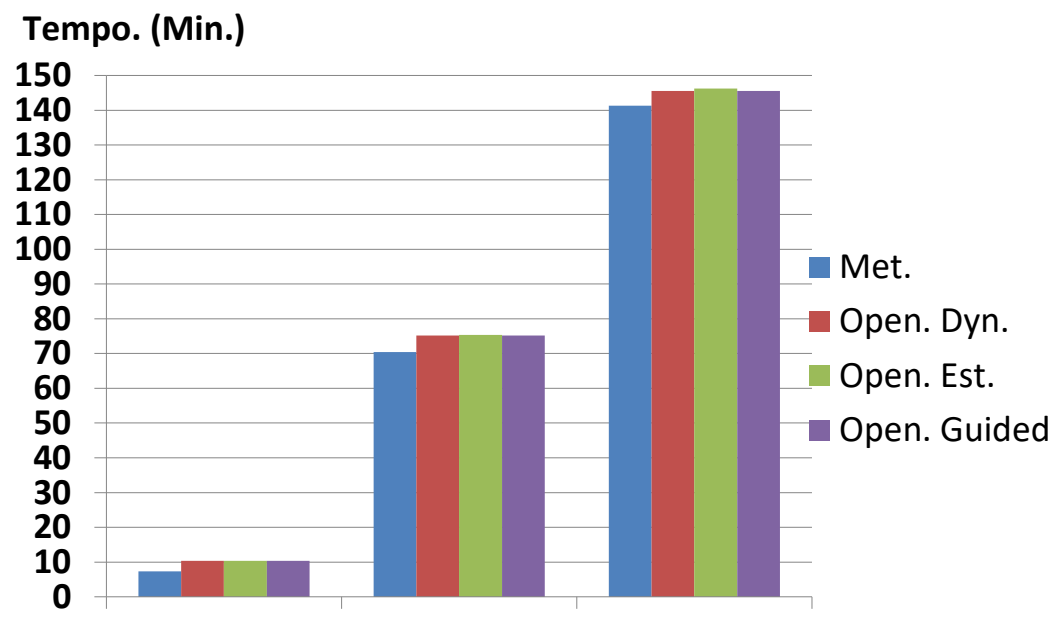

100 Iterações 1000 Iterações 2000 Iterações

Fonte: Próprio Autor 
A Figura 42 apresenta um gráfico com os Speedups obtidos neste experimento.

Figura 42: Speedups - Ambiente Paralelo.

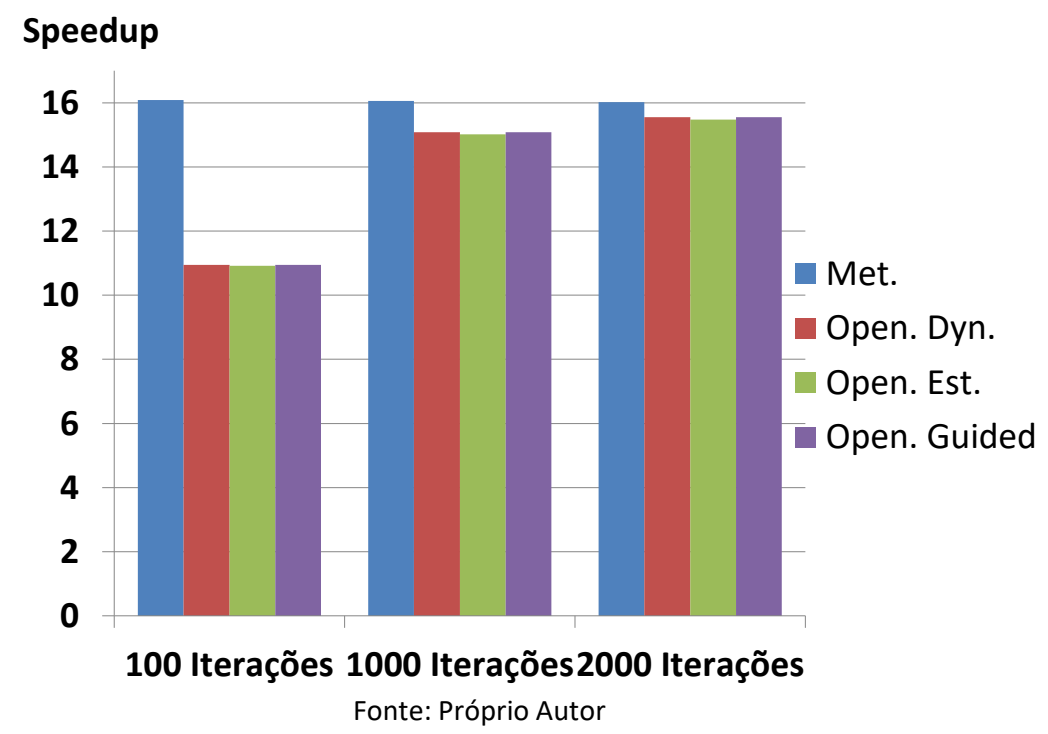

Observando os resultados experimentais apresentados nesta seção, é possível observar que a aplicação onde foi implementada a metodologia proposta, alcançou o menor tempo de execução e o maior Speedup. As principais hipóteses que podem explicar o fato da metodologia aqui proposta ter alcançado o menor tempo de processamento e também, o maior Speedup encontra-se em dois aspectos. Primeiro, a forma de distribuir as tarefas nos algoritmos de escalonamentos é diferente. A atividade de escalonamento da metodologia proposta se apoia em uma distribuição de tarefa específica onde, as tarefas de maiores pesos são atribuídas para os recursos com as menores cargas de trabalho. A segunda hipótese é o custo no gerenciamento do escalonamento dinâmico. No escalonamento dinâmico há dois fatores que impactam no desempenho da aplicação. No escalonamento dinâmico as tarefas são atribuídas em tempo de execução, isso faz com que a ociosidade dos recursos diminua. Entretanto, o escalonamento dinâmico implica em um custo de gerenciamento. No escalonamento dinâmico é necessário gerenciar e atribuir as tarefas em tempo de execução, implicando em um custo no gerenciamento do escalonamento. A atividade de escalonamento da metodologia 
aqui proposta além de se apoiar em uma estratégia de distribuição de tarefas específica, faz com que o escalonamento seja realizado antes do processamento, resultando em nenhum custo de gerenciamento na execução da aplicação.

O valor do tempo de cada tarefa e a maneira como são distribuídas pelos algoritmos de escalonamento impactam diretamente no desempenho da aplicação. Neste experimento as implementações com os algoritmos estático, dinâmico e guiado, tiveram tempos de execução muitos próximos. Uma possível hipótese que explica este fato encontra-se no fato de que o valor de tempo de execução de cada tarefa foi de tal forma determinada que promoveu-se uma boa distribuição de carga na distribuição das iterações realizada pelos algoritmos de escalonamento.

\section{Comparação Entre a Plataforma de Processamento MPI e a Metodologia Pro-} posta .

O objetivo deste experimento é comparar o desempenho dos algoritmos de escalonamento Self Shedule e Estático com o desempenho do algoritmo de escalonamento implementado na metodologia proposta no sistema distribuído utilizando MPI.

Neste experimento, três implementações sintéticas paralelas foram desenvolvidas na plataforma MPI. Na primeira implementação, todas as atividades da metodologia proposta foram implementadas. Na segunda implementação, o algoritmo de escalonamento estático foi implementado e na terceira, o algoritmo Self Shedule foi implementado. Neste experimento foi simulado um laço linearizado. Todos os experimentos apresentados nesta seção foram executados com 16 processadores.

A Figura 43 apresenta uma tabela com os tempos de execução obtidos no processamento. Foram considerados os valores de tempos apresentados na tabela da Figura 39. 
Figura 43: Tempo de processamento - Cenário - 1- Tabela - Cluster.

\begin{tabular}{|c|c|c|c|c|c|c|}
\hline & $\begin{array}{l}\text { Met. } \\
\text { (Min.) }\end{array}$ & $\begin{array}{l}\text { Desv. } \\
\text { Pad. }\end{array}$ & $\begin{array}{l}\text { Self. } \\
\text { Schedule } \\
\text { (Min.) }\end{array}$ & $\begin{array}{l}\text { Desv. } \\
\text { Pad. }\end{array}$ & $\begin{array}{l}\text { Estático } \\
\text { (Min.) }\end{array}$ & $\begin{array}{l}\text { Desv. } \\
\text { Pad. }\end{array}$ \\
\hline $\begin{array}{l}100 \\
\text { iterações }\end{array}$ & 7,30 & 0,05 & 11,19 & 0,06 & 11,34 & 0,05 \\
\hline $\begin{array}{l}1000 \\
\text { iterações }\end{array}$ & 70,44 & 0,15 & 75,14 & 0,16 & 75,27 & 0,16 \\
\hline $\begin{array}{l}2000 \\
\text { iterações }\end{array}$ & 141,28 & 0,21 & 146,07 & 0,21 & 155,24 & 0,21 \\
\hline
\end{tabular}

A Figura 44 apresenta os mesmos tempos graficamente.

Figura 44: Tempo de processamento - Cenário 1 - Gráfico - Cluster.

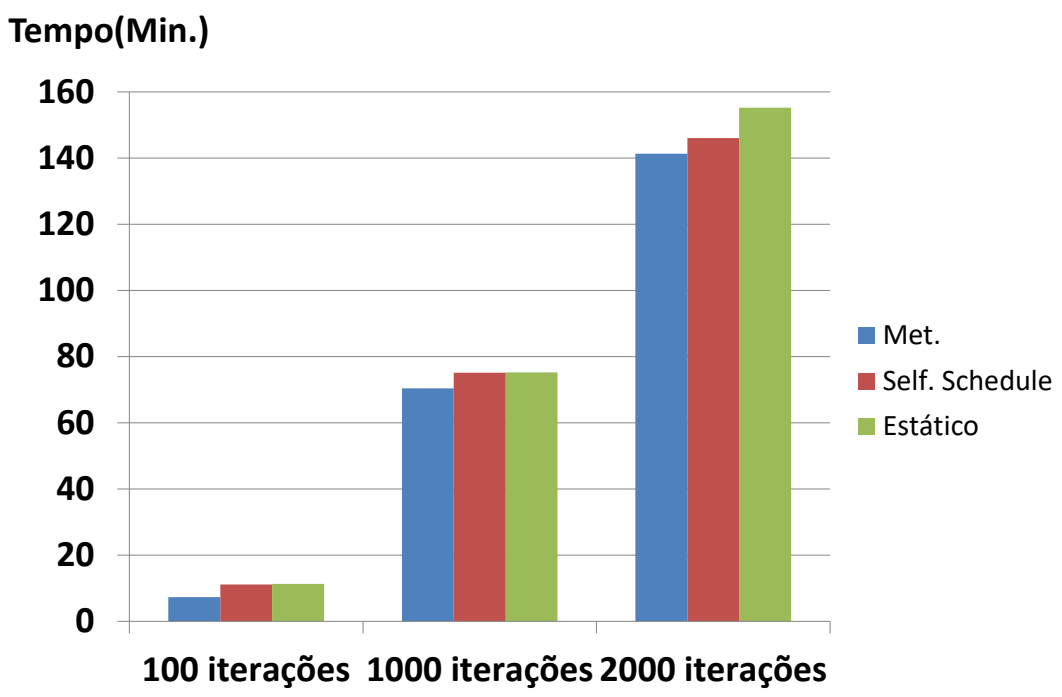

Fonte: Próprio Autor

A Figura 45 apresenta um gráfico com os Speedups obtidos neste experimento. 
Figura 45: Speedup - Cenário - 1 - Cluster.

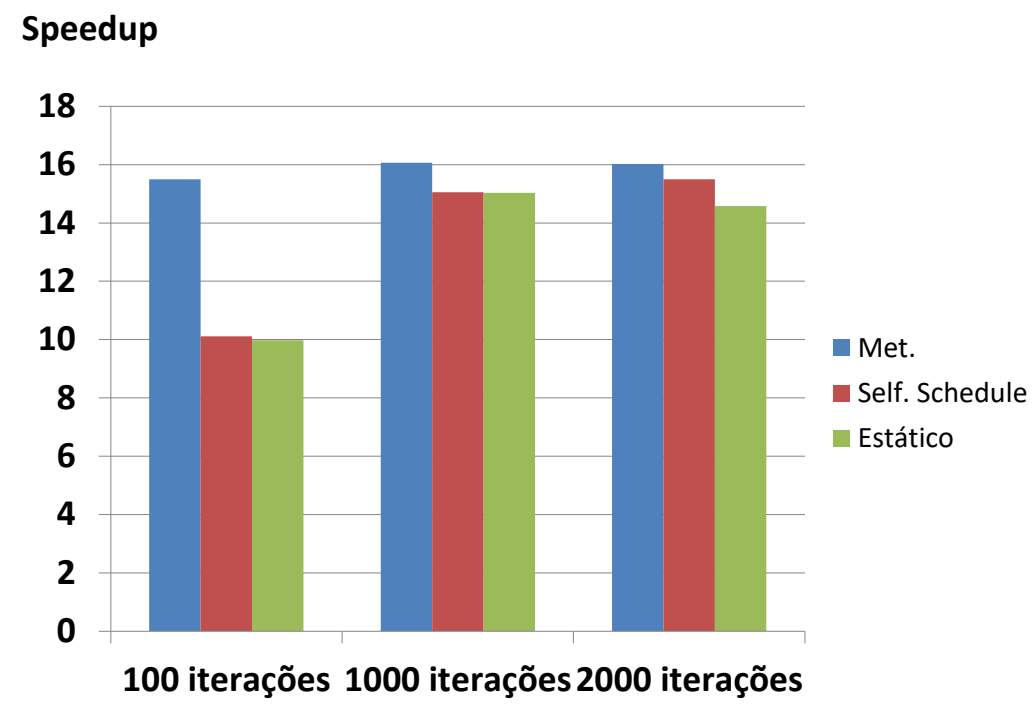

Fonte: Próprio Autor

Nos resultados experimentais apresentados nesta seção percebe-se que a metodologia, mais uma vez, alcançou o menor tempo de execução e o maior Speedup. Uma possível explicação para estes fatos encontra-se em alguns aspectos já mencionados, tais como, custo no gerenciamento do escalonamento e a estratégia de distribuição de tarefas no escalonamento.

Assim como no escalonamento dinâmico realizado no openMP, o Self Schedule do MPI possui um custo de gerenciamento. Em MPI o custo ainda é maior, no Self Schedule o processo pai envia os dados para os processos filhos, que recebem os dados, processam e enviam um aviso para o processo pai pedindo mais trabalho. Com isso, o custo de gerenciamento aumenta consideravelmente.

Na metodologia proposta, a distribuição de tarefa é realizada por um escalonamento estático que se baseia em uma distribuição de tarefas específica, por isso, não há custo de gerenciamento de escalonamento no processamento. O principal motivo para a metodologia alcançar o menor tempo de processamento, encontra-se na estratégia de distribuição das tarefas no escalonamento. A maneira como as tarefas são distribuídas no escalonamento interfere no desempenho da aplicação. 


\section{Cenário 2.}

Neste experimento é considerado o tempo de execução de um laço aninhado da aplicação adotada como estudo de caso. A metodologia proposta foi aplicada na modelagem de distribuição de espécies e é apresentada no Capítulo 6. Esta aplicação contém laços aninhados com processamento heterogêneo. Nos experimentos apresentados no Capítulo 6, não foi possível comparar a metodologia proposta com outras soluções paralela e distribuída, porque a modelagem é processada em uma plataforma específica, na plataforma R. Dessa forma, neste experimento é considerado o tempo de execução de um laço aninhado da modelagem de distribuição de espécies. Assim, é possível analisar como a modelagem se comporta nas plataformas OpenMP e MPI e também, comparar os desempenhos obtidos. Os tempos de execução das iterações do laço aninhado considerado neste experimento são apresentados na Figura 46. O objetivo deste experimento é simular um laço aninhado composto por três laços $(i, j, k)$, onde $i$ varia de 0 a $3, j$ de 0 a 5 e $k 0$ a 10 . Linearizando este laço aninhado, é obtido um único laço com 150 iterações, onde, os valores do laço mais interno se repetem 15 vezes. Os valores das iterações do laço mais interno $k$ são apresentados na Figura 46.

Figura 46: Tempos de execução das iterações do laço mais interno - Cenário 2 : Comparação entre Metodologia proposta com OpenMP e MPI - Modelagem.

\begin{tabular}{ll} 
Tarefas & Minutos \\
Tarefa 1 & 1 \\
Tarefa 2 & 3 \\
Tarefa 3 & 1 \\
Tarefa 4 & 1 \\
Tarefa 5 & 1 \\
Tarefa 6 & 2 \\
Tarefa 7 & 3 \\
Tarefa 8 & 5 \\
\hline Tarefa 9 & 11 \\
Tarefa 10 & 45 \\
& Fonte: Próprio Autor
\end{tabular}


A Figura 47 apresenta os resultados obtidos no processamento realizado pelo ambiente paralelo.

Figura 47: Tempo de processamento - Cenário 2 - Tabela - Ambiente Paralelo - Modelagem.

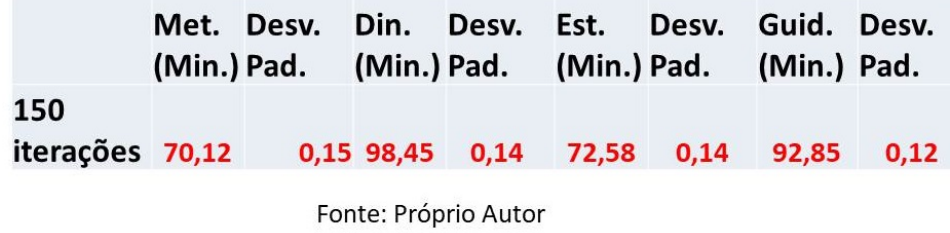

Os mesmos tempos são apresentados graficamente na Figura 48.

Figura 48: Tempo de processamento - Cenário 2 - Gráfico - Ambiente Paralelo - Modelagem.

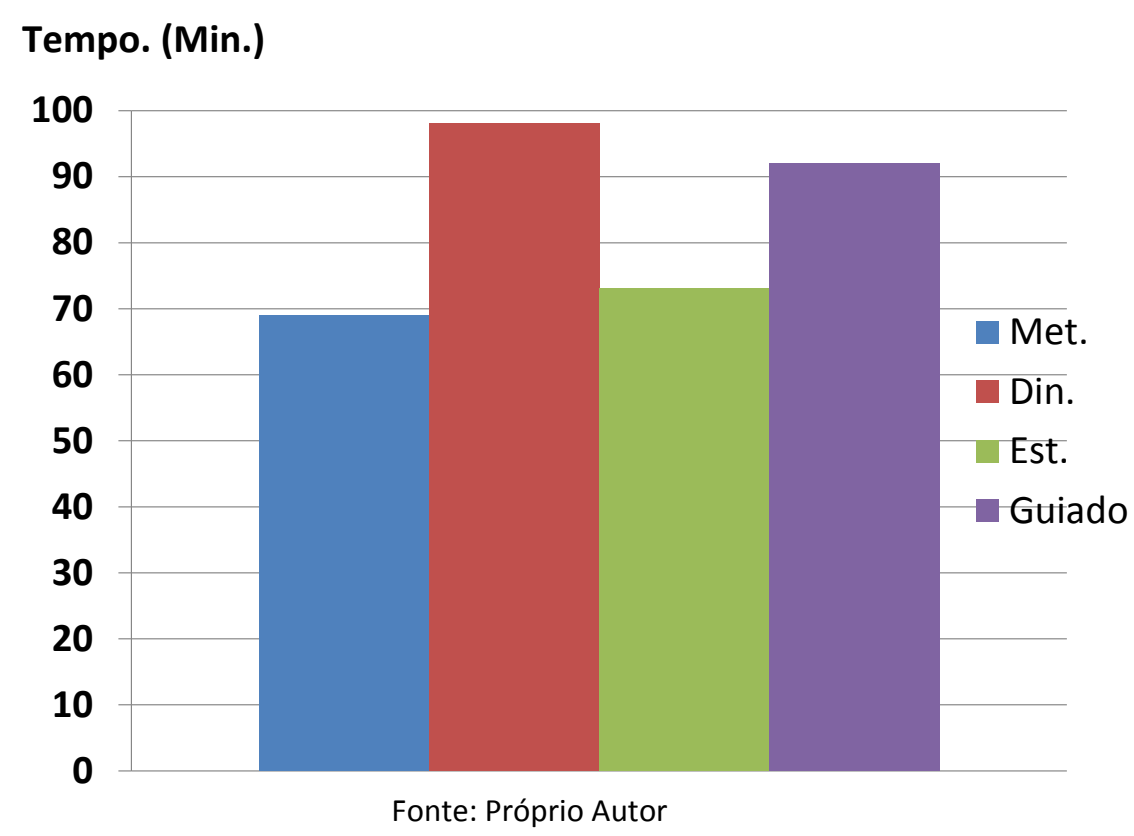

A tabela apresentada na Figura 49 apresenta os resultados obtidos no processamento realizado pelo Cluster. 
Figura 49: Tempo de processamento - Cenário 2 - Tabela - Cluster - Modelagem.

\begin{tabular}{|c|c|c|c|c|c|c|}
\hline & $\begin{array}{c}\text { Met. } \\
\text { (Min.) }\end{array}$ & $\begin{array}{c}\text { Desv. } \\
\text { Pad. }\end{array}$ & $\begin{array}{c}\text { Din. } \\
\text { (Min.) }\end{array}$ & $\begin{array}{c}\text { Desv. } \\
\text { Pad. }\end{array}$ & $\begin{array}{c}\text { Est. } \\
\text { (Min.) }\end{array}$ & $\begin{array}{c}\text { Desv. } \\
\text { Pad. }\end{array}$ \\
\hline $\begin{array}{c}150 \\
\text { iterações }\end{array}$ & 55,95 & 0,17 & 84,14 & 0,18 & 71,58 & 0,17 \\
\hline \multicolumn{5}{c}{ Fonte: Próprio Autor } \\
\end{tabular}

Os mesmos tempos são apresentados graficamente na Figura 50

Figura 50: Tempo de processamento - Cenário 2 - Gráfico - Cluster - Modelagem.

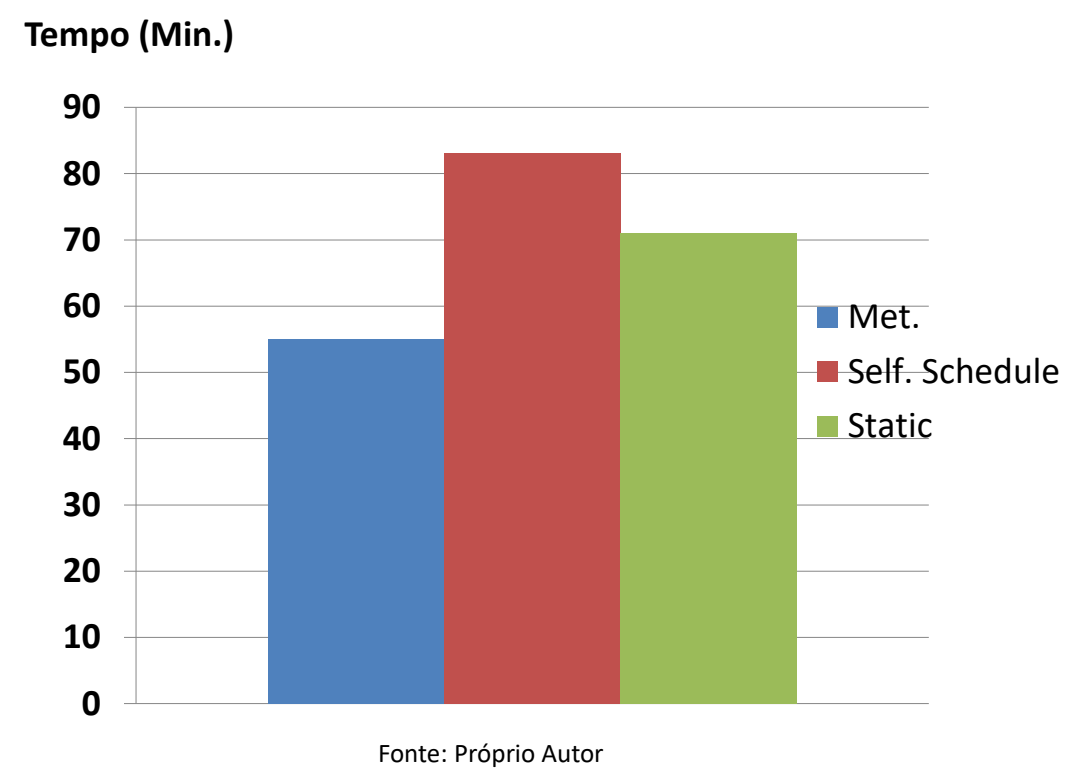

Neste experimento, a aplicação onde a metodologia proposta foi implementada alcançou o menor tempo de execução. As hipóteses que podem explicar este fato são as mesmas já mencionadas, o custo no gerenciamento do escalonamento e a estratégia de distribuição das tarefas.

Para este experimento, a metodologia proposta definiu que 25 é o número ideal de recursos de processamento para processar as 150 iterações do laço linearizado no tempo mínimo de 45 minutos. O Cluster possui apenas 20 processadores. Dessa forma, a execução do laço linearizado foi processada por 20 recursos de processamento. Um fato importante que deve ser observado é que, mesmo não utilizando a quantidade ideal 
de recursos de processamento, a metodologia proposta consegue diminuir a ociosidade no processamento e alcançar um bom desempenho.

Habitualmente, o algoritmo dinâmico alcança um tempo de processamento menor que o algoritmo estático. Neste experimento, comparando o algoritmo Self Shedule com o algoritmo Estático, o algoritmo Estático alcançou o menor tempo de processamento. Isto pode ser explicado pelo fato que, no algoritmo estático, a distribuição de tarefas é constante. Já no algoritmo dinâmico a distribuição de tarefas depende de alguns fatores, tais como, o tempo de criação dos processos, tempo que cada processo executa a sua tarefa e entre outros.

A tabela apresentada na Figura 51 mostra a distribuição de tarefas realizada no algoritmo estático.

Figura 51: Distribuição de tarefas no algoritmo Estático.

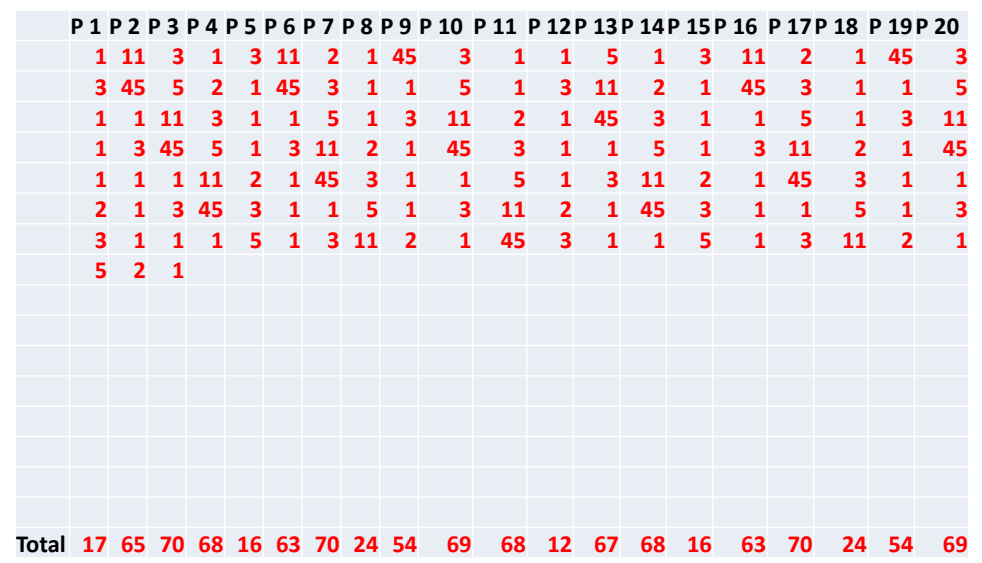

Fonte: Próprio Autor

Já a tabela apresentada na Figura 52 mostra a distribuição de tarefas realizada no algoritmo Self Schedule. 
Figura 52: Distribuição de tarefas no algoritmo Self Schedule.

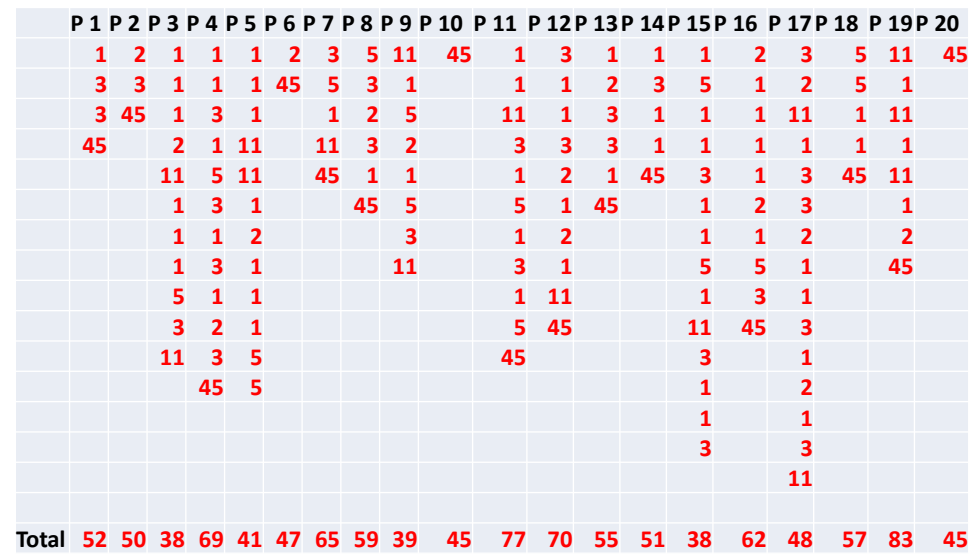

Fonte: Próprio Autor

Na distribuição de tarefas realizada no algoritmo dinâmico, pode ocorrer que, a distribuição de carga seja realizada equilibrando a carga de trabalho, mas no final, um processo pegue uma tarefa com tempo de execução muito elevado, neste caso, o tempo de processamento fica preso a este recurso. Neste experimento, isso ocorre com o processador 19 , que inicialmente pegou as tarefas $11,1,11,1,11,1,2$ e depois, pegou a tarefa 45. No final das atribuições, esse processo pegou uma tarefa com tempo de execução muito elevado e o tempo do processamento ficou preso a este recurso.

Cenário 3 . Outro experimento foi realizado com as aplicações com os algoritmos Estáticos, Self Shedule e com o algoritmo da metodologia proposta. Neste experimento, foi considerado um laço linearizado de 1.600 iterações, onde os valores de 1.595 iterações foram definidos por números aleatórios entre 0 a 10, 4 iterações por 850 e uma iteração com 800.

O gráfico apresentado na Figura 53 mostra o resultado obtido no processamento. 
Figura 53: Tempo de processamento.

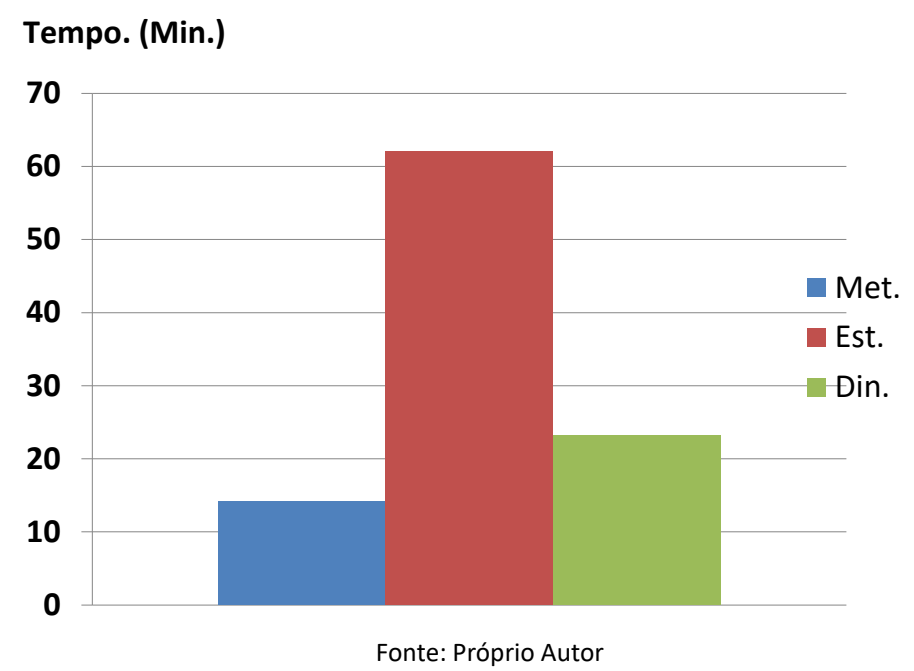

Neste experimento, mais uma vez, a aplicação com a implementação da metodologia proposta alcançou o menor tempo de processamento. Já a aplicação com a implementação do algoritmo Estático, alcançou o maior tempo de processamento, como habitualmente esperando, e o algoritmo Self Shedule ficou entre a metodologia e o algoritmo Estático. Observando o gráfico nota-se que a aplicação com a implementação do algoritmo de escalonamento estático consumiu muito mais tempo que as demais aplicações, neste caso, é provável que, houve um mau balanceamento de carga no processamento paralelo desta aplicação. Este fato também ressalta a eficiência da metodologia proposta. Na metodologia proposta a distribuição de tarefas é constante, sempre será possível alcançar o menor tempo de processamento possível e diminuir a ociosidade no processamento.

\subsubsection{Considerações Finais Sobre os Resultados e Análises}

A principal hipótese considerada neste trabalho envolve o desempenho de aplicações que contêm laços perfeitamente aninhados com processamentos heterogêneos. A hipótese considerada neste trabalho diz que é possível melhorar o desempenho de tais aplicações, utilizando uma quantia de recursos limitada a um número ideal; através 
de uma estratégia de paralelização adequada e a redução da ociosidade de recursos de processamento.

Para comprovar a viabilidade desta hipótese foram definidos cenários de testes. Nestes cenários de testes é analisado o comportamento da aplicação em diversas situações. Em todos os cenários de testes, os resultados e análises mostram o impacto do uso da metodologia aqui proposta. Os resultados experimentais apresentados neste capítulo comprovam a viabilidade da hipótese considerada e a viabilidade da metodologia aqui proposta.

Para cada cenário de teste, foram considerados laços perfeitamente aninhados de 3 níveis $(i, j, k)$. Em cada cenário de teste é variado o tempo de execução de cada iteração do laço. No caso de teste 1 , o tempo de execução das iterações varia de 0 a 300 segundos, no caso de teste 2 varia de 0 a 100 e com 2 iterações com os tempos de 500 e 450, e no caso de teste 3 varia de 0 a 300 e com 4 iterações com os tempos de $850,800,500$ e 450 segundos.

Em comparação com a aplicação sequencial, em todos os cenários de testes, a metodologia proposta conseguiu alcançar o menor de tempo de processamento. Isso demonstra a eficiência da metodologia proposta e comprova a viabilidade da hipótese estudada neste trabalho.

Observando os resultados obtidos nos cenários, é possível concluir que a heterogeneidade das iterações do laço influencia consideravelmente no desempenho da aplicação. Observa-se que, quanto maior é a heterogeneidade das iterações do laço, maior é a influência no desempenho e a ociosidade dos processadores. Um aspecto a ser observar é que a heterogeneidade das iterações do laço não inferiu no desempenho da metodologia, mesmo com uma quantidade considerável de heterogeneidade a metodologia alcançou o menor tempo de processamento comparando com as outras implementações. 
Nos resultados experimentais dos três cenários foi possível comprovar a eficiência das atividades de cálculo do número ideal de recursos e escalonamento da metodologia proposta. Para cada cenário de teste foi calculado um número ideal de recurso de processamento. Em todos os cenários com a quantia estipulada pelas atividades da metodologia, foi possível alcançar o tempo mínimo de processamento e, ao se adicionar mais recursos de processamento, não foi possível obter um tempo de processamento menor. A quantidade ideal de recursos de processamento depende da quantidade de iterações do laço aninhado e o quanto as iterações são heterogêneas.

Outro aspecto que é possível observar é o balanceamento de carga realizado na atividade de escalonamento da metodologia. A sua análise, também é uma forma de avaliar a eficiência do escalonamento realizado na metodologia. Em todos os cenários de testes, houve um bom balanceamento de carga entre os recursos de processamentos. Até mesmo os cenários onde houve uma heterogeneidade maior, como é o caso do cenário 3, alcançou-se um bom balanceamento de carga, deixando os processadores com a carga de trabalho equilibrada.

Foram realizados testes com algoritmos de escalonamento dinâmico, estático e guiado na plataforma OpenMP e, em todos os cenários a metodologia alcançou o menor tempo de execução. As possíveis hipóteses que podem explicar este fato encontram-se, no fato que a atividade de escalonamento da metodologia se baseia em uma distribuição de tarefas específica e estática, realizada antes do processamento. Já no algoritmo de escalonamento dinâmico realizado no OpenMP, comparando com o escalonamento estático, a distribuição realizada pode não ser a mais adequada e também contém um custo de gerenciamento no escalonamento, que não existe na metodologia de paralelização proposta.

Testes comparativos entre a plataforma de processamento distribuído MPI e a metodologia de paralelização proposta também foram realizados. Nestes experimentos, a metodologia também alcançou o melhor desempenho. As possíveis hipóteses que 
podem explicar este fato encontram-se no fato de alguns algoritmos realizarem o escalonamento dinamicamente em tempo de processamento. Isto implica em um custo de gerenciamento no escalonamento e de comunicação. Na plataforma MPI o custo é ainda maior, porque é necessário enviar os dados para serem processados pelos nós, esse envio encarece o custo de gerenciamento. Na metodologia de paralelização proposta, os dados também são enviados para serem processados pelos nós, todavia o escalonamento é realizado estaticamente antes do processamento. Dessa forma, não há custo de gerenciamento no escalonamento realizado pela metodologia, há apenas um custo de envio de dados, que por sua vez, na metodologia proposta é mínimo. Pelo fato da metodologia ter alcançado o menor tempo de processamento em todos os cenários de testes, também é possível concluir que a metodologia trabalhou melhor com a heterogeneidade do que as outras plataformas.

Um aspecto importante que deve ser observado é o valor de tempo de cada tarefa e a maneira como são distribuídas pelos algoritmos de escalonamento. A forma como o valor de tempo de execução da tarefa é determinada e a maneira como elas são distribuídas pelos algoritmos, interfere significativamente no desempenho da aplicação. Esse aspecto explica porque os tempos de execução de alguns experimentos das aplicações sintéticas em comparações similares foram próximos e em outros bem diferentes. É muito provável que nestes experimentos, houve boas e más distribuições das iterações . Esse aspecto também é o fator principal que explica o motivo da metodologia proposta sempre alcançar o menor tempo de execução.

No algoritmo de escalonamento implementado na metodologia proposta, a distribuição das iterações do laço linearizado é realizada de forma que sempre promove o balanceamento de carga, considerando o tempo de execução de cada uma e a quantidade de carga já atribuída para cada recurso de processamento. Já nos outros algoritmos de escalonamento a qualidade da distribuição de carga realizada depende de outros fatores, tais como, tempo de criação de processo ou thread, tempo que o re- 
curso demora para processar a sua tarefa e receber uma nova tarefa, entre outros. É possível observar estes fatores no experimento realizado comparando a metodologia entre as implementações distribuídas com os algoritmos de escalonamento dinâmico e estático. Para os mesmos tempos de execução das iterações do laço linearizado, o algoritmo estático alcançou o tempo de execução de 70 já o algoritmo dinâmico 83 . A forma como as iterações foram distribuídas interferiu fortemente no desempenho da aplicação. 


\section{ESTUDO DE CASO: MODELAGEM DE DISTRIBUIÇÃO DE ESPÉCIES}

A metodologia proposta foi implementada na aplicação de modelagem de distribuição de espécies. Neste capítulo, são apresentados resultados obtidos nos experimentos. Os resultados experimentais apresentados neste capítulo foram publicados no artigo (LUZ C.; SATO; MIDORIKAWA, 2017).

\subsection{Modelagem de Distribuição de Espécies em $\mathbf{R}$}

Fatores antropogênicos causam alterações ambientais que implicam diretamente em ameaças para a distribuição de espécies. É possível citar como exemplos de fatores antropogênicos a perda e fragmentação de habitats, mudanças climáticas, desvio de águas superficiais e subterrâneas, entre outros. Essas ameaças crescentes demandam novas tecnologias e ferramentas de análise, para que se possa adquirir ou aprofundar o conhecimento existente sobre as espécies e auxiliar em sua proteção e conservação (GIANNINI C.; SIQUEIRA, 2012).

A Modelagem Ecológica Computacional é umas das principais ferramentas para investigar quantitativamente os fatores que influenciam a distribuição de espécies (PHILLIPS; R., 2006). A modelagem matemática aliada às ferramentas computacionais gera a possibilidade da previsão de ocorrência de espécies através da geração de modelos de distribuição de espécies (IWASHITA, 2007). Por meio da modelagem de distribuição de espécies é possível gerar modelos que são usados em diversos tipos 
de análises ecológicas, por exemplo: análises biogeográficas, conservação de espécies raras ou ameaçadas, reintrodução de espécies e entre outros (GIANNINI C.; SIQUEIRA, 2012).

Habitualmente, o método de modelagem considera várias execuções de algoritmos e parâmetros. As combinações destas variações produzem um grande número de modelos, os quais são pré-avaliados por métodos matemáticos como AUC, KAPPA e TSS. O processo de avaliação requer informações sobre os locais com presença empírica da espécie e os locais de potencial ausência chamados de pseudo-ausências (PA). Requer, portanto, a geração de múltiplas localidades de pseudo-ausências no espaço geográfico considerado nos modelos, porém, de forma que nunca coincidam geoespacialmente com as presenças reais da espécie.

Existem vários métodos de modelagem, alguns consideram pontos de presença e pseudo-ausências da espécie. A Figura 54 ilustra um processo de modelagem que toma pontos de presença e pontos de pseudo-ausências da espécies. Nesta figura, são apresentados dois mapas, o do lado esquerdo, contém pontos de presença, que são representados por quadrados e pontos de PA representados por triângulos. Após o processo de predição é obtido o mapa da direita, que contém algumas regiões escuras, que representam as possíveis áreas em que a espécie em estudo pode estar presente.

Figura 54: Um exemplo de predição.

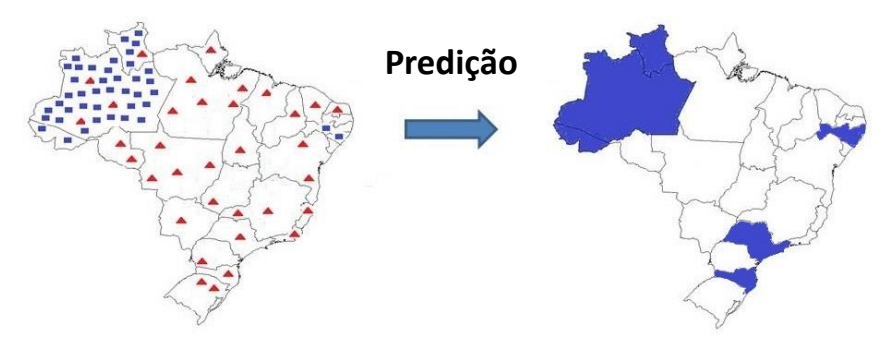

Figura criada com base na figura extraída de LUZ, SATO, ACOSTA, SARAIVA, MIDORIKAWA, 2017 
Atualmente ferramentas estão disponíveis para a geração de modelos, as quais implementam diversos algoritmos para a modelagem. BIOMOD2 é uma plataforma computacional que disponibiliza funções que permitem realizar predições de distribuição de espécies, tais funções permitem avaliar a relação espécie-ambiente (THUILLER W.; LAFOURCADE; ARAUJO, 2009). BIOMOD2 é disponibilizada em R (R FOUNDATION FOR STATISTICAL COMPUTING, 2008) e é um pacote open source.

No processo de predição realizado do BIOMOD2 são executadas diversas fases, sendo as essenciais, modelagem e projeção. No processo de modelagem, a plataforma BIOMOD2 fornece os algoritmos de modelagem: GLM, GBM, CTA, ANN, SRE, FDA, MARS, GAM, RF e MAXENT (R FOUNDATION FOR STATISTICAL COMPUTING, 2013). Cada algoritmo de modelagem fornece uma diferente representação matemática para o mesmo conjunto de dados considerados. Na fase de modelagem, o BIOMOD2 aplica vários algoritmos a fim de escolher o modelo com melhor porcentual de acerto. Cada algoritmo de modelagem consome um tempo diferente de processamento, isto causa uma heterogeneidade de tempo de execução no processamento.

A fase de modelagem requer conjunto de dados de PA. Dado um conjunto de PA, o BIOMOD2 seleciona aleatoriamente $n_{-} p a$ subconjuntos de PA. Cada subconjunto de $n \_p a$ é processado $m \_r u n$ vezes. Neste processamento cada execução é chamada de $R U N$. Na fase de modelagem, o BIOMOD2 realiza $y$ execuções, onde, $y=n \_p a \mathrm{x}$ m_run x p_models. $n \_p a$ é a quantidade de subconjuntos de PA, $m \_r u n$ é a quantidade de $R U N$ e $p \_$models é a quantidade de algoritmos de modelagem.

A quantidade de algoritmos de modelagem, PAs e RUN é configurada pelo usuário. $\mathrm{O}$ algoritmo apresentado abaixo mostra o laço aninhado que é executado na fase de modelagem. Nesta ilustração, são usados 10 algoritmos de modelagem que são especificados no vetor models_list. 


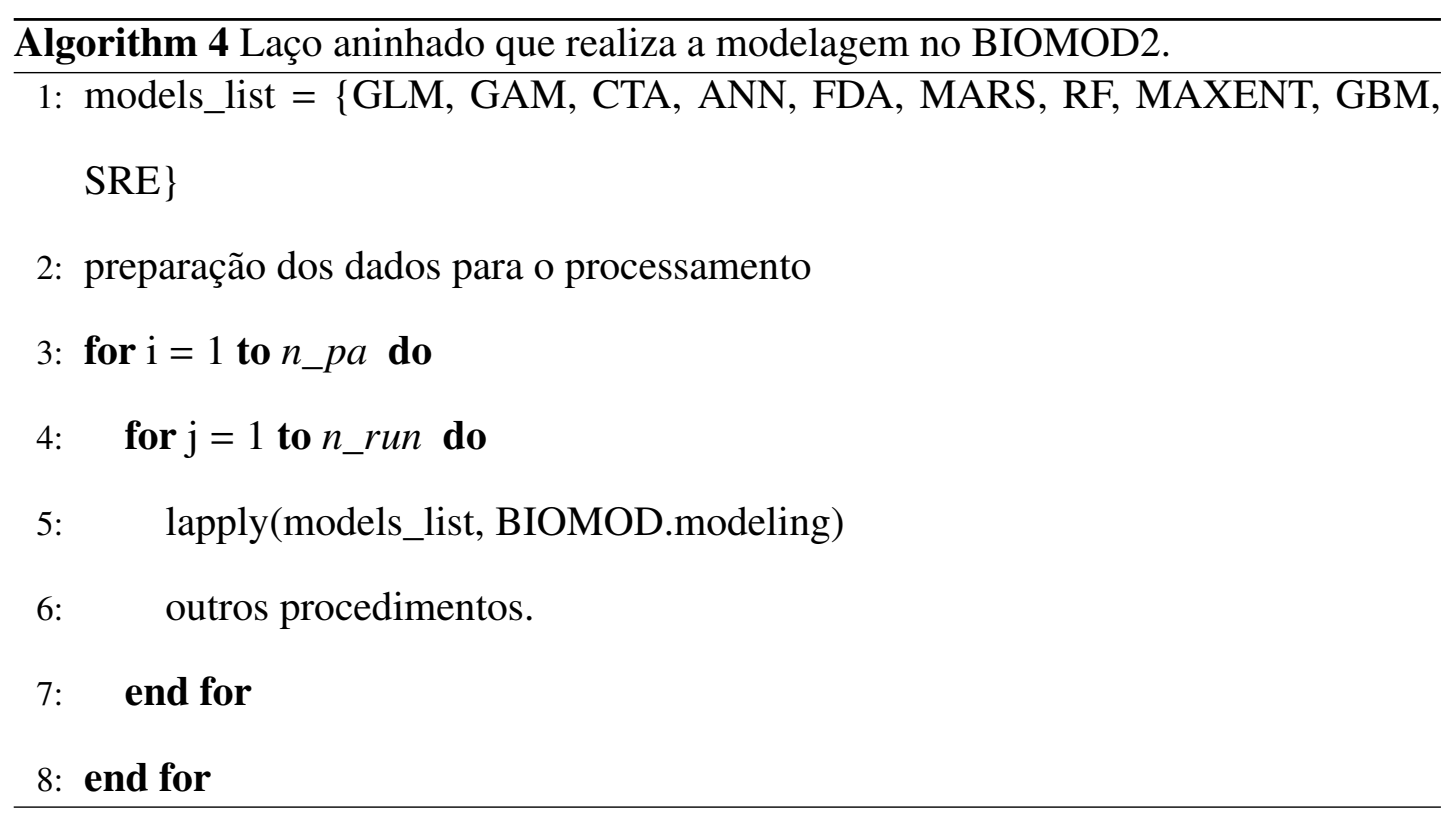

Na fase de modelagem, cada execução de algoritmo gera um modelo que será projetado na próxima fase. A fase de projeção não contém laços aninhados, esta fase é executada por apenas um laço. Desta forma, a atividade de linearização não é necessária. Todavia, o tempo de projeção de cada modelo é diferente, resultando em tempos heterogêneos na execução desta fase. As projeções são processadas por um único laço.

O Algoritmo 5 mostra o laço responsável por projetar todos os modelos criados na fase anterior. Neste laço, o vetor models_all contém todos os modelos criados na fase de modelagem e que são projetados nesta fase e BIOMOD2. Projection é a função que todos os recursos processam.

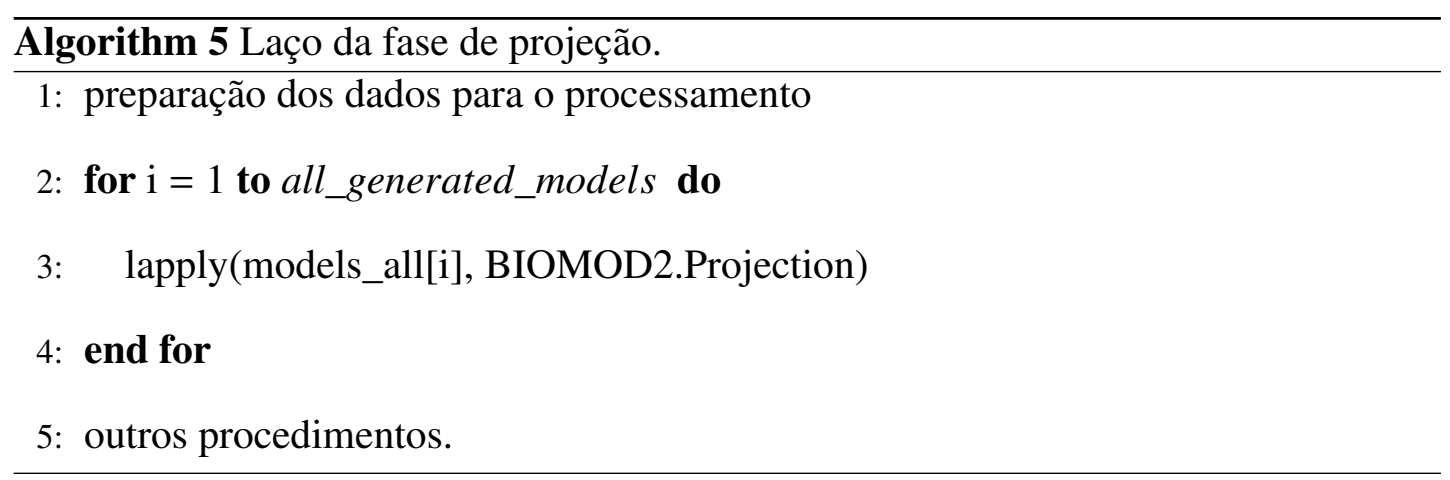




\subsubsection{Aplicação da Metodologia Proposta na Plataforma BIO- MOD2}

A metodologia proposta foi implementada na fase de modelagem e projeção do BIOMOD2. A próxima seção apresenta a estrutura da aplicação paralela.

\subsubsection{Estrutura da Aplicação Paralela BIOMOD2}

A implementação da metodologia na fase de modelagem e projeção da plataforma BIOMOD2 seguiu todas as atividades da metodologia proposta. Na atividade de Coleta de Tempo os tempos dos algoritmos de modelagem e projeção de cada modelo foram coletados e armazenados em arquivo de histórico. Na atividade de linearização os laços aninhados foram linearizados e também foram criadas as estruturas task. $\mathrm{Na}$ fase de modelagem, nome do algoritmo, tempo de processamento, id_PA e id_RUN são especificados nas task . Na fase de projeção, nome do modelo, tempo de projeção, id_PA and id_RUN são especificados nas tasks. A Figura 55 ilustra um exemplo de task para a fase de modelagem. Nesta ilustração é considerada a primeira execução do laço linearizado.

Figura 55: Exemplo de Task na fase de modelagem.

\begin{tabular}{|c|}
\begin{tabular}{|c|} 
Modeling Task \\
Gomputation \\
Time \\
40
\end{tabular} \\
\hline PA 1 \\
\hline RUN 1 \\
\hline
\end{tabular}

Figura extraída de LUZ, SATO, ACOSTA, SARAIVA, MIDORIKAWA, 2017.

Assim como na metodologia, cada task é um elemento de um vetor chamado 
task_vector. Na atividade de Cálculo do número ideal de recursos foi calculado o valor inicial do número ideal de recursos de processamento. Já na atividade de Escalonamento os elementos de task_vector foram atribuídos para as listas de tarefas de cada recurso e o valor do número ideal de recursos de processamento foi refinado. Na atividade de Processamento as listas de tarefas são processadas em paralelo.

Na etapa de processamento foi usado o pacote Snowfall (R FOUNDATION FOR STATISTICAL COMPUTING, 2009) para distribuir as tarefas entre os recursos. O Snowfall é disponibilizado para o ambiente R para realizar processamento paralelo e distribuído. A função sflapply fornecida pelo Snowfall foi usada para distribuir as computações entre os recursos.

No processamento paralelo cada recurso processa sua lista de tarefa em paralelo. O Algoritmo 6 apresenta um simples código usado na sflapply e mostra o processamento paralelo das listas de tarefas dos recursos.

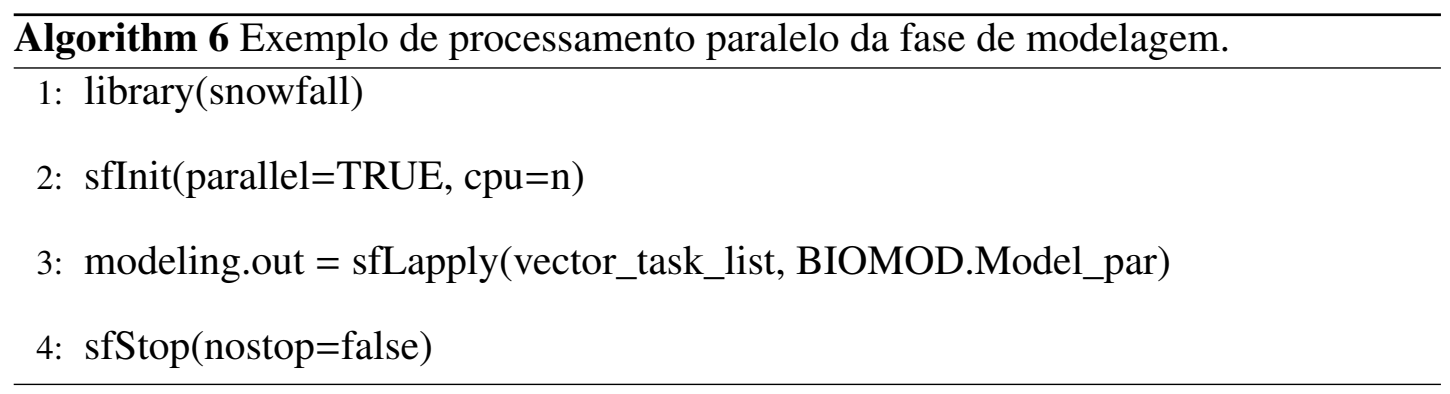

Neste algoritmo, o pacote Snowfall é inicializado entre as linhas 1 e 2. Na linha 3, a função sfLapply é chamada. Nesta, o vector_task_list é o vetor com as lista de tarefas de cada processador, e o BIOMOD . Model_par é a função que todos os recursos irão processar.

\subsubsection{Resultados Obtidos a Partir da Implementação da Metodo- logia Proposta na Predição de Espécies.}

Os experimentos foram realizados em um Cluster composto por cinco máquinas conectadas por uma rede Gigabit Ethernet. Cada nó contém um processador Intel 
Core i7-3770 quad-core de 3.40GHz, 16 GB de memória RAM e sistema operacional Linux na distribuição openSUSE v.13.2. O Cluster foi configurado com NIS (Network Information Service) e NFS (Network File System).

Cada teste experimental foi executado 10 vezes e foi obtido um tempo médio de execução que é apresentado nos gráficos desta seção. O número de recursos varia de 1 ( teste sequencial ) a 20 ( todos cores disponíveis ).

A metodologia foi aplicada na fase de modelagem e projeção do BIOMOD2. A fase de modelagem foi configurada com 3 PA, 5 RUNs e com os algoritmos; GLM, GBM, CTA, ANN, SRE, FDA, MARS, GAM, RF, e MAXENT. Portanto, esta configuração gera 150 tarefas computacionais.

A Figura 56 exibe o tempo de execução sequencial e paralelo da fase de modelagem. Neste experimento, o desvio padrão variou de 0,1 a 0,6 . Nesta fase de processamento, a quantidade ideal de recursos de processamento definida pela metodologia foi 18. O tempo de execução sequencial da fase de modelagem foi de 35 minutos e do paralelo 3 minutos, obtido com 18 recursos. Se o número de recursos for mudado para 20 recursos, o tempo de execução paralelo também seria de 3 minutos, como é possível ver no gráfico apresentado na Figura 56. Portanto, é possível concluir que 18 recursos é o número ideal de recursos de processamento e adicionando mais recursos, não irá diminuir o tempo de processamento paralelo. Neste experimento, o algoritmo de modelagem que mais consumiu tempo de processamento foi GAM, consumindo pouco mais de 3 minutos. Dessa forma, também é possível concluir que, o tempo mínimo de processamento foi alcançado com 18 recursos de processamento. 
Figura 56: Tempo de execução sequencial e paralelo da fase de modelagem.

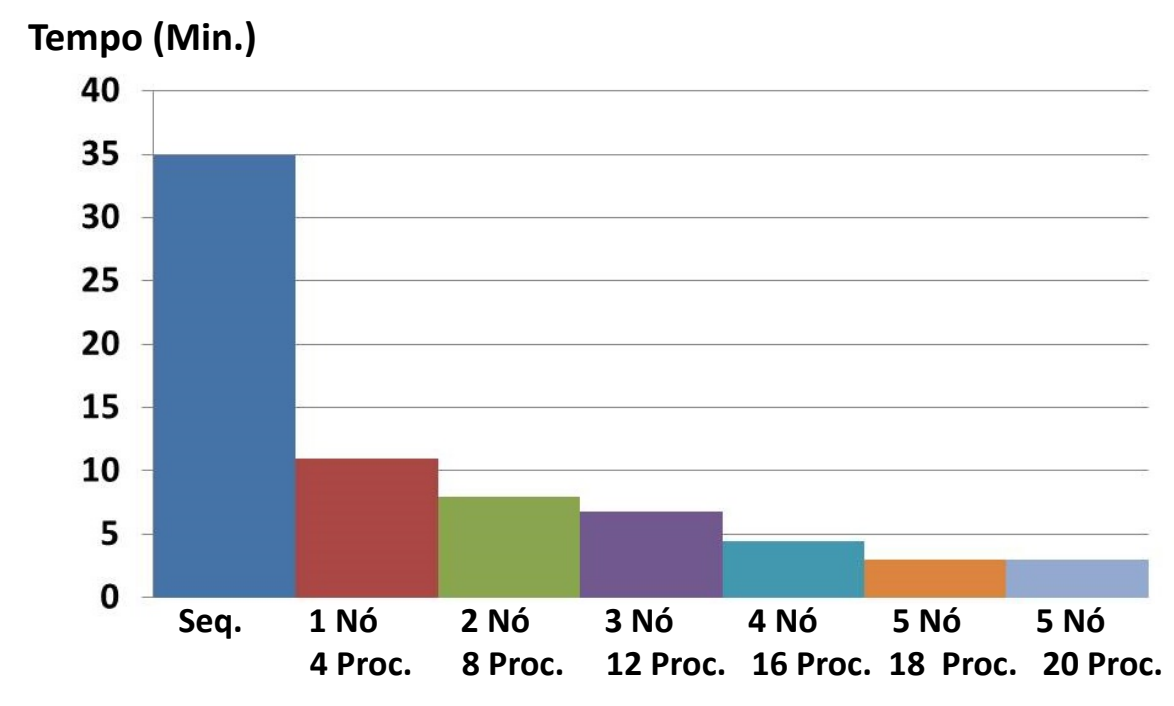

Figura extraída de LUZ, SATO, ACOSTA, SARAIVA, MIDORIKAWA, 2017.

A Figura 57 exibe o tempo sequencial e paralelo da fase de projeção. Nesta fase, a metodologia definiu que 20 é o número ideal de recursos de processamento para projetar os 150 modelos gerados na fase de modelagem. Neste experimento, o desvio padrão variou de 0,03 a 0,2 . Neste gráfico, é possível perceber que o tempo de projeção paralelo diminuiu de 14 minutos para pouco mais de 1 minuto utilizando 20 recursos de processamento. Também é possível concluir que o tempo mínimo de processamento foi alcançado com 20 recursos, e não foi necessário utilizar 150 recursos para alcançalo. Neste experimento, o modelo que mais consumiu tempo de projeção foi o GAM, consumindo, pouco mais de 1 minuto. Logo, é possível concluir que o tempo mínimo de projeção foi alcançado com apenas 20 recursos. A fase de projeção processa alguns procedimentos que obrigatoriamente são executados sequencialmente, por isso, neste experimento não foi possível obter um Speedup linear. 
Figura 57: Tempo de projeção sequencial e paralela.

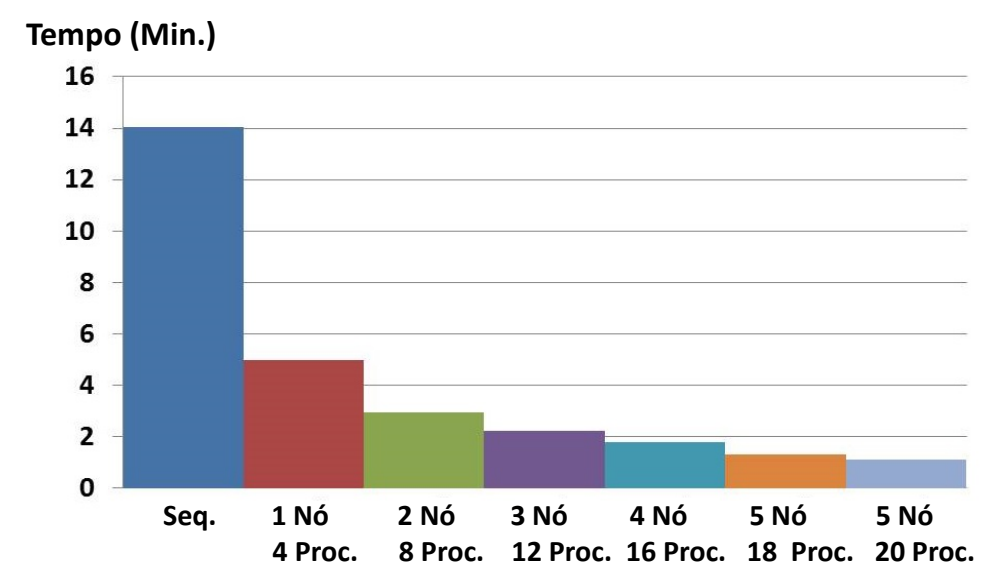

Figura extraída de LUZ, SATO, ACOSTA, SARAIVA, MIDORIKAWA, 2017.

A Figura 58 mostra o tempo total do processo de predição (modelagem, ensemble e projeção). Neste gráfico é possível perceber que o tempo de execução do processo de predição diminuiu ao passo que a quantidade de recurso foi aumentando, variam de 106 minutos para 9 minutos, usando 18 recursos de processamento na modelagem e 20 na projeção. Neste experimento, o desvio padrão variou de 0,2 a 0,7.

Figura 58: Tempo de execução do processo de predição.

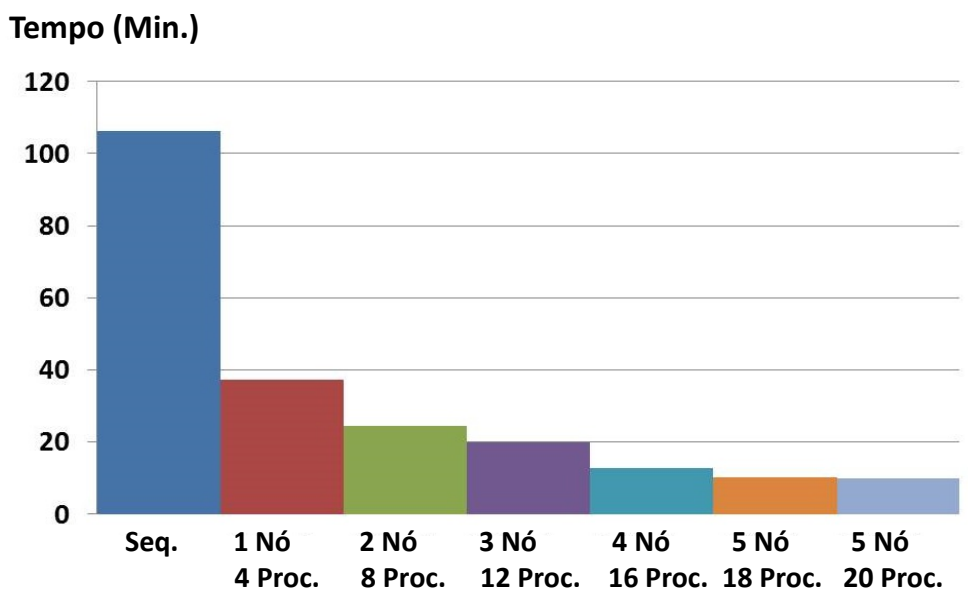

Figura extraída de LUZ, SATO, ACOSTA, SARAIVA, MIDORIKAWA, 2017.

Com os resultados apresentados nas Figuras de 56 a 58 é possível concluir que 
a metodologia aplicada na ferramenta BIOMOD2 foi efetiva e reduziu o tempo de execução do processo de predição, e também, foi corretamente definido o número de recursos de processamento para a fase de modelagem e projeção, o que otimizou o uso dos recursos disponível do Cluster.

Outro objetivo da metodologia proposta é realizar um balanceamento de carga justo e igualitário entre os recursos. A Figura 59 apresenta um gráfico que exibe o tempo de execução dos 18 recursos de processamento utilizados no processamento da fase de modelagem. Com um tempo médio de 2,8 minutos estes resultados mostram que é possível obter uma boa distribuição de carga entre os recursos de processamento.

Figura 59: Balanceamento de carga na fase de modelagem.

\section{Tempo (Min.)}

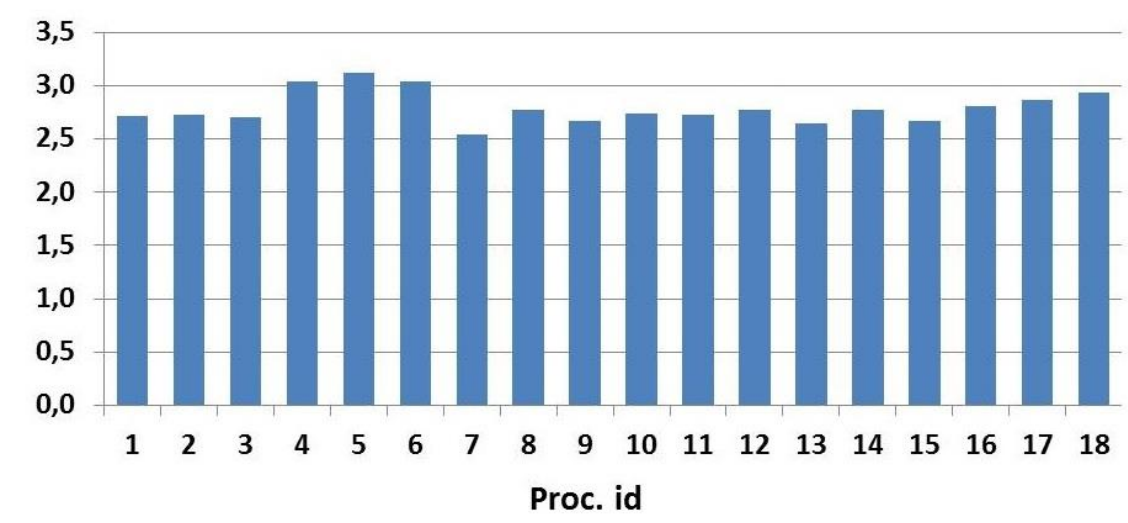

Figura extraída de LUZ, SATO, ACOSTA, SARAIVA, MIDORIKAWA, 2017.

A Figura 60 apresenta os tempos teóricos de execuções de todas as 150 tarefas realizadas na fase de modelagem. Estes são da faixa de 12 milissegundos a pouco mais de 3 minutos. Isto, mais uma vez, mostra a eficiência da atividade de escalonamento, é possível balancear as cargas computacionais entre os recursos disponíveis mesmo com tarefas que contêm tempos heterogêneos de execução. 
Figura 60: Tempos teóricos de execução de todas as tarefas na fase de modelagem.

Tempo (Min.)

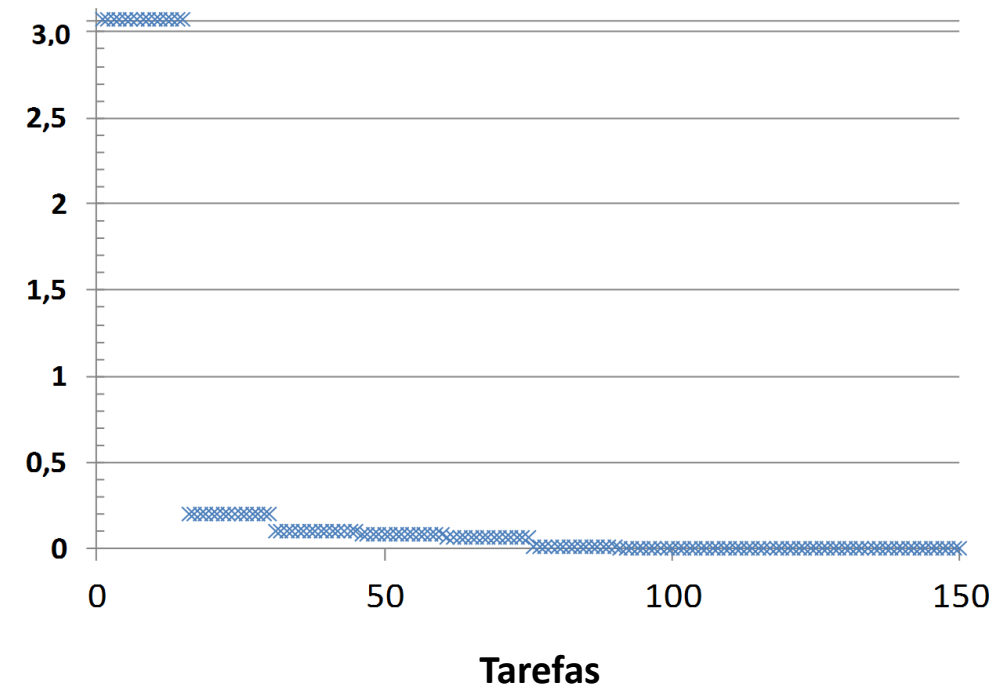

Figura extraída de LUZ, SATO, ACOSTA, SARAIVA, MIDORIKAWA, 2017.

\subsection{Computação Paralela versus Computação Distri- buída}

Nesta seção, é apresentada uma análise sobre computação paralela e distribuída. O objetivo deste experimento é analisar qual é a melhor alternativa de ganho de desempenho, processamento paralelo ou distribuído. Ambas as alternativas têm suas vantagens e desvantagens. De um lado, usando núcleos do mesmo nó, não há custo de comunicação. Por outro lado, um ambiente distribuído pode minimizar a interferência da execução em cada núcleo.

Foram definidos três casos de teste:

1. processamento paralelo com 4 núcleos de um nó,

2. processamento distribuído com 4 nós com 1 núcleo por nó e

3. uso de uma configuração mista com 2 nós com e 2 núcleos por nó. 
A Figura 61 apresenta os resultados de desempenho obtidos. Neste experimento, as três alternativas apresentam tempos de execução semelhantes. Consequentemente, um bom desempenho pode ser obtido com processamento paralelo ou distribuído. Isso pode ser explicado pelo fato das tarefas do BIOMOD2 possuem pouca comunicação e os algoritmos de modelagem processam conjuntos de dados independentes.

Figura 61: Computação Paralela versus Computação Distribuída.

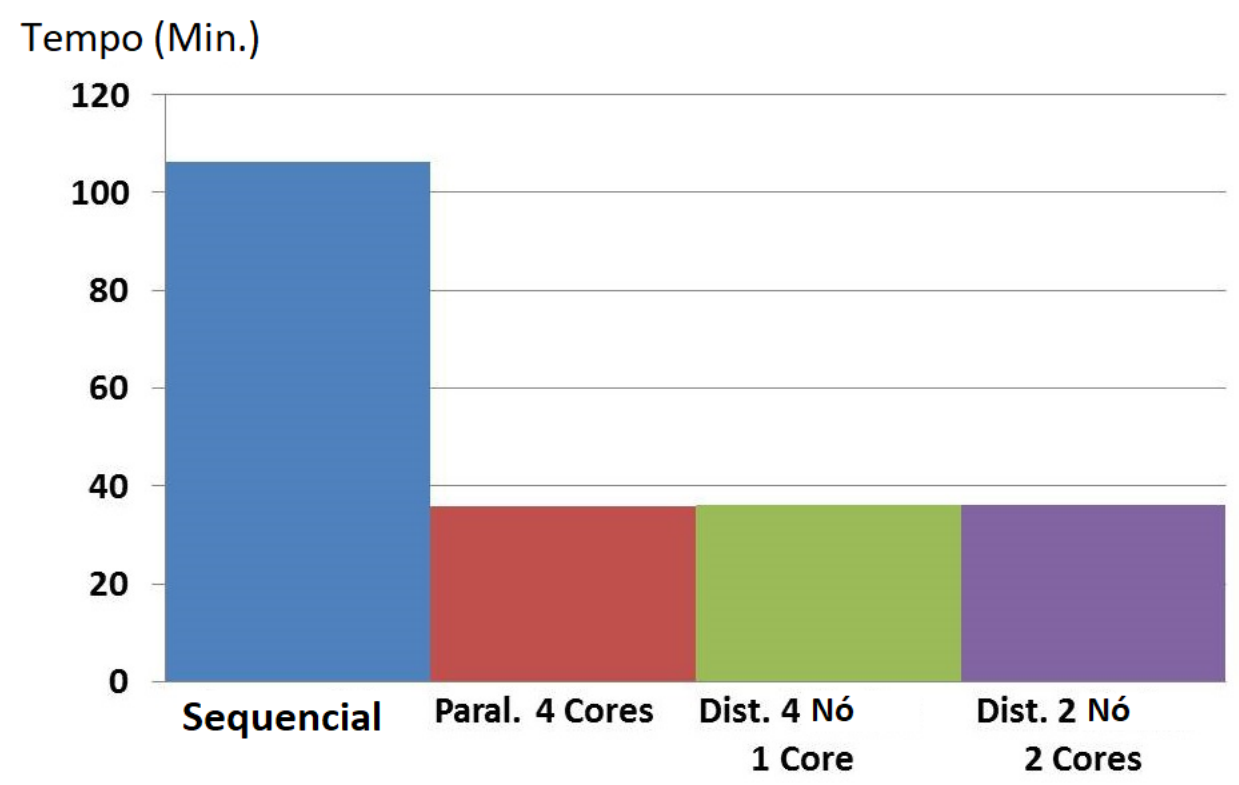

Figura extraída de LUZ, SATO, ACOSTA, SARAIVA, MIDORIKAWA, 2017. 


\section{CONCLUSÕES}

Habitualmente, aplicações processam grandes quantidades de dados que, muitas vezes, levam horas ou até mesmo dias para serem processados. Muitas vezes, estas aplicações utilizam laços aninhados com computações heterogêneas no processamento. Técnicas de paralelização são necessárias para melhorar o desempenho no processamento de tais aplicações.

A presença de computações heterogêneas nas iterações dos laços aninhados implica em uma heterogeneidade de tempo de execução das mesmas, resultando em um desbalanceamento de carga de trabalho na paralelização. O desbalanceamento de carga de trabalho causa ociosidade no processamento, não provendo o uso adequado dos recursos de processamento.

A hipótese considerada neste trabalho diz que é possível melhorar o desempenho de aplicações que contêm laços perfeitamente aninhados com computações heterogêneas, utilizando uma quantia de recursos limitada a um número ideal; através de uma estratégia de paralelização adequada e uma redução da ociosidade no processamento.

Considerando esta hipótese, este trabalho apresenta uma metodologia para paralelização de laços perfeitamente aninhados sem dependência de dados e com computação heterogênea para sistemas paralelos e distribuídos. Também são apresentadas duas ferramentas que auxiliam a metodologia. A primeira ferramenta auxilia a atividade de cálculo do valor inicial do número ideal de recursos de processamento. A segunda ferramenta auxilia a atividade de escalonamento realizada na metodologia proposta. 
O objetivo desta metodologia de paralelização é, além de proporcionar a redução do tempo de processamento de aplicações que contêm laços perfeitamente aninhados, é realizar o uso adequado dos recursos de processamento, minimizando a sua ociosidade. A metodologia proposta define o número ideal de recursos de processamento e também, realiza um escalonamento de tarefa adequado, visando minimizar a ociosidade no processamento.

$\mathrm{Na}$ estratégia de paralelização implementada na metodologia proposta, cada ocorrência de laço aninhado presente na aplicação é linearizada, obtendo um único laço que é paralelizado em seguida. Para cada ocorrência de laços linearizados, é calculado um número ideal de recursos de processamento que é alocado dinamicamente em seu uso. Na estratégia de paralelização também é realizado um escalonamento entre iterações do laço linearizado aos recursos computacionais visando balancear a carga de trabalho entre tais recursos, a fim de, diminuir a ociosidade.

Para comprovar a viabilidade da metodologia e das ferramentas propostas, foram criadas aplicações sintéticas. Pelos resultados obtidos verifica-se que a hipótese considerada é verdadeira. Foram definidos três casos de testes e em todos eles, a aplicação a qual foi implementada a metodologia proposta conseguiu bons resultados. Em um dos casos, a aplicação com a metodologia implementada conseguiu ser 16 vezes mais rápida do que a aplicação processada sequencialmente. Neste experimento, a metodologia proposta definiu que 16 é o número ideal de recursos de processamento, conseguindo assim, alcançar o tempo mínimo de processamento com os 16 recursos. Neste experimento houve um bom balanceamento de carga, no que impactou em uma diminuição de ociosidade no processamento. Em todos os cenários de testes, é possível comprovar a eficiência da metodologia proposta. Experimentos comparativos entre as plataformas MPI e OpenMP foram realizados também e, em todos os experimentos, a metodologia proposta alcançou o melhor tempo de processamento e diminuiu a ociosidade através de um balanceamento de carga adequado. Isso confirma a eficiência da 
metodologia aqui proposta.

Os resultados obtidos nos experimentos comprovam a viabilidade e a eficiência da metodologia proposta. O objetivo de melhorar o desempenho através da redução da ociosidade dos recursos computacionais foi atingido. A metodologia também foi implementada em uma aplicação real, a aplicação de modelagem de distribuição de espécies. A implementação da metodologia proposta na modelagem de distribuição de espécies, implicou em uma melhora no desempenho da aplicação. No processamento, foi possível obter um Speedup de 11 e um bom balanceamento de carga, que resultou em uma ociosidade quase nula. Neste experimento a metodologia proposta definiu que 11 é o número ideal de recursos de processamento e que, se adicionar mais recursos, não é possível obter um maior ganho de desempenho. Com a estratégia de paralelização aplicada no BIOMOD2, houve um bom balanceamento de carga entre os recursos de processamento, impactando em uma ociosidade quase nula. Os resultados experimentais obtidos nesta implementação, foram publicados em um artigo cientifico e também são apresentados neste trabalho.

\subsection{Contribuições}

Este trabalho apresenta as seguintes contribuições:

- Criação de uma metodologia para paralelizar laços perfeitamente aninhados com computações heterogêneas em sistemas paralelos e distribuídos. A heterogeneidade dos tempos de execução das iterações de um laço aninhado causa ociosidade no processamento, resultando em um baixo desempenho e não garantindo um bom uso dos recursos de processamento. A metodologia apresentada neste trabalho diminui o tempo de execução da aplicação, por realizar uma paralelização que diminui a ociosidade no processamento, através; de uma estratégia de paralelização que realiza um balanceamento de carga e consequentemente 
diminui a ociosidade.

- Disponibilização de uma ferramenta para determinar o valor inicial do número ideal de recursos de processamento.

- Disponibilização de uma ferramenta para escalonar as iterações de cada ocorrência de laço aninhado da aplicação entre os recursos de processamento.

A metodologia proposta neste trabalho provê o uso adequado dos recursos de processamento, melhorando o desempenho da aplicação e minimizando a ociosidade de tais recursos. No processamento da aplicação, se utilizado o número ideal de recursos calculado pela metodologia proposta, o ganho de desempenho é o máximo possível de ser atingido e a ociosidade gerada é a mínima possível.

Para cada ocorrência de laço aninhado presente na aplicação é definido um número ideal de recursos de processamento que é alocado dinamicamente no momento do seu uso, e deslocado após seu uso. Não havendo a necessidade de manter um número fixo de recurso alocado do começo ao fim do processamento. Também é realizado um escalonamento adequado das iterações do laço, visando realizar um balanceamento de carga no processamento. Um bom balanceamento de carga permite diminuir a ociosidade no processamento, que resulta em uma melhora no desempenho da aplicação.

O uso da metodologia proposta em um Cluster virtual alocado na nuvem pode refletir em um menor custo na alocação de máquinas virtuais. São ativadas máquinas virtuais de forma a não ultrapassar o número de recursos definido pela metodologia.

\subsection{Trabalhos Futuros}

Novos desafios podem ser encontrados na metodologia de paralelização proposta. Alguns deles são:

- Modificação da metodologia para que se possa considerar laços aninhados com 
dependência de dados ou iterações. Atualmente a metodologia proposta considera apenas laços aninhados sem dependência de dados.

- Modificação da metodologia para que se possa considerar laços imperfeitamente aninhados. Até o momento, a metodologia de paralelização proposta neste trabalho, considera apenas laços perfeitamente aninhados.

- Implantação da metodologia no processo de compilação. A metodologia proposta contêm algumas atividades que são realizadas pelo usuário. A automatização destas atividades facilitaria o uso da metodologia para o usuário.

- Aplicar a metodologia proposta em outras aplicações reais.

- Realizar testes da metodologia proposta na nuvem. 


\section{REFERÊNCIAS}

BECK, F. L. Escalonamento de tarefas job-shop realistas utilizando algoritmos geneticos em MATLAB. Tese (Mestrado) - Universidade Federal de Santa Catarina, 2000.

CANDELA L.; CASTELLI, D. C. G. P. P.; SINIBALDI, F. Species distribution modeling in the cloud. Concurrency Computat.: Pract. Exper, v. 28, p. 1056-1079, 2016.

CARINO., L.; BANICESCU, I. A load balancing tool for distributed parallel loops. Cluster Computing, Springer Science, v. 8, p. 313,321, 2005.

CHIN C.; LAI, L.; CHIU, P. Parallel loop self-scheduling for heterogeneous cluster systems with multi-core computers. In: ASIA-PACIFIC SERVICES COMPUTING CONFERENCE, 2008. APSCC '08. IEEE. Proceedings. Yilan, Taiwan, 2008.

CIORBA M.; ANDRONIKOS, T. R. A.; PAPAKONSTANTINOU, G. Dynamic multi phase scheduling for heterogeneous clusters. In: PARALLEL AND DISTRIBUTED PROCESSING SYMPOSIUM, 2006. IPDPS 2006. 20TH INTERNATIONAL. Proceedings. Rhodes Island, Greece, 2006.

DAGUM, L.; MENON, R. Openmp: an industry standard api for shared-memory programming. IEEE Computational Science and Engineering, v. 5, n. 1, p. 45-46, 1998.

GIANNINI C.; SIQUEIRA, F. A. A. . B. C. S. A. e. S. A. Desafios atuais da modelagem preditiva de distribuicao de especies. Rodriguesia, v. 63, n. 3, p. 733-749, 2012.

HAJIESKANDAR, A.; LOTFI, S. Parallel loop scheduling using an evolutionary algorithm. In: ADVANCED COMPUTER THEORY AND ENGINEERING (ICACTE), 2010 3RD INTERNATIONAL CONFERENCE ON. Proceedings. Chengdu, China, 2010.

HUANG C.; W., W. Y. Y. T. L. C.; CHEN, T. Improvement of workload balancing using parallel loop self-scheduling on intel xeon phi. In: 2015 SEVENTH INTERNATIONAL SYMPOSIUM ON PARALLEL ARCHITECTURES, ALGORITHMS AND PROGRAMMING. Proceedings. [S.1.], 2015.

IWASHITA, F. Sensibilidade de Modelos de Distribuicao de Especies a Erros de Posicionamento de Dados de Coleta. Tese (Mestrado) — Instituto Nacional de Pesquisas Espaciais (INPE), 2007. 
JOHN, B.; GHOSH, A. Control loop interaction in parallel connected high frequency grid converters. In: POWER ENGINEERING CONFERENCE (AUPEC), 2016 AUSTRALASIAN UNIVERSITIES. Proceedings. Brisbane, QLD, Australia, 2016.

KEJARIWA A.; NICOLAU, A.; POLYCHRONOPOULOS, D. Enhanced loop coalescing: A compiler technique for transforming non-uniform iteration spaces. In: SPRINGER. Proceedings. [S.1.], 2008.

LUZ C.; SATO, L. A. A. S. A.; MIDORIKAWA, E. Parallelization in predicting species distribution. In: 7TH INTERNATIONAL ADVANCE COMPUTING CONFERECE (IACC) 2017. Proceedings. Hyberabad, India: IEEE, 2017.

MACHTANS E.; SATO, L.; DEPPMAN, A. Improvement on scheduling dependent tasks for grid applications. In: INTERNATIONAL CONFERENCE ON COMPUTATIONAL SCIENCE AND ENGINEERING. Proceedings. Vancouver, BC: IEEE, 2009.

NICOLAU A.; CAMMAROTA, R.; VEIDENBAUM, A. A fault tolerant selfscheduling scheme for parallel loops on shared memory systems. In: HIGH PERFORMANCE COMPUTING (HIPC), 2012 19TH INTERNATIONAL CONFERENCE ON. Proceedings. Pune, India: IEEE, 2012.

NICOLAU A.; VEIDENBAUM, A. B. U. P. D. Efficient scheduling of nested parallel loops on multi-core systems. In: 2009 INTERNATIONAL CONFERENCE ON PARALLEL PROCESSING. Proceedings. [S.1.], 2009.

PHILLIPS, S.; R., S. Maximum entropy modeling of species geographic distributions. Ecological Modelling, v. 190, n. 3, p. 231-259, 2006.

POLYCHRONOPOULOS, C. Parallel Programming and Compilers. Boston: Kluwe Academic Publishers, 1988.

R FOUNDATION FOR STATISTICAL COMPUTING. $R$ : a language and environmentfor statistical computing. [S.1.], 2008.

. Easier Parallel Computing in R with snowfall and sfClusters. [S.1.], 2009.

. Biomod2:Ensemble platform for species distribution modeling. [S.1.], 2013.

RAVISHANKAR M.; EISENLOHR, J. P. L. R. A.; SADAYAPPAN, P. Code generation for parallel execution of a class of irregular loops on distributed memory systems. In: SC '12: PROCEEDINGS OF THE INTERNATIONAL CONFERENCE ON HIGH PERFORMANCE COMPUTING, NETWORKING, STORAGE AND ANALYSIS. Proceedings. Salt Lake City, UT, USA, 2012.

RIAKIOTAKIS, I.; TSANAKAS, P. Dynamic scheduling of nested loops with uniform dependencies in heterogeneous networks of workstations. In: 8TH INTERNATIONAL SYMPOSIUM ON PARALLEL ARCHITECTURES, ALGORITHMS AND NETWORKS. Proceedings. [S.1.], 2005. 
S. W.; CHUNG, Y.; SHIAN, T. A hybrid parallel scheduling scheme on heterogeneous pc clusters. In: PARALLEL AND DISTRIBUTED COMPUTING, APPLICATIONS AND TECHNOLOGIES, 2005. PDCAT 2005. Proceedings. [S.1.], 2005.

SAIM A.; MELLAH, R. H. A. D. A.; MACHMOUM, M. Multi-loop control strategy for parallel distributed generation units in standalone applications. In: MODELLING, IDENTIFICATION AND CONTROL (ICMIC), 2016 8TH INTERNATIONAL CONFERENCE ON. Proceedings. Algiers, Algeria, 2016.

TANENBAUM, A. Sistemas Operacionais Modernos. Brasil: Pearson, 2010.

TEICH J.; TANASE, A.; HANNIG, A. Symbolic parallelization of loop programs for massively parallel processor arrays. In: APPLICATION-SPECIFIC SYSTEMS, ARCHITECTURES AND PROCESSORS (ASAP), IEEE 24TH INTERNATIONAL CONFERENCE ON. Proceedings. Washington, DC, USA, 2014.

THUILLER W.; LAFOURCADE, B. E. R.; ARAUJO, M. Biomod - a platform for ensemble forecasting of species distributions. Ecography, v. 32, n. 3, p. 369-373, 2009.

YAN Y.; LIU, J. C. K.; UMAR, M. Homp: Automated distribution of parallel loops and data in highly parallel accelerator-based systems. In: 2017 IEEE INTERNATIONAL PARALLEL AND DISTRIBUTED PROCESSING SYMPOSIUM. Proceedings. [S.1.], 2017. 


\section{APÊNDICE A - CÓDIGO DO EXEMPLO DE IMPLEMENTAÇÃO DA METODOLOGIA EM COMPUTADORES MULTICORES}

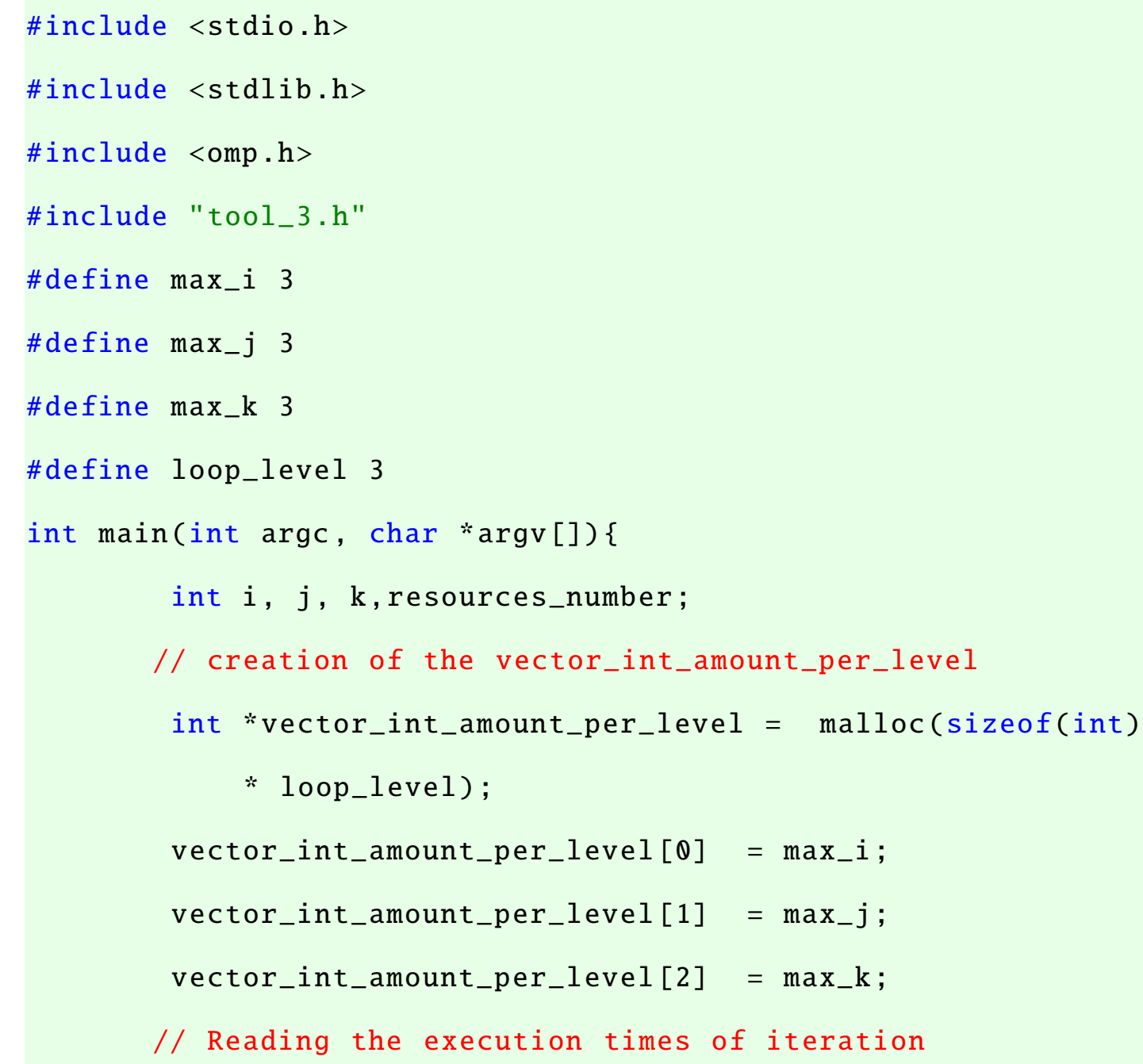




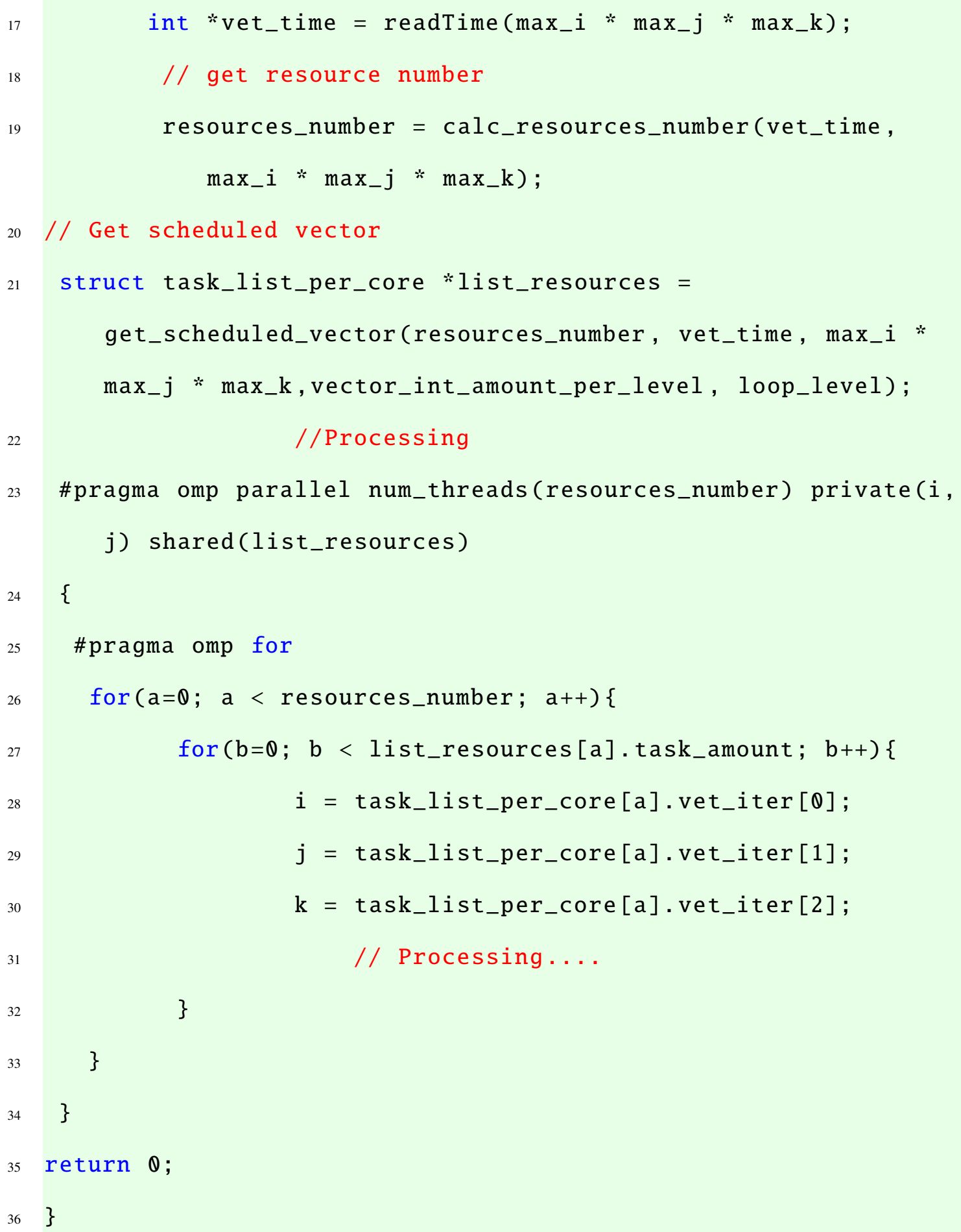




\section{APÊNDICE B - CÓDIGO DO EXEMPLO DE IMPLEMENTAÇÃO DA METODOLOGIA EM SISTEMAS DISTRIBUÍDOS}

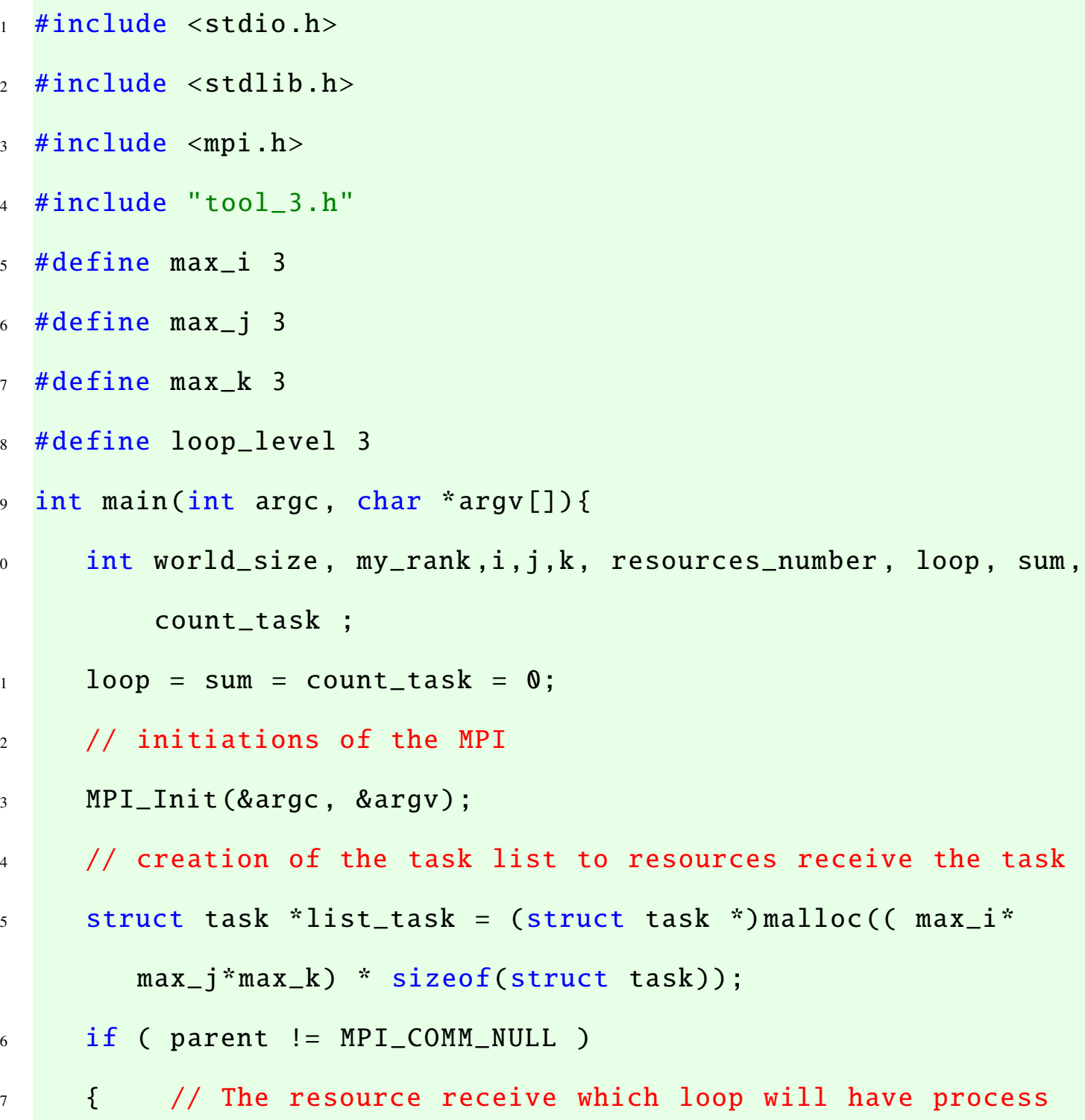


MPI_Recv (\&loop, 1,MPI_INT, 0,11, parent ,\&status);

// receive the tasks amount

MPI_Recv (\&count_task, 1, MPI_INT , 0,10 , parent , \&status);

int task_info $=$ count_task $* 4$;

// receive the task list

MPI_Recv(list_task, task_info, MPI_INT, 0,10, parent , \& status) ;

switch (loop) \{

case 1 :

goto loop 1 ;

break ;

case 2 :

goto loop2;

break;

\}

loop 1:

$$
\begin{aligned}
& \text { for }(a=0 ; a<\text { count_task; } a++)\{ \\
& \left.i=1 \text { ist_task }[a] \cdot v e t \_i \operatorname{ter}[0]\right) \text {; }
\end{aligned}
$$

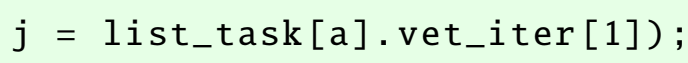

$$
\begin{aligned}
& \left.\mathrm{k}=\mathrm{list}_{\text {task}}[\mathrm{a}] \cdot \operatorname{vet} \text { _iter }[2]\right) \text {; } \\
& \text { // Processing }
\end{aligned}
$$

\}

1oop2:

for $(a=0 ; a<$ count_task; $a++)\{$

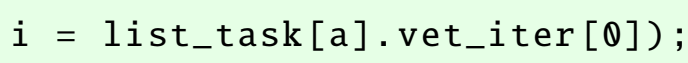

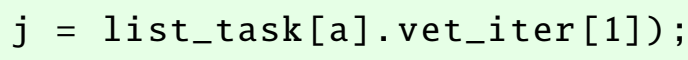

$\left.\mathrm{k}=\mathrm{list}_{-} \operatorname{task}[\mathrm{a}] \cdot \operatorname{vet} \_i \operatorname{ter}[2]\right)$;

// Processing

\} 


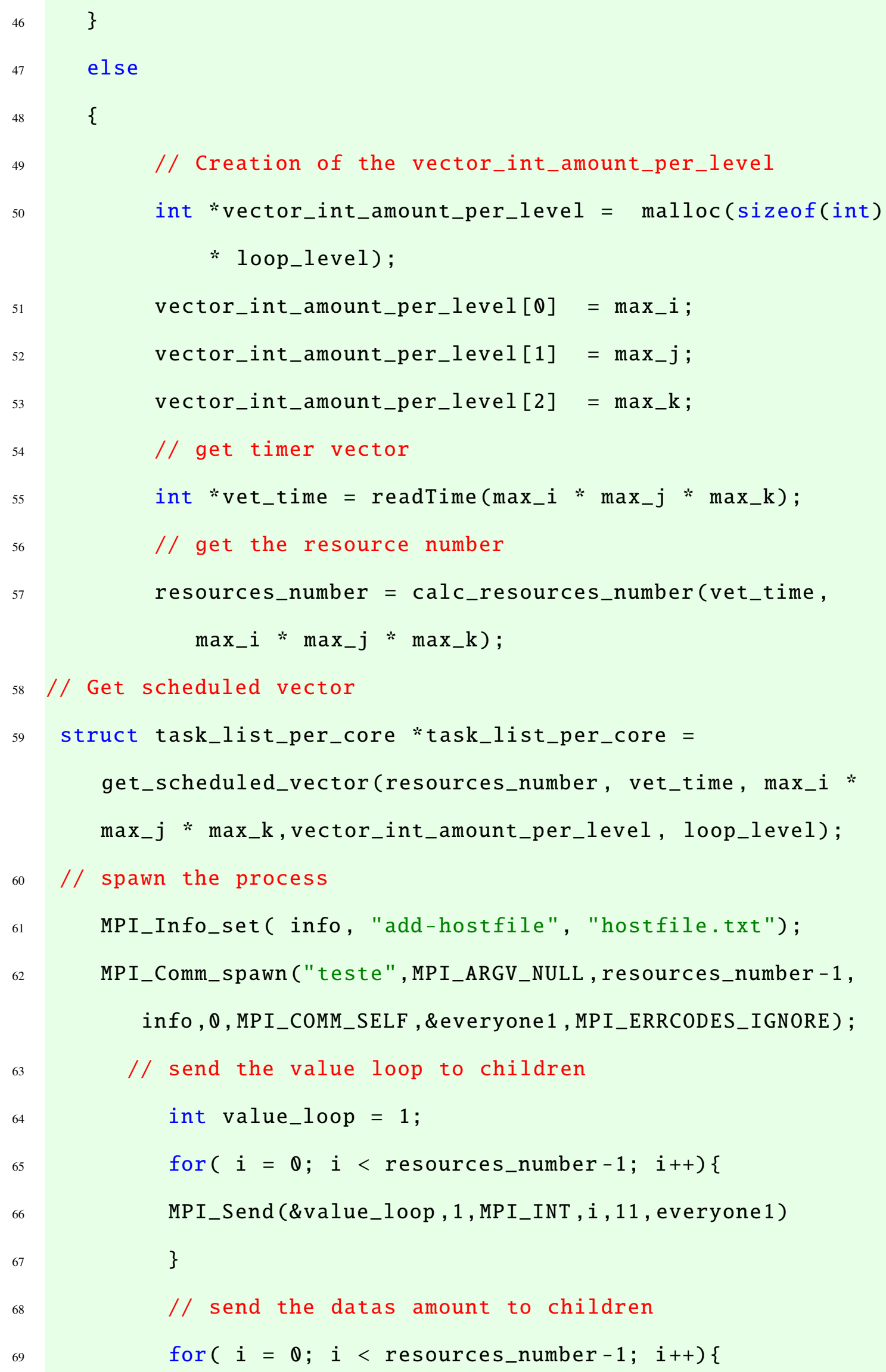


MPI_Send (\&task_list_per_core [i].task_amount , 1 ,MPI_INT , i , 10 , everyone 1 );

\}

// send the datas loop to children

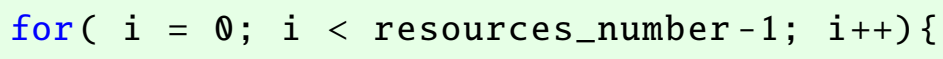

\}

//The processe $\theta$ execute the task list

\}

MPI_Finalize();

return 0 ; 


\section{APÊNDICE C - CÓDIGO DO EXEMPLO DE IMPLEMENTAÇÃO DA METODOLOGIA EM R E PARA A BIODIVERSIDADE.}

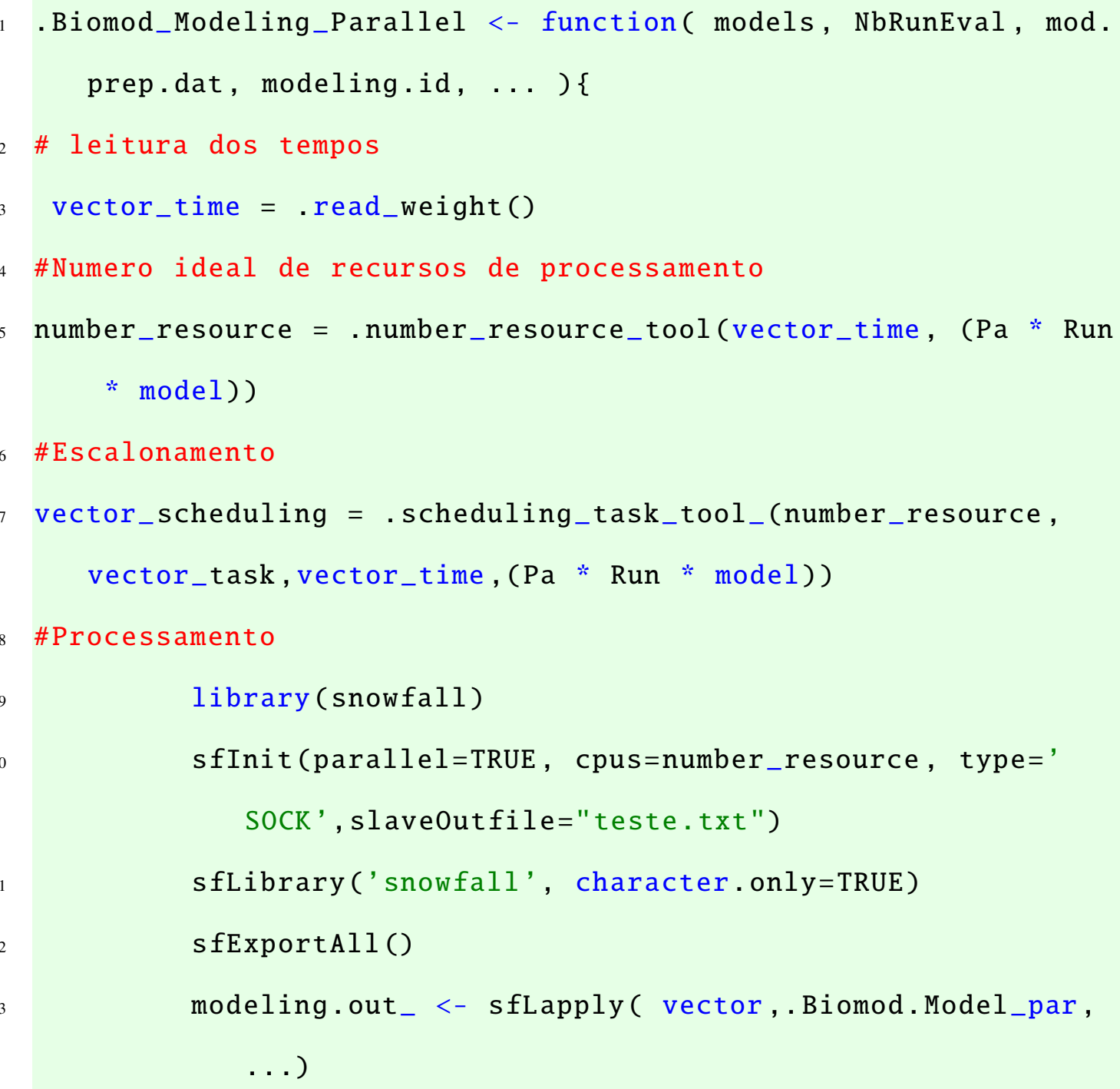


sfStop ( nostop=FALSE )

$15 \quad\}$ 